\title{
ABCA1 Increases Extracellular ATP to Mediate Cholesterol Efflux to ApoA-I
}

\author{
Jee Yeon Lee
}

Thesis submitted to the Faculty of Graduate and Postdoctoral Studies in partial fulfillment of the requirements for the degree of Master of Science in

Biochemistry

Department of Biochemistry, Microbiology, and Immunology

Faculty of Medicine

\author{
University of Ottawa \\ Ottawa Ontario, Canada
}

(C) Jee Yeon Lee, Ottawa, Canada, 2012 


\begin{abstract}
ABCA1 is a key plasma membrane protein required for the efflux of cellular cholesterol to extracellular acceptors, particularly to apoA-I. This process is essential to maintain cholesterol homeostasis in the body. The detailed molecular mechanisms, however, are still insufficiently understood. Also, the molecular identity of ABCA1, i.e. channel, pump or flippase, remains unknown. In this study we analyzed the extracellular ATP levels in the medium of ABCA1-expressing BHK cells and RAW macrophages and compared them to the medium of relevant non-expressing cells. We found that the extracellular ATP concentrations are significantly elevated when cells express ABCA1. Importantly, a dysfunctional ABCA1 mutant (A937V), when expressed similarly as WT-ABCA1, is unable to raise extracellular ATP concentration. This suggests a causal relationship between functional ABCA1 and elevated extracellular ATP. To explore the physiological role of elevated extracellular ATP, we analyzed ABCA1-mediated cholesterol efflux under the conditions where extracellular ATP levels were modulated. We found that increasing extracellular ATP within the physiological range, i.e. $<\mu \mathrm{M}$, promotes cholesterol efflux to apoA-I. On the other hand, removing extracellular ATP, either by adding apyrase to the medium or by expressing a plasma membrane bound ecto-nucleotidase CD39, abolishes cholesterol efflux to apoA-I. Based on these results we conclude that, through direct or indirect mechanisms, ABCA1 functions to raise ATP levels in the medium. This elevated extracellular ATP is required for ABCA1-mediated cholesterol efflux to apoA-I.
\end{abstract}

Keywords: ABCA1, extracellular ATP, RAW macrophages, BHK cells, CD39, apyrase 


\section{Acknowledgements}

I wish to first particularly thank my supervisor, Dr. Xiaohui Zha for her wisdom, guidance and encouragement throughout my graduate studies. It would not have been possible without her patience and optimism that has helped greatly for writing this thesis. I am very grateful to have had the chance to be part of her laboratory.

I would also like to thank my thesis advisory committee members, Drs. Alexander Sorisky and Thomas Lagace for their insights and helpful advice that has contributed to my project.

Special thanks to all the old and new members of the Zha lab for not only providing the suggestions and experimental help, but making the past two years a lot of fun, especially Dr. Fumin Dong, Loretta Ma, Maryam Zaid, and Walaa Eid. I sincerely appreciate everything they have done to make this research possible.

Finally, I would like to thank my family and friends for the love and support during the tough times of my studies. I truly am grateful and I appreciate from the bottom of my heart. 
This thesis is dedicated to God, who has given me wisdom and guidance throughout my studies.

Also to my loving family, who has supported me all the way with understanding and encouragement 


\section{Table of Contents}

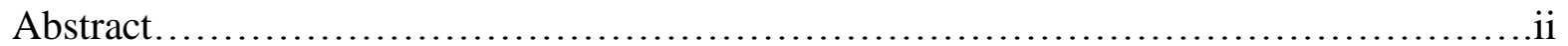

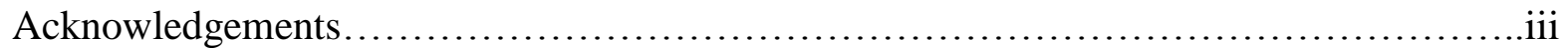

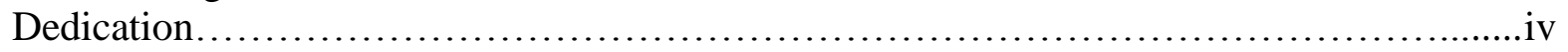

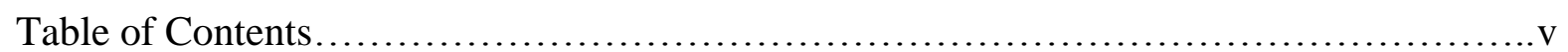

List of Abbreviations................................................................. vii

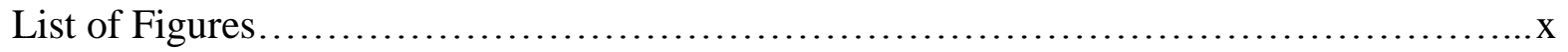

Chapter I: Introduction...........................................................1

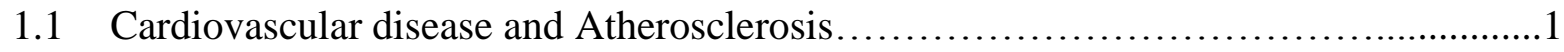

1.2 Cholesterol homeostasis....................................................... 5

1.3 Reverse cholesterol transport: production of HDL............................... 13

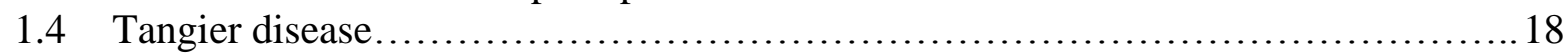

1.5 ABCA1 structure and functions............................................. 19

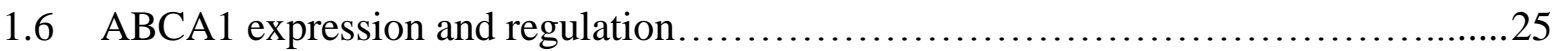

1.7 Signalling pathways regulating ABCA1 functions................................ 27

$1.8 \mathrm{Ca}^{2+}$ signalling in ABCA1-mediated apoA-I lipidation............................ 29

1.9 The secretion of extracellular nucleotides........................................ 30

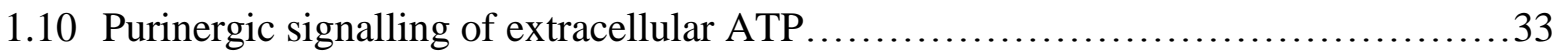

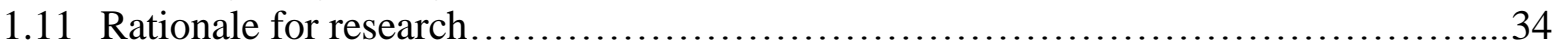

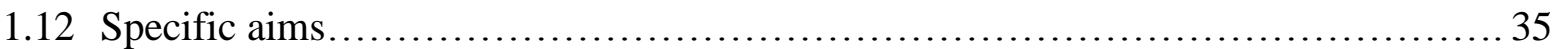

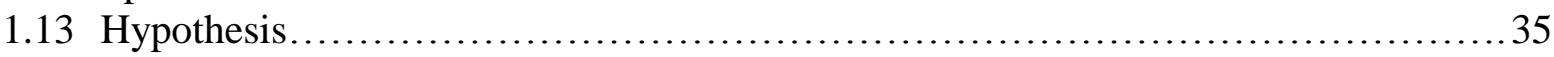

Chapter II: Materials and Methods.................................................36

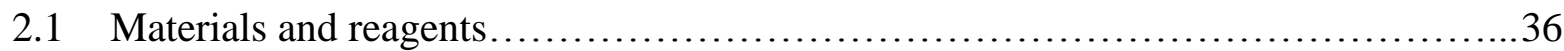

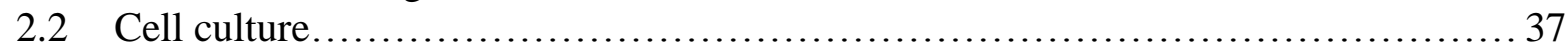

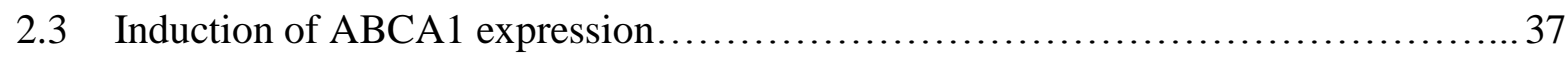

2.4 Cholesterol efflux............................................................. 38

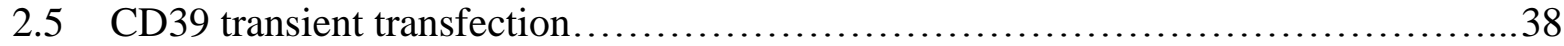

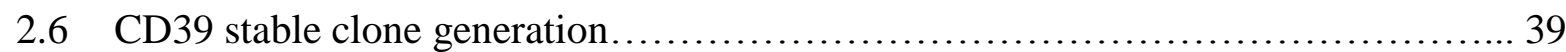

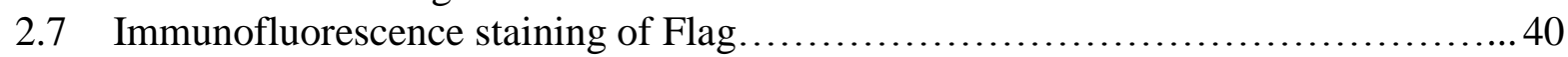

2.8 Cell lysis ..................................................................... 40

2.9 SDS Polyacrylamide gel electrophoresis (SDS-PAGE) and Immunoblotting.........41

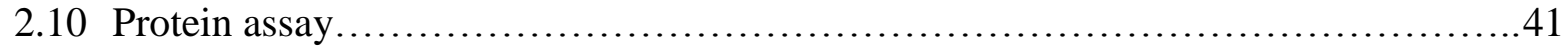

2.11 ATP luciferin/luciferase Assay ............................................. 42

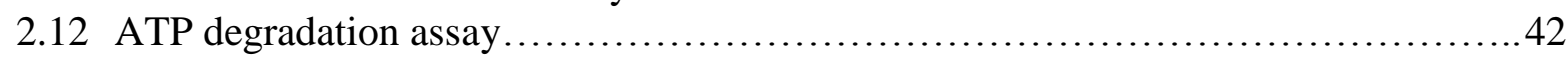

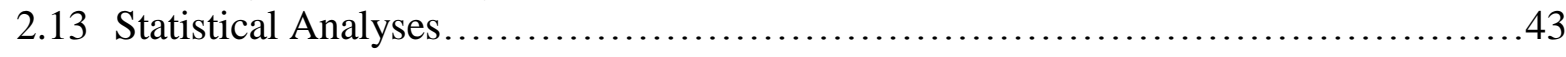

Chapter III: Results..................................................................44

3.1 ABCA1 is expressed and functional in BHK and RAW cells.................... 44

3.2 Functional ABCA1 expression raises steady state extracellular ATP ............... 47 
3.3 Increasing extracellular ATP results in a biphasic response in cholesterol efflux .....58

$3.4 \mathrm{P} 2$ receptors may not be involved in ABCA1-mediated cholesterol efflux............62 62

3.5 Hydrolyzing extracellular ATP by apyrase inhibit cholesterol efflux to apoA-I.......66

3.6 CD39 overexpressed cells inhibit cholesterol efflux to apoA-I.................... 72

3.7 ATP release is independent of apoA-I and microparticle secretion..................83

Chapter IV: Discussion............................................................. 91

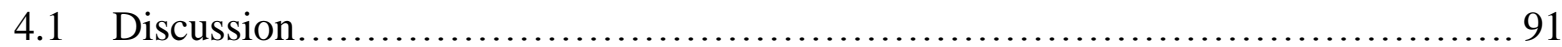

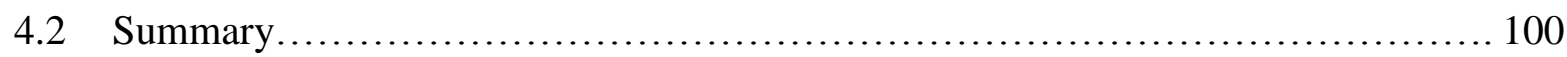

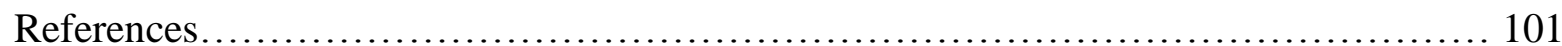

Contributions of Collaborators ................................................. 118

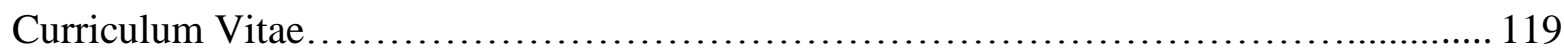




\section{List of Abbreviations}

$\begin{array}{ll}\text { 8-Br-cAMP } & \text { 8-Bromo-cyclic adenosine monophosphate } \\ \alpha, \beta-\text {-MeATP } & \alpha, \beta \text {-Methyleneadenosine 5'-triphosphate } \\ \text { A937V } & \text { Alanine937Valine } \\ \text { ABCA1 } & \text { ATP binding cassette transporter A-1 } \\ \text { ABCG1 } & \text { ATP-binding cassette transporter G-1 } \\ \text { ABCG4 } & \text { ATP-binding cassette transporter G-4 } \\ \text { AC } & \text { Adenylyl cyclase } \\ \text { ACAT } & \text { Acyl-coenzyme A: cholesterol acyltransferase } \\ \text { AD } & \text { Activation domain } \\ \text { ADP } & \text { Adenosine 5'-diphosphate } \\ \text { AKAP } & \text { Protein kinase A-anchoring protein } \\ \text { AMP } & \text { Adenosine 5'-monophosphate } \\ \text { ApoA-I } & \text { Apolipoprotein A-I } \\ \text { ApoB } & \text { Apolipoprotein B } \\ \text { ApoB-48 } & \text { Apolipoprotein B-48 } \\ \text { ApoB-100 } & \text { Apolipoprotein B-100 } \\ \text { ApoC-II } & \text { Apolipoprotein C-II } \\ \text { ApoE } & \text { Apolipoprotein E } \\ \text { ATP } & \text { Adenosine 5'-triphosphate } \\ \text { ATP } & \text { Adenosine-5'-O-(3-thio triphosphate) } \\ \text { A.U. } & \text { Arbitrary unit } \\ \text { BHK } & \text { Baby hamster kidney } \\ \text { bHLH-Zip } & \text { Basic-helix-loop-helix-leucine zipper } \\ \text { BSA } & \text { Bovine serum albumin } \\ \text { CAD } & \text { Coronary artery disease } \\ \text { CaM } & \text { Calmodulin } \\ \text { CaMK } & \text { CaM kinase } \\ \text { cAMP } & \text { Cyclic adenosine monophosphate } \\ \text { CE } & \text { Cholesterol ester } \\ \text { CFTR } & \text { Cystic fibrosis transmembrane regulator } \\ \text { CK2 } & \text { Casein kinase 2 } \\ \text { CoA } & \text { Coenzyme A } \\ \text { cpm } & \text { Counts per minute } \\ \text { CsA } & \text { cyclosporine A } \\ \text { CVD } & \text { Cardiovascular disease } \\ \text { DBD } & \text { DNA binding domain } \\ \text { DGAT1 } & \text { Acyl-CoA:diacylglycerol acyltransferase 1 } \\ \text { DMEM } & \text { Dulbecco's modified medium } \\ \text { E } & \text { Glutamic acid } \\ \text { eATP } & \text { Extracellular ATP } \\ \text { ECD } & \text { Extracellular domain } \\ \text { ENTPD1 } & \text { Ectonucleoside triphosphate diphosphohydrolase 1 } \\ \text { ER } & \text { Endoplasmic reticulum } \\ & \\ & \end{array}$


FBS

FC

FRET

HDL

HDL-C

hPR-LBD

IDL

IL

JAK2

JNK

LCAT

LDL

LDL-C

LDLR

LPL

LRP

LXR

Mif

mRNA

MRP1

MTP

NBD

NFAT

NO

nSREBP

oxLDL

$\mathrm{P}$

P1

$\mathrm{P} 2$

P2X

P2Y

PBS

PKA

PKC

PVDF

$\mathrm{P} / \mathrm{S}$

P1R

P2R

P2XR

P2YR

PPADS

PPAR

PXR

RAW

RCT

RXR

$\mathrm{S}$
Fetal bovine serum

Free cholesterol

Fluorescence resonance energy transfer

High density lipoprotein

HDL-cholesterol

Progesterone receptor ligand binding domain

Intermediate density lipoprotein

Interleukin

Janus kinase 2

c-Jun N-terminal kinase

Lecithin: cholesterol acyltransfease

Low density lipoprotein

LDL-cholesterol

LDL receptor

Lipoprotein lipase

LDLR related protein

Liver-X receptor

Mifepristone

Messenger RNA

Multidrug-resistance protein 1

Triglyceride transfer protein

Nucleotide binding domain

Nuclear factor of activated T cells

Nitric oxide

Nuclear sterol regulatory element binding protein

Oxidized LDL

Proline

Purinergic receptor 1

Purinergic receptor 2

Purinergic receptor $2 \mathrm{X}$

Purinergic receptor $2 \mathrm{Y}$

Phosphate buffer saline

Protein kinase A

Protein kinase $\mathrm{C}$

Polyvinylidene fluoride

Penicillin/streptomycin

Purinergic 1 receptor

Purinergic 2 receptor

Purinergic $2 \mathrm{X}$ receptor

Purinergic $2 \mathrm{Y}$ receptor

Pyridoxal phosphate-6-azo (benzene-2, 4-disulfonic acid)

Peroxisome proliferator-activated receptor

Pregnane-X receptor

RAW 264.7 mouse macrophages

Reverse cholesterol transport

Retinoic-X receptor

Serine 
SCAP

$\mathrm{SD}$

SDS-PAGE

SEM

SRE

SREBF-1

SREBF-2

SREBP

STAT

$\mathrm{T}$

TG

TK

TLR4

TMD

TMS

TNF- $\alpha$

TR

UDP

UTP

VCAM1

VLDL

WT
SREBP cleavage-activating protein

Standard deviation

SDS polyacrylamide gel electrophoresis

Standard error of the mean

Sterol response element

Sterol regulatory element-binding transcription factor-1

Sterol regulatory element-binding transcription factor-2

Sterol regulatory element binding protein

Signal transducer and activator of transcription

Threonine

Triglyceride

Thymidine kinase

Toll-like receptor 4

Transmembrane domain

Transmembrane segment

Tumor necrosis factor- $\alpha$

Thyroid hormone receptor

Uridine 5'-diphosphate

Uridine-5'-triphosphate

Vascular cell-adhesion molecule 1

Very low density lipoprotein

Wild type 


\section{List of Figures}

Figure 1.1 Overview of the progression of atherosclerotic lesion.....................2

Figure $1.2 \quad$ Lipid Metabolism in humans.......................................... 7

Figure 1.3 Sterol-mediated proteolytic release of SREBPs.........................11

Figure 1.4 Reverse cholesterol transport and cholesterol efflux in macrophages.......... 15

Figure 1.5 Schematic view of the topological arrangement of ABCA1 ...............21

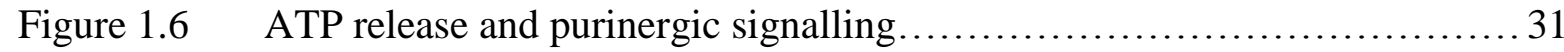

Figure 3.1 Characterization of BHK cells with inducible ABCA1 expression.......... 45

Figure 3.2 Characterization of RAW 264.7 macrophages with ABCA1 expression...... 48

Figure 3.3 Extracellular ATP levels in ABCA1 expressing BHK cells and RAW macrophages.................................................... 51

Figure 3.4 Various ABCA1 expressions on extracellular ATP secretion level.......... 53

Figure 3.5 ATP degradation assay and steady state extracellular ATP levels with different cell numbers...............................................56

Figure 3.6 The influence of increased extracellular ATP on cholesterol efflux to apoA-I and ABCA1 expression................................................................ 59

Figure 3.7 Effects of P2 receptor modulators on cholesterol efflux to apoA-I.............. 63

Figure 3.8 ATP metabolites in cholesterol efflux to apoA-I...................... 67

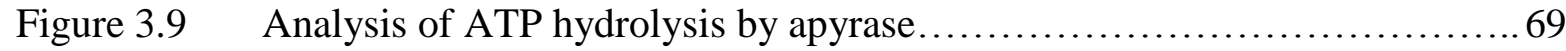

Figure 3.10 CD39 overexpression in BHK cells ................................... 74

Figure 3.11 CD39 overexpression in RAW macrophages.......................... 78

Figure 3.12 Stable overexpression of CD39 in ABCA1 induced RAW macrophages.... 80

Figure 3.13 Effect of apoA-I binding on extracellular ATP levels in ABCA1-

expressing BHK and RAW macrophages............................. 84

Figure 3.14 st-Ht31 stimulation in ATP secretion from ABCA1 expressing BHK cells .......................................................... 86

Figure 3.15 Analysis of supplementing exogenous ATP to BHK-A937V cells......... 89 


\section{Chapter I: Introduction}

\subsection{Cardiovascular disease and atherosclerosis}

Cardiovascular disease (CVD) is the leading cause of death, claiming 17.1 million lives per year or $30 \%$ of all estimated deaths worldwide $^{1}$. Although CVD is more prevalent in developed countries, the incidents of CVD are on the rise equally for both men and women in developing countries ${ }^{2}$. According to World Health Organization (WHO), by the year 2030, the deaths from CVD will rise to 23.6 million people, which would account for more than three-fourths of all deaths ${ }^{3}$. Thus, CVD is a global health problem that demands a global action for early prevention. Among CVDs, atherosclerosis is a major underlying factor. Atherosclerosis is defined as a condition where lipids buildup in arteries resulting in thickening of the vessel wall and thus narrowing of the artery ${ }^{4}$. This can eventually lead to heart attack or stroke. Cholesterol accumulation in the cardiovascular system, predominantly at sites of disturbed laminar flow such as arterial branch points and bifurcations, is one of the direct causes of atherosclerosis.

Atherosclerosis is initiated when arterial intima, a small area between the endothelium and the underlying smooth muscle cells, begins to accumulate lipids, cells and collagen-rich extracellular matrix. This leads to the formation of atherosclerotic plaques ${ }^{5}$ (Figure 1.1). More specifically, these plaques contain lipids, leukocytes, inflamed endothelial cells,

smooth muscle cells, foam cells as well as calcified regions and necrotic cores ${ }^{6}$. It is shown by careful morphological and functional studies that the apolipoprotein B (ApoB)-containing lipoproteins are the main factors that initiate the lesion formation ${ }^{7}$. ApoB-containing lipoproteins consist of a core of neutral lipids surrounded by a monolayer 


\section{Figure 1.1}

Overview of the progression of atherosclerotic lesion. The first step of atherosclerosis involves formation of early fatty streaks with dysfunction of the endothelial cell in the artery wall due to entry of LDL. Fatty streaks form when apoB-containing lipoproteins accumulate in the subendothelial space, which subsequently recruit dendritic cells and macrophages. These lipid-laden macrophages are called foam cells, which release chemokines that accelerate atherosclerotic lesion formation into an established lesion. At this stage, migration of smooth muscle cells into the intima occur leading to the development of fibrous caps. Vulnerable plaques are characterized by the accumulation of cell debris and defective phagocytosis of macrophages resulting in lipid-filled necrotic core. The continuous influx of lipids and secretion of matrix-degrading proteases by macrophages at the site are responsible for thinning of the fibrous cap. Finally, thrombus form when the lesion becomes unstable and the plaque gets vulnerable for rupture. (Image adopted from figure 1 of Moore, K., and Tabas, I. Cell. 145(3): 341-55. 2011. Permission was obtaind from publisher.) 


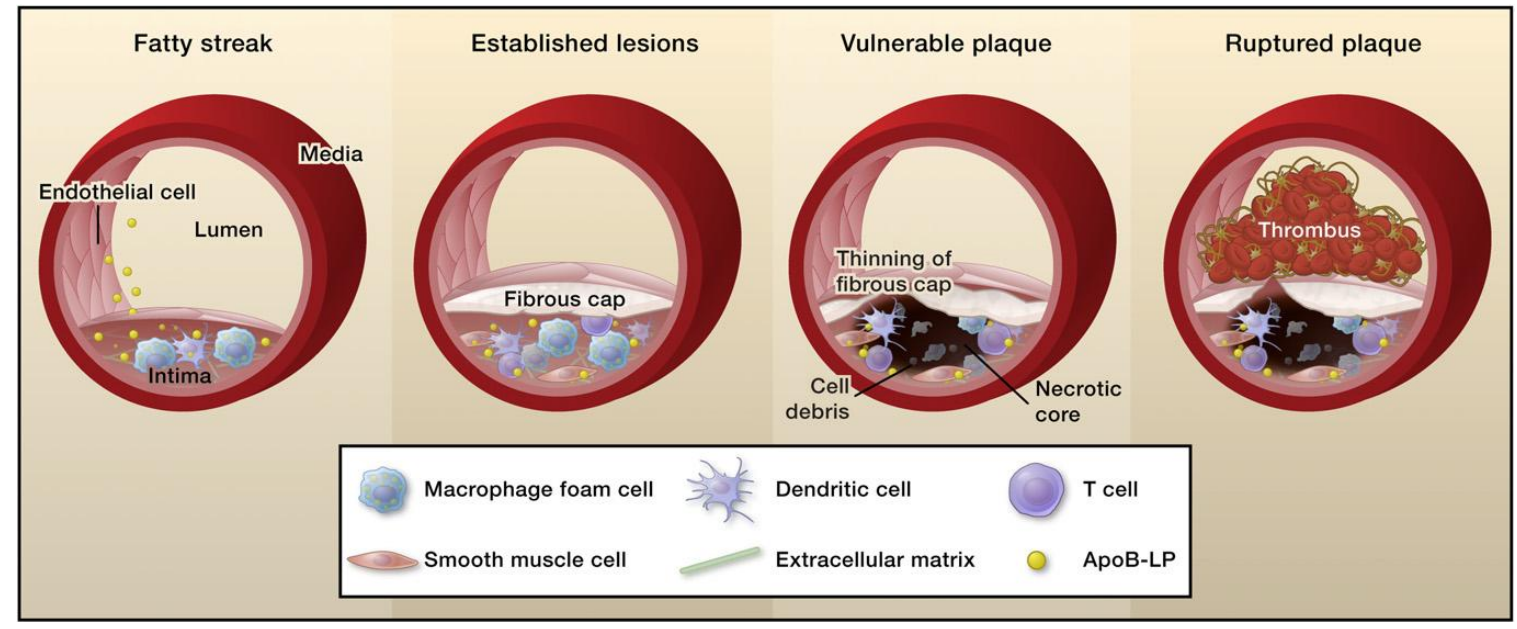


phospholipid/cholesterol as well as proteins such as apoB. The primary source of apoBcontaining proteins is very low density lipoprotein (VLDL) secreted from hepatic cells. VLDL is converted to low density lipoprotein (LDL) in the circulation. The most common reason for plaque development is elevated circulating levels of LDL-cholesterol (LDL-C) ${ }^{8}$, although other factors such as blood rheology and increased homocysteine levels are also involved $^{6}$. This is largely due to the fact that high concentrations of circulating LDL compromise endothelial integrity, resulting in LDL infiltration into the intima. Once in the intima, LDL is converted to oxidized LDL (oxLDL) by different enzymes and free radicals ${ }^{4}$. oxLDL then stimulates endothelial cells in the arteries to express leukocyte adhesion molecules such as vascular cell-adhesion molecule 1 (VCAM1) ${ }^{9}$. As a result, blood monocytes are recruited into the intima and differentiated into dendritic cells and macrophages. This initiates the pathogenesis of atherosclerosis through a process similar to the acute response of inflammation ${ }^{10}$. These monocyte-derived cells then take up oxLDL and other lipids through scavenger receptors ${ }^{11}$, notably scavenger receptor type A and a member of the type B family, CD36 ${ }^{12}$. When cholesterol uptake by these cells greatly exceeds their cholesterol removal capacity, they become cholesterol overloaded, or foam cells. Foam cell formation is one of the characteristics of early plaques and often leads to rapid progression of the lesion. This is largely due to their capacity to secrete cytokines and growth factors that further recruit monocytes. They also actively secrete extracellular matrix components. Over time, there is a steady increase in free cholesterol (FC) and decrease in cholesterol ester (CE) content as more macrophages become foam cells, resulting in increasingly more advanced lesions $^{13}$. This mature plaque, also known as atheroma, can disrupt blood flow in the artery due to the thickening of the vessel wall and narrowing of the artery. Importantly, the activation of macrophages is also responsible for size-independent advancing of the plaques, 
namely the formation of the necrotic core and thinning of the artery. This produces "vulnerable" plaque ${ }^{5}$. Such plaque is prone to rupture as the protective layer (fibrous cap) becomes weak. In such vulnerable plaques, macrophages trigger smooth muscle cell apoptosis by releasing pro-inflammatory cytokines such as tumor necrosis factor- $\alpha$ (TNF- $\alpha$ ), as well as nitric oxide (NO) and activating Fas apoptotic pathway ${ }^{14}$. Ultimately, weakened fibrous cap can break down, which triggers thrombosis and coagulation cascade when the plaque debris release tissue factor into the blood stream ${ }^{15}$. The sudden thrombotic occlusion of the artery can lead to myocardial infarction in the heart as well as heart failure, whereas in the brain it can cause ischaemic stroke and transient ischaemic attacks ${ }^{4}$.

In addition to circulating cholesterol, there is a variety of other causes for development of atherosclerosis including smoking, sedentary lifestyle, obesity as well as genetic factors ${ }^{16}$. Many promising targets of therapeutics against atherosclerosis are arising either to prevent or decrease the risk of artery blockage. These include HMG-CoA reductase inhibitors (statins), which reduce cholesterol synthesis thus circulating LDL levels ${ }^{17}$, and anti-coagulants that prevent the formation of blood clots in the artery ${ }^{18}$. Given the increasing prevalence of CVDs, particularly atherosclerosis, in our society, understanding the molecular mechanisms of how our body handles cholesterol is urgent. Hence, even modest progress in this area of research could have a huge beneficial effect.

\subsection{Cholesterol homeostasis}

Cholesterol is an essential biological molecule that controls normal functions of mammalian cells. Cholesterol, in the form of FC, interacts with phospholipids in the plasma membrane to stabilize the membrane bilayer and to control membrane fluidity and permeability ${ }^{19}$. This is due to the unique structural characteristics of cholesterol that facilitate 
optimal packing of phospholipids in the membrane bilayers. Cholesterol is also a key player in organizing membrane microdomains, or lipid rafts, to assemble signalling molecules into signalling complexes and regulate membrane protein sorting/trafficking ${ }^{20}$. The primary function of cellular cholesterol is on the plasma membrane but it is also a precursor for steroid hormones, bile acids and vitamin $\mathrm{D}^{21}$. In addition, cholesterol may act as an antioxidant $^{22}$.

In humans, the center of cholesterol homeostasis is the metabolism of lipoproteins. Lipoproteins are complex, micelle-like amalgamations of various proteins and lipids and are essential components for circulating cholesterol. Cholesterol itself cannot be transported to and from tissues in the plasma on its own due to its high hydrophobicity ${ }^{23}$. Instead, it utilizes lipoproteins as a carrier. Cholesterol metabolism is therefore largely dependent on the functions of lipoproteins. There are two major pathways where lipoprotein cholesterol is supplied to the circulation. First is the "exogenous" pathway through intestinal dietary chylomicrons and second is the "endogenous" pathway by hepatic synthesis and secretion of VLDL (Figure 1.2). In the "exogenous" pathway, absorbed lipids in the intestinal cells are assembled with apolipoprotein B-48 (apoB-48) and form chylomicrons ${ }^{24}$ (Figure 1.2, left). These nascent chylomicrons are secreted from the intestinal epithelial cells in the lymphatic vessels to bypass the liver and are eventually drained into the blood via the thoracic duct ${ }^{24}$. Within minutes of entering the bloodstream, triacylglycerols in the chylomicrons are hydrolyzed by lipoprotein lipase (LPL), converting them into chylomicron remnants. These remnants are taken up by the liver, which ultimately delivers cholesterol that is then recycled for the "endogenous" pathway ${ }^{24}$ (Figure 1.2, right). In the liver, the VLDL particle is synthesized from triacylglycerol, cholesterol and apolipoprotein B-100 (apoB-100) and matures when further loaded with apolipoprotein C-II (apoC-II) and apolipoprotein E (apoE). 


\section{Figure 1.2}

Lipid Metabolism in humans. "Exogenous" pathway: dietary lipids absorbed from the gut are incorporated with triglycerides by triglyceride transfer protein (MTP) into chylomicrons in the intestine. Chylomicrons containing apoB-48 enter the capillary, eventually losing their triglyceride to fatty acids by LPL to form chylomicron remnants. Following the uptake of remnants by LDLR or LDLR related protein (LRP) in the liver, lipids enter the "endogenous" pathway. "Endogenous" pathway: VLDL particles are synthesized in the liver and then hydrolyzed by LPL once they reach the circulation to produce IDL. IDL is either taken up by the liver LDLR or converted to LDL. LDL is further taken up by the liver and extrahepatic cells, such as macrophages. (Image adopted from figure 3 of Daniels, T. F. et al. Int. J. Biol. Sci. 5(5): 474-488. 2009. Permission was obtained from publisher.) 


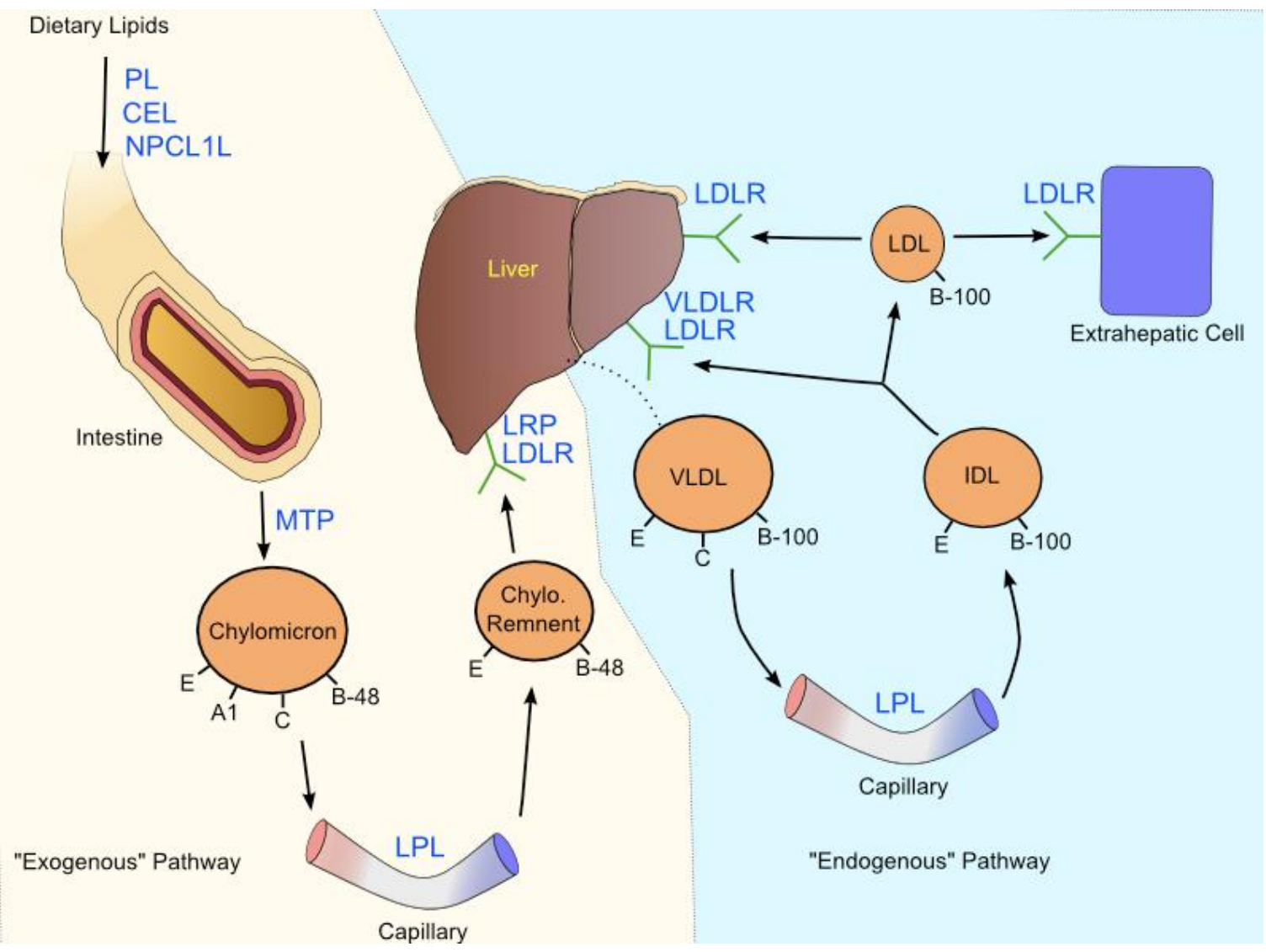


Similar to chylomicron metabolism, LPL hydrolyzes VLDL to form intermediate-density lipoprotein (IDL) and eventually LDL. LDL is the major source of cholesterol and phospholipids for extrahepatic tissues ${ }^{25}$. It delivers cholesterol by binding to ubiquitously expressed LDL receptors (LDLRs). This leads to LDL endocytosis via clathrin-coated pits and their subsequent hydrolysis in lysosomes, a Nobel-winning discovery by Dr. Michael Brown and Dr. Joseph Goldstein ${ }^{26}$.

Due to essential functions of cholesterol in animal cells, cholesterol levels have to be stringently regulated. The maintenance of cellular cholesterol level is mainly achieved by regulating uptake, biosynthesis, metabolism and efflux of cholesterol through various feedback and feed-forward metabolic pathways. For example, when the cholesterol level is low, it can be raised through uptake, i.e. LDL endocytosis. Alternatively, cholesterol can be synthesized endogenously. The cholesterol acquisition processes are primarily regulated by a family of endoplasmic reticulum (ER) membrane-bound transcriptional factors, namely sterol regulatory element binding proteins (SREBPs $)^{27,28}$. SREBPs act as transcriptional activators for more than 30 genes in addition to cholesterol biosynthesis, such that they regulate the synthesis of phospholipids, triglycerides and fatty acids ${ }^{29}$. The SREBP family exists as three isoforms, SREBP-1a, SREBP-1c and SREBP-2. SREBP-1a and SREBP-1c are encoded by sterol regulatory element-binding transcription factor-1 (SREBF-1) and differ in their first exon. However, SREBP-2 is encoded by a distinct gene, sterol regulatory element-binding transcription factor-2 (SREBF-2) ${ }^{30}$. SREBP-1 and SREBP-2 participate in cholesterol homeostasis in all tissues and in actively dividing cell lines cultivated in vitro. SREBP-2 preferentially activates genes that are involved in the uptake and biosynthesis of cholesterol $^{31}$. It especially up-regulates the LDL receptor and 3-hydroxy-3-methylglutarylCoA reductase (HMG-CoAR) genes that encodes for the enzyme controlling the rate-limiting 
step in de novo cholesterol biosynthesis ${ }^{29}$. Animal cells have evolved to efficiently use LDLRs to utilize cholesterol from dietary sources present in the circulation because endogenous biosynthesis of cholesterol consumes large amounts of energy. SREBPs upregulate LDLR synthesis to take up circulating LDL in addition to upregulating de novo cholesterol biosynthesis. Once the cellular pool of cholesterol is restored back to normal levels, SREBPs become inactivated. This effectively shuts down LDLR synthesis along with key enzymes involved in lipid synthesis including HMG-CoAR.

SREBP (collectively referring to SREBP-1a, -1c and -2) activity is primarily regulated by its transport from ER to Golgi apparatus and subsequent proteolytical cleavage. Under cholesterol repleted conditions, SREBP is retained in the the ER by forming a protein complex with Insig-1 and Insig-2 through SREBP cleavage-activating protein (SCAP) ${ }^{32}$ (Figure 1.3). In addition, cholesterol causes Insigs to bind the sterol-sensitive domain of HMG-CoAR for degradation ${ }^{33}$. At low cholesterol levels, SCAP changes its conformation and releases Insig-1 and Insig-2 that are then degraded by the ubiquitination pathway ${ }^{34}$. This allows SCAP/SREBP complex to exit ER and traffic to the Golgi apparatus by COPIImediated vesicular transport pathway ${ }^{27}$. Once in the Golgi, SREBP is cleaved by two proteolytic enzymes, resulting in the release of N-terminal DNA binding basic-helix-loophelix-leucine zipper (bHLH-Zip) fragments ${ }^{29}$. Consequently, the free bHLH-Zip fragment, also known as nuclear SREBP (nSREBP), translocates to the nucleus to bind sterol response elements (SREs) ${ }^{29}$. This activates the transcription of genes involved in cholesterol uptake and synthesis. In addition, nSREBP up-regulates the synthesis of phospholipids, triglycerides and fatty acids ${ }^{29}$.

Animal cells can also take up cholesterol, independent of SREBP regulated mechanisms. For example, oxLDL can be endocytosed through scavenger receptors. 


\section{Figure 1.3}

Sterol-mediated proteolytic release of SREBPs. In sterol-depleted cells, cholesterol dissociates from SREBP/SCAP complex in the ER that causes Insig-1 to dissociate as well. Dissociated Insig-1 undergoes proteasomal degradation. The separated SREBP/SCAP complex binds to COPII proteins and gets transported to the Golgi. SREBP is processed by proteases in the Golgi to be moved to the nucleus, where transcription of genes required for cholesterol synthesis occurs. This replenishes cholesterol levels and increases Insig-1 transcription at the same time. Cholesterol binding to SREBP/SCAP triggers a conformational change that causes the complex to bind to Insig-1 to retain the stable complex in the ER. (Image adopted from figure 7 of Gong, Y. et al. Cell Metabolism. 3(1): 15-24. 2006. Permission was obtained from publisher.) 


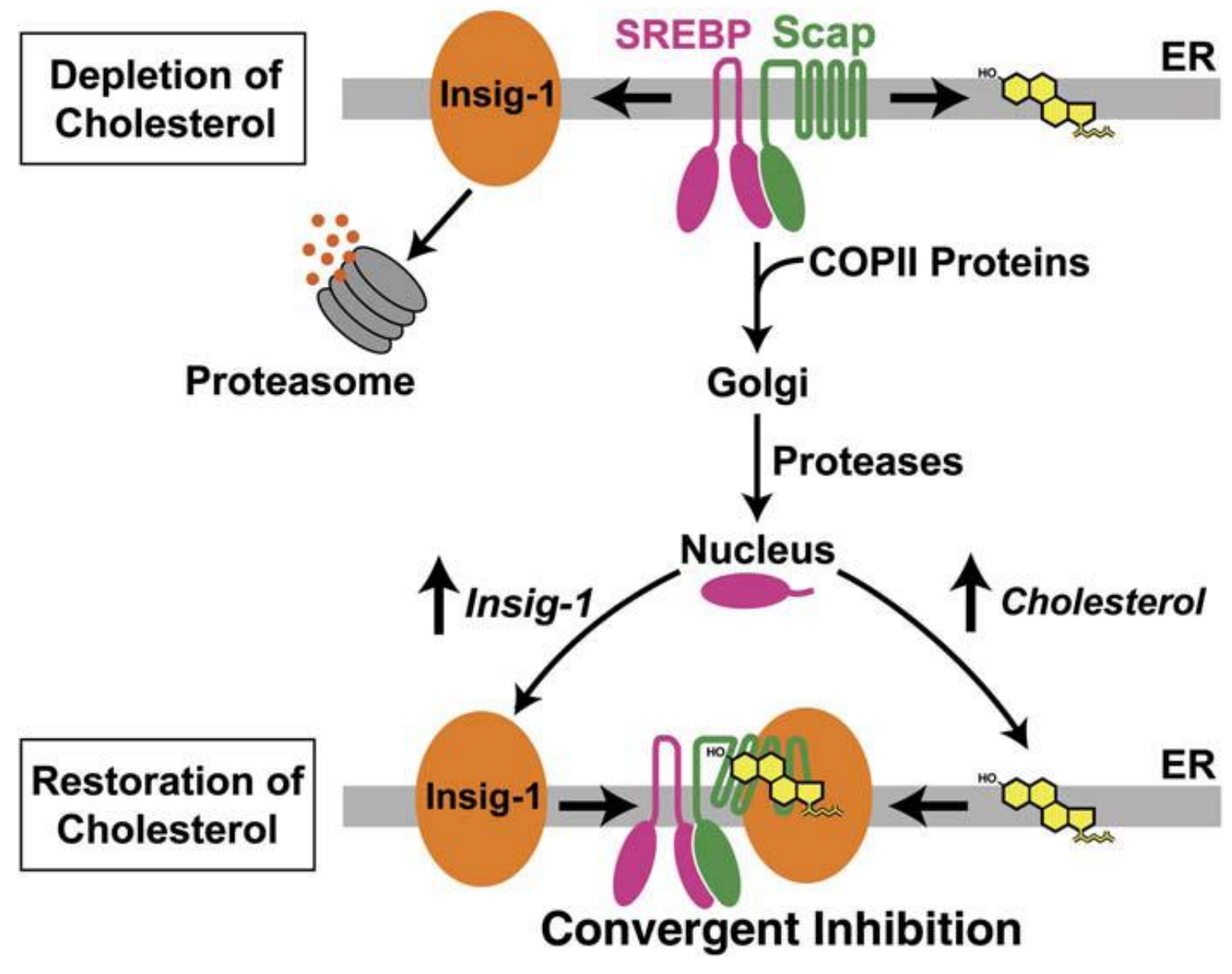


Additionally, macrophages can accumulate excess cholesterol through phagocytosis of apoptotic debris. In most cell types, such "un-regulated" accumulation of cholesterol causes little harm, due to their capacity to esterify FC into CE via acyl-coenzyme A (CoA):cholesterol acyltransferase (ACAT) ${ }^{35}$. CE can then be packed away into lipid droplets, thus maintaining cellular FC levels within the normal range. The ACAT family consist of $\mathrm{ACAT1}^{36}, \mathrm{ACAT2}^{37}$, and Acyl-CoA:diacylglycerol acyltransferase 1 (DGAT1) ${ }^{38}$. ACAT1 and ACAT2 shares high homology and similar enzymological properties but are not identical in terms of cell locations, membrane orientations, tissue-specific expression and substrate specificity $^{39}$. ACAT1 is known to be the major isoenzyme in monocytes and foamy macrophages that initiate and progress atherosclerotic plaques in experimental animal models and perhaps in humans ${ }^{40,41,42}$. ACAT1 resides in the ER and its activity is driven by the availability of FC. For instance, at low FC level, SREBPs are activated and ACAT activity is minimal. In contrast, when cellular FC is high, SREBP is suppressed and ACAT is activated. This allows cells to store excess FC as CE for future use while minimizing potential toxic effect of un-regulated cholesterol uptake.

Another unique feature of cholesterol homeostasis is that most animal cells lack efficient means to metabolize cholesterol, with the exception of steroidogenic tissues and the liver. Cholesterol is taken up and utilized to generate steroids in steroidogenic tissues or metabolized in liver to bile acid. This latter process provides the only means in animals to excrete excess cholesterol. Excess cholesterol in peripheral tissues therefore has to be transported back to the liver for excretion. This process is called reverse cholesterol transport (RCT).

\subsection{Reverse cholesterol transport: production of HDL}


RCT is mediated mainly by high density lipoproteins or HDL. It is widely known that an increased level of LDL-C is the major factor in the progression of CVD ${ }^{19}$. Conversely, there are extensive epidemiological data showing an inverse relationship between HDL levels and $\mathrm{CVD}^{43,}{ }^{44}$. This is largely due to the fact that HDL removes cholesterol from peripheral tissues such as lipid-laden macrophages and transports cholesterol to the liver for excretion (Figure 1.4). HDL is a heterogeneous population of particles that contains a variety of proteins of diverse functions. The main component, representing approximately $70-80 \%$ of the total protein, is apolipoprotein A-I (apoA-I) ${ }^{45}$. The first step of RCT involves ATP (Adenosine 5'-triphosphate)-binding cassette transporter A-I (ABCA1). It has been shown that ABCA1 enables apoA-I binding to cells and facilitates the transfer of cellular cholesterol to apoA-I. This generates nascent discoidal pre- $\beta-\mathrm{HDL}^{46}$, a particle containing $2-4$ molecules of apoA-I and membrane phospholipid classes as well as some cholesterol. These nascent HDL particles begin to acquire additional cholesterol in the circulation, through multiple mechanisms as discussed below.

Although ABCA1 plays predominant roles in RCT, other factors are also required for HDL maturation. For example, HEK293 cells overexpressing ABCA1 can use apoA-I to produce only pre- $\beta$-HDL, but without modifying factors like lecithin: cholesterol acyltransfease (LCAT), ATP-binding cassette transporter G-I (ABCG1), scavenger receptor class-B, type 1 (SR-BI), more mature $\alpha$-HDL particles cannot be formed ${ }^{47}$. In general, newly formed nascent HDL particles are able to acquire more cholesterol through aqueous diffusion from cell membranes containing higher FC concentration ${ }^{48}$. This process produces cholesterol-rich pre- $\beta_{2}$-HDL and pre- $\beta_{3}-\mathrm{HDL}$ and is mediated by ABCG1 and perhaps also ATP-binding cassette transporter G-4 (ABCG4) ${ }^{49}$. Another factor contributing to the 


\section{Figure 1.4}

Reverse cholesterol transport and cholesterol efflux in macrophages. ABCA1-mediated cholesterol efflux is the first step in RCT. Lipid-poor apoA-I interact with ABCA1 in macrophages leading to efflux of FC and phospholipids. Nascent HDL becomes more mature HDL containing CE by LCAT, where it is either uptaken by the liver through SR-BI to be excreted in bile or in humans it is transferred to VLDL/LDL by CETP for further clearance by the LDLR in the liver. Mature HDL particle can serve as acceptors for ABCG1-mediated cholesterol efflux. (Image adopted from figure 1 of Tall, A. R. et al. Cell Metabolism. 7(5): 365-75. 2008. Permission was obtained from publisher.) 


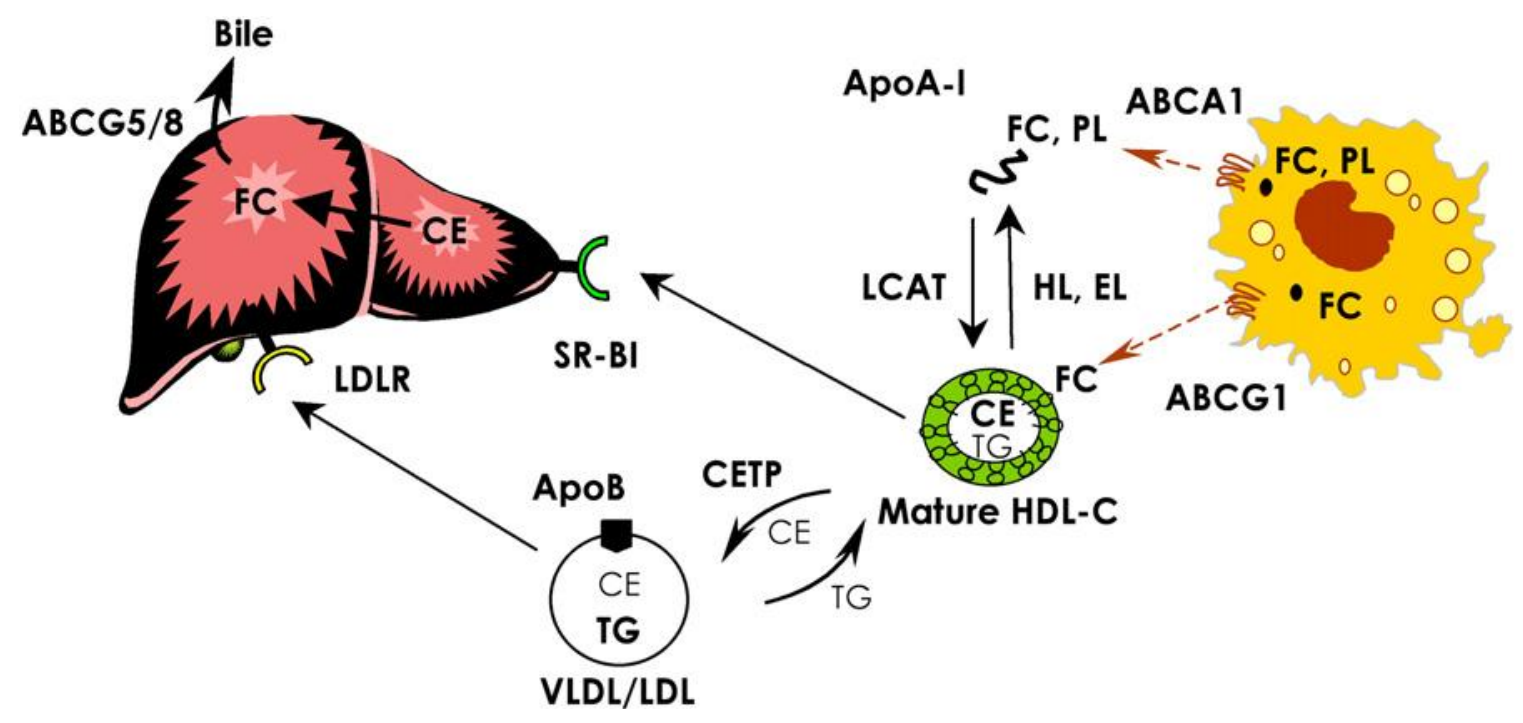


maturation of nascent HDL is through its association with SR-BI. SR-BI mediates the bidirectional flux of CE and phospholipids between HDL and cells ${ }^{50}$.

HDL-cholesterol (HDL-C) is further processed by LCAT, activated by apoA-I, to form CE. This allows the transition of nascent pre- $\beta$-HDL and more cholesterol-rich pre- $\beta_{2}-\mathrm{HDL}$ and pre- $\beta_{3}-\mathrm{HDL}$ into mature spherical $\alpha$-HDL particles. CE is more hydrophobic than FC; hence can get packed in the centre of HDL particle, causing a change in the particle geometry from discoidal to spherical. Importantly, $\alpha$-HDL particles serve as effective acceptors of FC from ABCG1-expressing cells. In macrophages, ABCG1 plays a complementary role with respect to ABCA1, since ABCA1 interacts with lipid-poor apoA-I but does not interact well with more mature $\alpha_{2}$-HDL and $\alpha_{3}-\mathrm{HDL}^{46,51}$. ABCG1, on the other hand, promotes cholesterol efflux to $\alpha_{2}$-HDL and $\alpha_{3}$-HDL but not lipid-poor apoA-I ${ }^{52}$. Therefore, the interaction of apoA-I with ABCA1 must occur before ABCG1-mediated cholesterol efflux to more mature HDL ${ }^{53}$. The mechanism of ABCG4-mediated cholesterol efflux is not as well characterized as ABCG1.

Fully matured HDL particles are rich in CE and this CE component can be transferred to the liver through SR-BI for excretion. In human, HDL CE can also be transferred to LDL, VLDL and chylomicrons via cholestryl ester transfer protein (CETP) in exchange for triglycerides $^{54}$. In addition, HDL can acquire phospholipids from VLDL/LDL by phospholipid transfer protein (PLTP). CETP and PLTP allow intermediate sized $\alpha$-HDL to form larger HDL particles. This leads to an enhanced capacity to take up cellular cholesterol by the liver via SR-BI ${ }^{55}$. SR-BI mediates selective transfer of CE from HDL particles to the liver, which releases lipid-poor apoA-I for a new cycle of RCT. Indeed, mice with inactivated SR-BI gene have a two-fold increase in plasma cholesterol with unusually large and homogenous HDL ${ }^{56}$. 
Once in the liver, cholesterol enters the bile synthesis pathway, which begins with an enzyme, $7-\alpha$-hydroxylase that converts hepatic cholesterol to 7 - $\alpha$-hydroxycholesterol ${ }^{57}$. Then 7- $\alpha$-hydroxycholesterol is $f$ urther converted into bile salts such as taurocholic and glycocholic acid. After the bile acid synthesis, it moves into the gall bladder and finally to the duodenum for excretion via feces. Here, another set of $\mathrm{ABC}$ transporters, ABCG5/ABCG8, is required to facilitate hepatobiliary cholesterol transport into bile ${ }^{58}$. ABCG5 and ABCG8 are half transporters and form functional heterodimers for cholesterol efflux to bile ${ }^{59}$. Mutations in ABCG5 and ABCG8 genes are known to cause sitosterolemia, an inability to concentrate plant and shellfish sterols into bile ${ }^{58}$. Mutations in ABCA1, on the other hand, are the cause of Tangier disease in human.

\subsection{Tangier disease}

The first case of this autosomal recessive disease had been identified in 1961 by Dr. Donald S. Fredrickson in an isolated island called Tangier Island off the Virginia coast in United States ${ }^{60}$. The patient had phenotypes of orange, CE-laden tonsils, peripheral neuropathy and strong predisposition for coronary artery disease ${ }^{61}$. It was later found that the patients with Tangier disease had strikingly low or near absent levels of HDL in the plasma. To investigate the reason behind the low levels of HDL, Schmitz and colleagues suggested in 1983 that the defect in Tangier disease might be in the process of converting pre-apoA-I to mature apoA-I ${ }^{62}$. However, neither apoA-I defects nor deficiency of the converting-enzyme activity could be found in patients with Tangier disease ${ }^{63}$. In 1999, three independent studies published their finding in Nature Genetics that mutations in ABCA1 are the cause of Tangier disease $^{64-66}$. Curiously, although Tangier patients have little HDL, the risk for early atherosclerosis, though enhanced (by about 5 fold), is not as dramatic as might be expected. 
This is thought to be largely due to abnormally low LDL levels in Tangier patients, a parameter highly protective from atherosclerosis ${ }^{67}$. Without ABCA1, LDL is hypercatabolized. Hence, even though ABCA1 is dysfunctional, this deficiency can be partially rescued by lower total LDL-C in human and ABCA1 knockout animals ${ }^{60}$. Although Tangier disease is a rare disease, research in Tangier disease has provided much insight in HDL metabolism. It is now well established that ABCA1 exerts a strong anti-atherogenic effect and explains the development of atherosclerosis in Tangier patients. There, however, still remains more questions regarding the relationship between specific sub-phenotypes of Tangier disease and $\mathrm{ABCA} 1$, such as peripheral neuropathy in Tangier disease.

\subsection{ABCA1 structure and functions}

ABCA1 is a member of a highly conserved superfamily known as the $\mathrm{ABC}$ transporters. These transporters primarily function to transport various substrates across the membrane. Overall, the family is comprised of 7 distinct subclasses termed A- $\mathrm{G}^{68}$, according to their gene sequence similarity, structural homology or phylogenesis ${ }^{69}$. The core structure of eukaryotic $\mathrm{ABC}$ transporters contain two hydrophobic transmembrane domains (TMDs) alternating with two cytosolic nucleotide binding domains (NBDs). Frequently, TMDs are at the $\mathrm{NH}_{2}$-terminal to the $\mathrm{NBDs}^{70}$. $\mathrm{ABC}$ proteins have different domain configurations because some are full transporters and others are half transporters. In full transporters, a single gene encodes two NBDs and TMDs, such as $\mathrm{ABCA} 1$ and $\mathrm{ABCB} 1^{71}$. Half transporters only have one NBD and one TMD and form homodimers with each other or heterodimers with another $\mathrm{ABC}$ half transporter. For example, ABCG5 and ABCG8 are half transporters that heterodimerize with each other ${ }^{59}$. All of the $\mathrm{ABC}$ transporters have the characteristic of coupling ATP hydrolysis at the NBDs to provide energy for the translocation of their 
substrates. Most eukaryotic ABC transporters export substrates from the cell or into organelles but prokaryotic $\mathrm{ABC}$ transporters can either export or import substrates. In human, there are many diseases that are associated with the mutations of these transporters. For example, mutations in $\mathrm{ABCA} 4, \mathrm{ABCC} 7$ and $\mathrm{ABCA} 1$ genes cause retinal degeneration, cystic fibrosis and Tangier disease, respectively ${ }^{72-73,64}$.

Studies of human diseases and mouse models have shown that ABCA1 is cardioprotective and essential for generation of HDL as described above $\mathrm{e}^{74,75}$. ABCA1 was first identified in 1994 , which brought to a new $\mathrm{ABC}$ family subclass $\mathrm{A}^{76}$. ABCA1 is the prototypic member of the ABCA subfamily, containing 2261 amino acids in length with a size of $240 \mathrm{kDa}$. It has a symmetrical structure with each TMD consisting of six transmembrane segments (TMS) and a NBD, repeated in tandem (Figure 1.5). It also possesses two extremely large extracellular loops located between the TMS 1 and 2 and also between TMS 7 and 8 that are highly glycosylated and linked by 1 or more cysteine bonds ${ }^{77}$. $\mathrm{ABCA} 1$ is unique in that it lacks a classical substrate as opposed to other $\mathrm{ABC}$ transporters like multidrug-resistance protein 1 (MRP1) and P-glycoprotein ${ }^{78,79}$. However, ABCA1 transports lipids and metabolites including cholesterol and phospholipids across the membrane ${ }^{80}$ from cells to lipid-poor apoA1, providing an efficient means for cells to excrete excess cholesterol $^{81}$. In addition to cholesterol and phospholipids, ABCA1 also appears to mediate the transport of apoE $E^{82}$, interleukin (IL)- $1 \beta^{83}$ and $\alpha$-tocopherol ${ }^{84}$. Loss-of-function mutations in human ABCA1 are known to increase the prevalence and severity of atherosclerosis. This essential function of ABCA1 is fully supported by animal studies. Overexpression of human ABCA1 in transgenic atherogenic mouse models protects against atherosclerosis $^{85}$. On another hand, ablation of the ABCA1 gene in macrophages increases atherosclerotic lesions in mice ${ }^{86}$. ABCA1 expression is also known to significantly influence 


\section{Figure 1.5}

Schematic view of the topological arrangement of ABCA1. ABCA1 transporter is a fulllength transporter of 2261 amino acids in length and $240 \mathrm{kDa}$ in size. The following sites are shown: two NBD each containing Walker A and B motifs, two TMD containing $6 \alpha$-helices, two extracellular domains (ECDs), PEST sequence and posttranscriptional modification sites related to ABCA1 trafficking. The intracellular position of $\mathrm{N}$ and $\mathrm{C}$ terminus is also indicated. (Image adopted from figure 2 of Kang, M. H. Singaraja, R., and Hayden, M. R. Trends Cardiovasc Med. 20(2): 41-49. 2010. Permission was obtained from publisher.) 


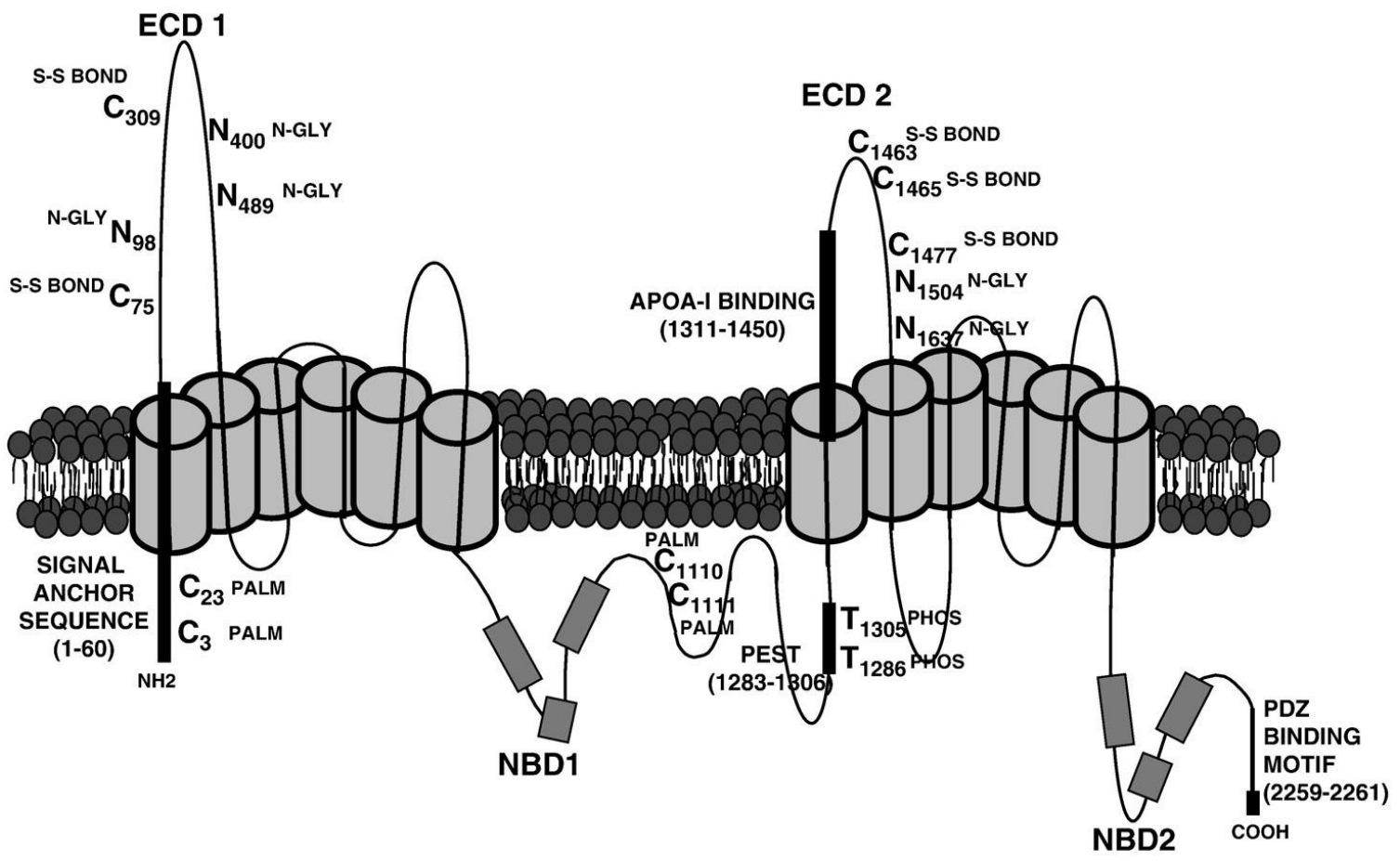


the functions of plasma membrane, such as endocytosis and phagocytosis ${ }^{87,88}$. It has also been established that $\mathrm{ABCA} 1$ redistributes cholesterol, sphingomyelin, caveolin from lipid rafts to non-rafts regions to facilitate apoA-I cell association and cholesterol efflux ${ }^{89}$. This further modulates the functions of the plasma membrane. However, despite the importance of ABCA1 in human health, the precise molecular identity of ABCA1 is not yet known.

Several models have been proposed to explain the molecular mechanism of cholesterol efflux from peripheral cells to lipid-poor apoA-I. The so-called retro-endocytosis model states that apoA-I binds to ABCA1 at the plasma membrane and this facilitates apoA-I internalization into the intracellular compartments to acquire cholesterol and phospholipids ${ }^{90,}$ 91. Indeed, there is a correlation between apoA-I/cell associations and ABCA1 expression. Chemical cross-linking approaches are also able to demonstrate that ABCA1 and apoA-I form a close molecular complex $(<3 \AA)$ with high affinity $(\mathrm{Kd}=7 \mathrm{nM})^{92,93}$. In addition, four different naturally occurring mutations in the extracellular loops of ABCA1 resulted in diminished cholesterol efflux to apoA- $\mathrm{I}^{94}$. This supports the notion that ABCA1 act as a receptor for apoA-I, which brings apoA-I into intracellular cholesterol-rich organelles, such as recycling compartment and late endosomes, to be lipidated. The newly formed nascent HDL then traffic back to the plasma membrane through exocytosis ${ }^{95}$. A study by Faulkner et al. has shown that approximately $30 \%$ of endocytosed ABCA1 recycles back to the plasma membrane after 1 hour incubation at $37^{\circ} \mathrm{C}^{96}$.

There are also evidences that ABCA1-mediated lipidation involves the plasma membrane as a main platform instead of retro-endocytosis pathway. This was demonstrated by a study from our laboratory showing that, of internalized apoA-I, only minority was converted to HDL, and the rest was degraded by lysosomes ${ }^{97}$. The majority of apoA-I interacts with the plasma membrane and is then rapidly released as HDL before it could enter 
the intracellular compartments. Thus, this argues that ABCA1 promotes the transfer of cholesterol and phospholipids to apoA-I at the plasma membrane, perhaps by forming a channel in the membrane that "flip-flops" lipids from the inner leaflet to the outer leaflet ${ }^{98,99}$. This process is likely to be ATP-dependent because mutations of the NBD domains prevent apoA-I lipidation.

Another so-called "sequential" model proposes that ABCA1 would lipidate apoA-I with phospholipids first. The pre- $\beta$ nascent HDL formed would further acquire FC from lipid domains on the plasma membrane ${ }^{100}$. This model was based on observations that conditioned medium containing phospholipidated apoA-I can mediate FC efflux from ABCA1 deficient vascular endothelial cells ${ }^{100}$. Also, HEK293 cells pre-treated with $20 \mathrm{mM}$ cyclodextrin, which specifically depletes cholesterol, retains phospholipid efflux to apoA-I, even though FC efflux to apoA-I is absent ${ }^{46}$. However, other studies found simultaneous transfer of cholesterol and phospholipids, raising questions for this sequential lipidation model. Indeed, the kinetic studies of phospholipid and cholesterol efflux show that, in the first 10 minutes of efflux, both were released at similar rates ${ }^{101}$. Despite in depth studies in each model, the precise mechanism by which ABCA1 mediates efflux of phospholipids and FC remain unclear.

In addition to mediating cholesterol/phospholipid efflux, ABCA1 has antiinflammatory functions, which may significantly contribute to cardioprotection. Patients with familial HDL deficiencies and dysfunctional ABCA1 positively correlate with chronic lowgrade inflammation ${ }^{102,}{ }^{103}$. Moreover, Zhu and colleagues have shown that murine macrophages lacking ABCA1 have increased expression and secretion of pro-inflammatory cytokines, TNF- $\alpha$, IL-6, and IL-12p40, when treated with an inflammatory stimulus, lipopolysaccharide (LPS) ${ }^{104}$. This anti-inflammatory function of ABCA1 was further 
confirmed by an in vitro study showing that ABCA1-/- murine peritoneal macrophages have increased cholesterol content in lipid rafts and increased production of inflammatory cytokines through the toll-like receptor 4 (TLR4) pathway ${ }^{105}$. Interestingly, cyclodextrin, an ABCA1-independent cholesterol acceptor, and ABCG1 are also anti-inflammatory ${ }^{104,106}$. This suggests that the anti-inflammatory effects of ABCA1 may be linked to its function in lipid homeostasis ${ }^{104}$.

\subsection{ABCA1 expression and regulation}

ABCA1 is expressed in a variety of tissues including liver, small intestines, lung, placenta, adrenal glands, heart, macrophages, adipocytes and others ${ }^{107}$. However, expression in liver and macrophages appear to be most physiologically relevant. Transcriptional and translational regulation of ABCA1 in these cells has thus been intensely studied in the last decade ${ }^{81}$

The transcriptional regulation of ABCA1 is controlled by a variety of molecular factors. Among these, nuclear orphan receptors are the largest group of factors regulating transcription of $\mathrm{ABCA} 1$. These include liver-X receptors $(\mathrm{LXR} \alpha$ and $\beta)$, retinoic-X receptor (RXR), peroxisome proliferator-activated receptor (PPAR $\alpha$ and $\gamma$ ), thyroid hormone receptor (TR) and pregnane-X receptor $(\mathrm{PXR})^{108-110}$. LXR and RXR form a heterodimer triggered by oxysterols and/or retinoic acids, respectively. LXR/RXR complex then bind to DR4 DNA response elements within the ABCA1 promoter as well as the first intron ${ }^{111,112}$. Oxysterol or 9-cis-retinoic acid can increase ABCA1 expression individually and has synergistic effects when administered at the same time ${ }^{110,113}$. LXR/RXR can also be activated by lipid metabolites as well as cholesterol loading in cells ${ }^{114,}{ }^{113}$. Furthermore, PPAR $\alpha$ and $\gamma$ upregulate ABCA1 expression indirectly via enhancing transcription of $\operatorname{LXR} \alpha^{115}$. On the other 
hand, PXR down-regulates ABCA1 expression through TR/RXR dimers by competing with LXR/RXR for the DR4 element ${ }^{108}$. Also, geranylgeranyl pyrophosphate, an intermediate in the endogenous mevalonate pathway reduces ABCA1 expression by decreasing the transactivation of LXR through blocking DNA binding to DR4 elements ${ }^{116}$.

Other factors such as secondary messengers and cytokines (interferon- $\gamma^{117}$ and oncostatin $\mathrm{M}^{118}$ ) also regulate transcription of ABCA1 in macrophages. A ubiquitous second messenger, cyclic adenosine monophosphate (cAMP), upregulates ABCA1 expression in murine macrophages by acting both at transcriptional and post-transcriptional level. For instance, in RAW 264.7 macrophages and J774 cells, cAMP is known to induce ABCA1 messenger RNA (mRNA) and protein levels up to 50-70 folds ${ }^{119}$. In contrast, cAMP is not able to increase ABCA1 expression in human tissue, showing the different regulating mechanisms between species ${ }^{120}$. More recently, cAMP response element, a downstream target activated by cAMP induction, and signal transducer and activator of transcription (STAT) 3/4 element have been identified in the same promoter region of murine ABCA1, although the mechanism of action to increase ABCA1 expression is still unknown ${ }^{121}$. This study also verifies that STAT3/4 element is not conserved in human ABCA1 gene ${ }^{121}$.

ABCA1 function is posttranscriptionally regulated by either protein stability or activity. The stability is mainly controlled by calpain-mediated degradation, whereas the activity is governed by protein kinases ${ }^{122,123}$. There frequently is a difference between ABCA1 protein level and mRNA abundance in mice, showing that posttranscriptional regulation plays a significant role in ABCA1 expression ${ }^{107}$. ABCA1 has a PEST sequence that determines its half-life around 1-3 hours ${ }^{123,124}$. PEST motifs are hydrophilic loops or extensions made up of residues of proline $(\mathrm{P})$, glutamic acid $(\mathrm{E})$, serine $(\mathrm{S})$ and threonine $(\mathrm{T})$ located between residues, 1283 and 1306 in ABCA1 (Figure 1.5). The process of ABCA1 turnover at the cell 
surface is not completely understood, but seems to be inhibited by the presence of calpain specific protease inhibitor, calpeptin ${ }^{124}$. Wang and colleagues has shown that the PEST motif enhances the degradation of ABCA1 by calpain protease and thereby regulates the cell surface expression and cholesterol efflux activity of $\mathrm{ABCA} 1^{124}$. Deletion of the PEST significantly increases $\mathrm{ABCA} 1$ at the cell surface while decreasing its trafficking to late endosomes $^{124}$. In support of the posttranscriptional regulation concept, cytotoxic levels of $\mathrm{FC}^{125}$ or unsaturated fatty acids ${ }^{123}$ in macrophages decrease ABCA1 by accelerating its degradation. Also, apoA-I stabilizes ABCA1 on the cell surface through phosphorylation of ABCA1 by various kinases ${ }^{126,127}$.

\subsection{Signalling pathways regulating ABCA1 functions}

Recent studies have implicated many signalling pathways governing ABCA1 functions. The key signalling molecules identified include protein kinase A (PKA) ${ }^{128}$, Janus kinase 2 $(\mathrm{JAK} 2)^{129,130}, \mathrm{Cdc} 42^{131}$ and casein kinase $2(\mathrm{CK} 2)^{132}$. ABCA1 is thought to be constitutively phosphorylated by PKA. Disrupting such phosphorylation by PKA inhibitors, H89 and PKI, reduce cholesterol and phospholipid efflux activity by $50-100 \%{ }^{133,134,99}$. ABCA1 phosphorylation is thought to directly modulate its activity and downstream efflux of phospholipids and cholesterol to apoA-I ${ }^{128-130}$. However, how phosphorylation of ABCA1 by PKA affects lipid efflux is not yet known. It is also possible that PKA may target molecules downstream of ABCA1 because mutating two PKA phosphorylation sites on ABCA1 had no effect on cholesterol export ${ }^{130}$. PKA activity is initiated by cAMP, which is generated by transmembrane and soluble adenylyl cyclases (ACs) ${ }^{135}$. PKA is a broad spectrum Serine/Threonine kinase consisting of two regulatory and two catalytic subunits. Binding of cAMP to the regulatory subunit results in a conformation change that releases the catalytic 
subunits. As PKA is known to regulate a wide range of physiological events, its activity has to be precisely controlled at specific cellular locations and at specific times ${ }^{136}$. This spatial and temporal regulation is conveyed in part by interacting with protein kinase A-anchoring proteins (AKAPs). Interestingly, AKAPs anchor not only PKA but often phosphatases to coordinate phosphorylation dynamics. In addition, AKAPs participate in cAMP biogenesis by sequestering $\mathrm{ACs}$ and esterases, which generate localized cAMP microdomains to regulate PKA activity ${ }^{137}$. Also, AKAP seem to participate in ABCA1-mediated cholesterol efflux $^{138}$, but the detailed mechanism is not yet defined.

While PKA activity is essential for ABCA1-mediated efflux, JAK2 activation appears to be correlated with enhanced ABCA1/apoA-I binding ${ }^{133}$. JAK2 is a well-characterized tyrosine kinase that is activated by many cytokine/hematopoietin superfamily of receptors ${ }^{139}$. Of many, the JAK2/STAT3 pathway seems to regulate both RCT and anti-inflammatory roles of ABCA1. For instance, apoA-I binding to ABCA1 rapidly stimulates JAK2 autophosphorylation $^{140}$. Activated JAK2 then induces a conformational change of ABCA1 enhancing apoA-I binding ${ }^{133}$. This conformational change recruits STAT3 to ABCA1 to be phosphorylated by JAK2. STAT3 is then translocated to the nucleus to regulate antiinflammation regulatory protein transcription ${ }^{141}$. Interestingly, STAT3 activation is not responsible for ABCA1-mediated lipid efflux, as mutating STAT3 docking site on ABCA1 completely abolishes STAT3 binding, but does not affect cholesterol efflux to apoA-I ${ }^{141}$.

Although the mechanism is not clear, another signalling molecule that regulates ABCA1-mediated lipid efflux to apoA-I is a Rho family G protein, $\mathrm{Cdc} 42^{131}$. Cdc42 is activated with incubating cells with apoA-I ${ }^{142}$. c-Jun N-terminal kinases (JNKs) are the downstream target of apoA-I/Cdc42 and, when activated, promote apoA-I-induced cholesterol efflux ${ }^{131}$. 
Conversely, there are kinases that inhibit ABCA1 functions. CK2 constitutively phosphorylates ABCA1 protein residues between NBD1 and TMD7 ${ }^{132}$. Mutation at this location abolishes CK2 mediated phosphorylation and enhances apoA-I binding and cholesterol efflux $^{132}$.

\section{8 $\mathrm{Ca}^{2+}$ signalling in ABCA1-mediated apoA-I lipidation}

Secondary messenger $\mathrm{Ca}^{2+}$ is the most ubiquitous and pluripotent signalling molecule that controls many spatial and temporal intracellular signalling events. At a resting state, intracellular concentration of $\mathrm{Ca}^{2+}$ is very low $(100 \mathrm{nM})$ compared to the extracellular concentration $(1-2 \mathrm{mM})^{143}$. Intracellular $\mathrm{Ca}^{2+}$ levels increase by releasing $\mathrm{Ca}^{2+}$ from internal stores such as sarcoplasmic reticulum or through signalling pathways that cause influx of extracellular $\mathrm{Ca}^{2+}$ into the cytoplasm through $\mathrm{Ca}^{2+}$ channels ${ }^{144-146}$. One important intracellular $\mathrm{Ca}^{2+}$ target is calmodulin $(\mathrm{CaM})$, a ubiquitous $17 \mathrm{kDa}$ protein expressed in all eukaryotic cells $^{147}$. Upon $\mathrm{Ca}^{2+}$ binding, $\mathrm{CaM}$ undergoes a structural rearrangement such that it can bind to wide variety of downstream target proteins including phosphatases (calcineurin) and $\mathrm{CaM}$ kinases (CaMKs) I, II and $\mathrm{IV}^{148}$. Calcineurin is a heterodimeric protein comprised of catalytic A subunit and $\mathrm{Ca}^{2+}$ binding regulatory $\mathrm{B}$ subunit ${ }^{149}$. Once $\mathrm{CaM}$ binds to its regulatory B subunit, calcineurin is activated and known to dephosphorylate a large number of proteins, such as nuclear factor of activated T cells (NFAT) ${ }^{150}$.

It was reported that extracellular $\mathrm{Ca}^{2+}$ was required for $\mathrm{ABCA} 1-$ mediated cholesterol efflux to apoA-I ${ }^{151}$. This is largely due to the fact that apoA-I binding triggers $\mathrm{Ca}^{2+}$ influx to the cytoplasm and such influx is essential for the process. $\mathrm{Ca}^{2+}$ then increases $\mathrm{CaM}$ activity as well as consequent activation of calcineurin ${ }^{143}$. Calcineurin can apparently influence JAK2 phosphorylation, as inhibition of calcineurin by cyclosporine A (CsA) decreases JAK2 
phosphorylation and abolishes cholesterol efflux to apoA-I ${ }^{143}$. Neither $\mathrm{Ca}^{2+}$ manipulations nor CsA affect ABCA1 expression, cellular distribution or ability to remodel lipid rafts, demonstrating that this $\mathrm{Ca}^{2+}$ signalling pathway does not directly modify ABCA1 activity. It is apoA-I lipidation that is specifically regulated by $\mathrm{Ca}^{2+}$. Presently, we do not understand the mechanism that governs $\mathrm{Ca}^{2+}$ influx.

\subsection{The secretion of extracellular nucleotides}

One of the regulators of extracellular $\mathrm{Ca}^{2+}$ influx into the cytoplasm is extracellular ATP (eATP $)^{152}$. The primary roles of nucleotides and ATP are to serve as energy currency in all cell functions. It was surprising for many researchers when nucleotides were first recognized to be released from many different cells. We now know that eATP can act as an extracellular signalling molecule in paracrine and autocrine signalling, ubiquitously used for cell-cell communication in many different types of mammalian cells including nerve cells, endothelial cells, and cells responsible for immune functions ${ }^{153,154}$. eATP is normally maintained at around $10 \mathrm{nM}$, in contrast to $3-10 \mathrm{mM}$ in the cytoplasm. The steady state eATP concentration depends on the rate of secretion and hydrolysis. ATP hydrolysis, i.e. from ATP to ADP, AMP and adenosine, is catalyzed by extracellular ecto-apyrase and ectoadenosine triphosphatases (ecto-ATPases) (Figure 1.6). On the other hand, mammalian cells also release ATP, particularly at the time of shear stress, stretch, hypoxia, inflammation, osmotic swelling and cell death ${ }^{152}$. Studies have proposed various mechanisms of ATP secretion into extracellular milieu, but it is still unclear if these mechanisms are operating under non-stress conditions and how variable among different type of cells. Briefly, there are three potential mechanisms of ATP release. Firstly, ATP can be released by exocytosis of ATP-filled secretory vesicles, as in neuronal cells. These vesicles contain nearly $5 \mathrm{mM}$ of 


\section{Figure 1.6}

ATP release and purinergic signalling. Various stimulus leads to the release of ATP into the extracellular milieu. This eATP is regulated in the ATP-releasing cells (autocrine) or neighboring cells (paracrine) for various physiological and pathophysiological processes via purinergic receptors, $\mathrm{P} 2 \mathrm{X}$ and $\mathrm{P} 2 \mathrm{Y}$. Ectoncleotidase, such as ectoncleoside triphosphate diphosphohydrolase 1 (ENTPD1) promotes hydrolysis of ATP and formation of ADP, which also activates P2Rs. Another ectonucleotidase, CD73 further hydrolyses ADP to adenosine for P1 signalling through P1Rs. The response of eATP in cells depends on combination of factors: stimulus for the ATP release, amount of release, purinergic receptors, breakdown of ATP by ectonucleotidases, cellular signalling pathways and effector processes within the stimulated cells. (Image adopted from figure 1 of Novak, I. News Physiol Sci. 18: 12-17. 2003. Permission was not required.) 


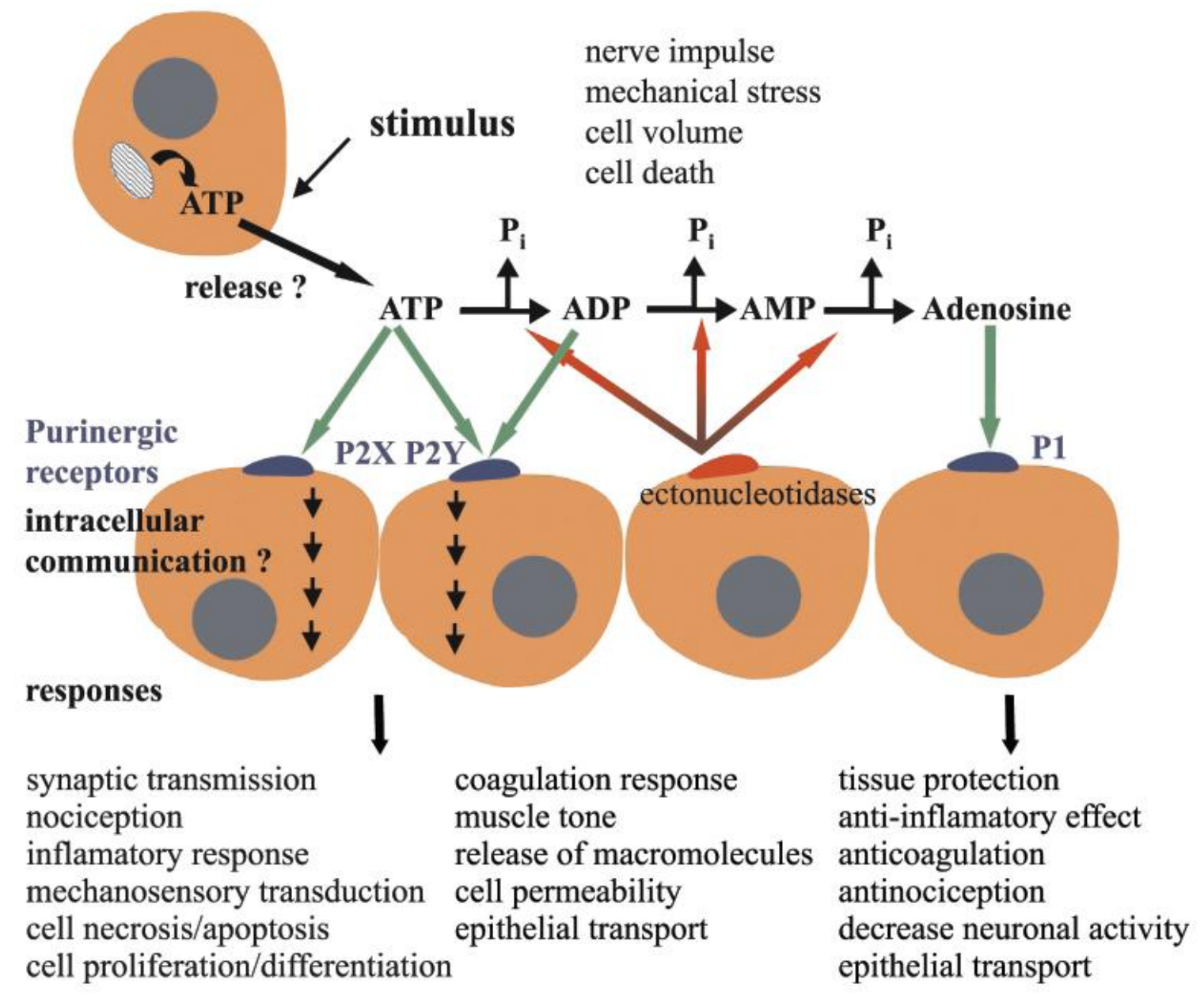


ATP and are secreted along with acetylcholine, noradrenaline and neuropeptide $\mathrm{Y}^{152}$. Uridine 5'-triphosphate (UTP) is also contained within the vesicle but in much less concentration. The second mechanism is through passive transport mechanisms using nonconductive, bidirectional transporters down concentration gradient of ATP. For example, epithelial cells are thought to directly transport ATP through cystic fibrosis transmembrane regulator (CFTR), an ABC transporter protein implicated in the transport of ions, proteins and hydrophobic substances ${ }^{155}$. Whether CFTR directly conducts ATP itself is still under debate. It is possible that CFTR regulates a closely associated $\mathrm{Cl}^{-}$ion channel that exports $\mathrm{ATP}^{156}$. The third mechanism is mainly found in primary $\mathrm{T}$ cells and red blood cells where ATP is released through nonselective, permeable pannexin-1 channels. These channels are activated by mechanical stimulation, depolarization, and changes in intracellular $\mathrm{Ca}^{2+}$ concentrations. They are also heavily regulated by purinergic signalling ${ }^{157,158}$.

\subsection{Purinergic signalling of extracellular ATP}

Cell surface purinergic signalling dictates a variety of physiological and pathophysiological processes shown in Figure 1.6. For example, purinergic signalling is involved in synaptic transmission, tissue blood flow, platelet aggregation, immune defense, cell volume regulation, cell proliferation, mitogenesis, apoptosis and epithelial ion transport $^{152}$. Purinergic receptors are activated once its ligands bind to the extracellular loop and initiate downstream signalling pathways. There are a total of 19 different types of purinergic receptors that has been identified and characterized. For example, P1 receptors (P1Rs), A1, A2 and A3 receptors, respond to adenosine, whereas $\mathrm{P} 2$ receptors (P2Rs), P2XR and P2YR, are activated by ATP. P2Rs can also be activated through other nucleotides such as ADP, UTP and uridine 5'-diphosphate (UDP) ${ }^{159}$. Among P2Rs, P2XRs are nonspecific 
cation channels (mainly $\mathrm{Ca}^{2+}$ ) consisting of 8 members $\left(\mathrm{P} 2 \mathrm{X}_{1}-\mathrm{P} 2 \mathrm{X}_{7}\right.$ and $\left.\mathrm{P} 2 \mathrm{XM}\right)$. Unusually, $\mathrm{P} 2 \mathrm{X}_{7}$ has an ability to activate several specific signalling pathways at the same time ${ }^{160}$. Notably, activation of $\mathrm{P} 2 \mathrm{X}_{7}$ receptors requires higher concentrations ( $\left.>100 \mu \mathrm{M}\right)$ of eATP relative to other P2XRs. Such activation causes necrosis or apoptosis. More interestingly, a study by Suadicani et al. also proposes that $\mathrm{P} 2 \mathrm{X}_{7}$ triggers a direct release of ATP and therefore amplifies $\mathrm{Ca}^{2+}$ signalling ${ }^{161}$. P2YRs, which include $\mathrm{P} 2 \mathrm{Y}_{1}, \mathrm{P} 2 \mathrm{Y}_{2}, \mathrm{P} 2 \mathrm{Y}_{4}, \mathrm{P} 2 \mathrm{Y}_{6}$, $\mathrm{P}_{2} \mathrm{Y}_{11}, \mathrm{P} 2 \mathrm{Y}_{12}$ and $\mathrm{P} 2 \mathrm{Y}_{13}$, are G-protein coupled receptors that all generally activate phospholipase $\mathrm{C}$, phosphoinositide hydrolysis, mobilization of intracellular $\mathrm{Ca}^{2+}$ and activation of $\mathrm{PKC}^{159}$. Depending on the context, amplitude and duration of the rise in eATP concentration, often more than one type of purinergic receptors are activated at the same time, indicating the complex nature of purinergic signalling and challenge in studying these receptors.

\subsection{Rationale for research}

In the process of delineating the mechanism by which ABCA1 lipidate apoA-I, our laboratory has recently established that influx of $\mathrm{Ca}^{2+}$ is required for proper $\mathrm{ABCA} 1$ functions ${ }^{143}$. This $\mathrm{Ca}^{2+}$ influx activates calcineurin/JAK2 pathway to mediate ABCA1mediated cholesterol efflux to apoA-I. For instance, when extracellular $\mathrm{Ca}^{2+}$ is removed using the cationic chelator EDTA or $\mathrm{Ca}^{2+}$ specific chelator EGTA, cholesterol efflux to apoA-I was abolished. Moreover, specifically chelating intracellular $\mathrm{Ca}^{2+}$ by BAPTA-AM, a membrane permeable precursor of a $\mathrm{Ca}^{2+}$ chelator capable of buffering $\mathrm{Ca}^{2+}$ influx, inhibited cholesterol efflux as well. We have also observed that apoA-I is able to increase $\mathrm{Ca}^{2+}$ influx. However, the upstream mechanism of this $\mathrm{Ca}^{2+}$ influx and its regulation remain unanswered. In searching for potential $\mathrm{Ca}^{2+}$ influx mechanisms, we noted that purinergic signalling can be 
activated by eATP to allow $\mathrm{Ca}^{2+}$ influx ${ }^{162}$. Of the purinergic receptors, $\mathrm{P}_{2} \mathrm{X}_{1,4,5}$ and 7 receptors and most P2YRs are found to release intracellular $\mathrm{Ca}^{2+}$ in macrophages ${ }^{163}$. In epithelial cells, activation of $\mathrm{P}_{2} \mathrm{Y}_{2}$ receptor leads to an increase of $\mathrm{Ca}^{2+}$ influx and activation of PKC. PKC is involved in apoA-I dependent ABCA1 functions ${ }^{159}$. Another reason for the potential eATP participation in $\mathrm{ABCA} 1$ functions is that other members of $\mathrm{ABC}$ transporters with high homology to ABCA1, namely CFTR (ion channel) and p-glycoprotein (transports hydrophobic drugs across the plasma membrane), have been reported to facilitate ATP release from cells to the extracellular medium ${ }^{164,165}$. A CFTR mutation study has observed that, compared to wild-type (WT) CFTR-expressing fibroblasts, mutated $\triangle$ F508-CFTR cells did not seem to release ATP upon hypotonic challenge ${ }^{166}$. In addition, improper ATP transport by a dysfunctional CFTR is a relevant factor in cystic fibrosis, showing the importance of eATP in pathological conditions ${ }^{167}$. Taken together, we wondered whether ABCA1 also modulates eATP levels. If ABCA1-expressing cells do release more ATP, eATP may have a role in ABCA1 functions, particularly cholesterol efflux to apoA-I.

\subsection{Specific aims}

Our overall aim was to study the role of eATP on ABCA1 function. To achieve this, our first objective was to characterize eATP levels in cells with or without ABCA1 expression. Secondly, if ABCA1 did influence eATP levels, we would investigate the roles of eATP in ABCA1-mediated cholesterol efflux to apoA-I by modulating eATP levels.

\subsection{Hypothesis}

ABCA1 directly or indirectly facilitates ATP release and this eATP is required for ABCA1-mediated cholesterol efflux to apoA-I. 


\section{Chapter II: Materials and Methods}

\subsection{Materials and reagents}

Cell culture growth media, antibiotics (penicillin/streptomycin (P/S)), OPTI-MEM, Lipofectamine 2000 Reagent, and fetal bovine serum (FBS) were purchased from Invitrogen (Burlington, ON). A mammalian expression vector contained CD39, hCD39Flag-pAPuro, was a gift from Dr. Michael R. Elliott and Dr. Kodi S. Ravichandran (University of Virginia, Charlottesville, VA). pEYFP-N1 was from Clontech. The following antibodies were acquired from various vendors: rabbit polyclonal anti-ABCA1 (Novus Biological Inc., Littleton, CO), Alexa Fluo 488 goat anti-rabbit IgG (Molecular Probes, Eugene, OR), CD39 (H-85) rabbit polyclonal antibody (Santa Cruz Biotechnology Inc., Santa Cruz, CA), monoclonal mouse M2 anti-FLAG (Sigma-Aldrich, St. Louis, MO), anti-mouse HSP-70 monoclonal antibody (BD Biosciences Mississauga, $\mathrm{ON}$ ) and peroxidase-conjugated sheep anti-mouse and donkey anti-rabbit IgGs were purchased from Jackson Immunoresearch Laboratories (West Grove, PA). $\left[{ }^{3} \mathrm{H}\right]$ cholesterol was purchased from PerkinElmer-Canada Inc. (Vaudreuil-Dorion, QC). Purified human apoA-I was purchased from Biodesign International (Saco, ME). Mifepristone (mif), 8-Br-cAMP, T0901317, bovine serum albumin (BSA), ATP bioluminescent assay kit, ATP, AMP, ADP, UTP, $\alpha, \beta$-MeATP, ATP $\gamma$, Suramin, and apyrase (exogenous ecto-ATPase, 5 and $10 \mathrm{U} / \mathrm{ml}$ ) were purchased from Sigma. st-Ht31 was purchased from Promega (Madison, WI). Scintillation liquid ScintiSafe Gel Cocktail and puromycin was purchased from Fisher (Whitby, ON). FuGene HD Transfection Reagent was purchased from Roche (Laval, QC). Bio-Rad Protein Assay dye reagent was obtained from Bio-Rad Laboratories (Montreal, QC). 


\subsection{Cell culture}

Baby hamster kidney (BHK) cell lines were generous gifts from Dr. John F. Oram and Dr. Ashley M. Vaughan (University of Washington, Seattle, WA) and RAW 264.7 macrophages (RAW), an adherent mouse macrophage cell line, was purchased from ATCC (Manassas, VA). BHK cells stably expressing an empty mif-inducible vector (Mock), and human WT ABCA1 (ABCA1) or A937V ABCA1 (A937V) gene inserts were prepared as described previously ${ }^{168}$. RAW cells endogenously express ABCA1 upon induction with a cAMP analog, 8-Bromo-cyclic adenosine monophosphate (8-Br-cAMP) or with an LXRagonist, T0901317. Both BHK and RAW cell lines were maintained in Dulbecco's modified medium (DMEM) (DMEM high glucose powder, $44 \mathrm{mM} \mathrm{NaHCO} 3, \mathrm{pH}$ 7.2) supplemented with $10 \%$ fetal bovine serum (FBS) and $1 \% \mathrm{P} / \mathrm{S}(100$ units $/ \mathrm{ml}$ penicillin and $100 \mu \mathrm{g} / \mathrm{ml}$ streptomycin) at $37{ }^{\circ} \mathrm{C}$ in a $5 \% \mathrm{CO}_{2}$ incubator (HERA Cell 150, Heraeus). In most of the experiments, Mock cells and non-induced RAW macrophages were used as negative controls.

\subsection{Induction of ABCA1 expression}

BHK and RAW Cells were seeded and maintained in DMEM containing 10\% FBS until experimental treatments. Prior to induction of ABCA1 expression, cells were washed with $37{ }^{\circ} \mathrm{C} 1 \mathrm{X}$ phosphate buffer saline (PBS) $(137 \mathrm{mM} \mathrm{NaCl}, 2.7 \mathrm{mM} \mathrm{KCl}, 4.3 \mathrm{mM}$ $\mathrm{Na}_{2} \mathrm{HPO}_{4}, 1.47 \mathrm{mM} \mathrm{KH} \mathrm{PO}_{4}, \mathrm{pH}$ adjusted to 7.4). BHK cells were incubated for 18-20 hours in DMEM plus $1 \mathrm{mg} / \mathrm{ml}$ BSA with $10 \mathrm{nM}$ mif. Mock and A937V cells were treated identically. To obtain different levels of ABCA1 expression, different concentrations of mif (0.05 nM to $10 \mathrm{nM})$ were used. Similarly, RAW cells were incubated 18-20 hours in DMEM plus $1 \mathrm{mg} / \mathrm{ml}$ BSA with either $50 \mu \mathrm{M}$ 8-Br-cAMP or $10 \mu \mathrm{M}$ T0901317. 


\subsection{Cholesterol efflux}

BHK or RAW macrophage cells were seeded in 24-well plates (BHK: 8x10 4 cells/well, RAW: $1 \times 10^{5}$ cells/well) and incubated with growth medium containing $1 \mu \mathrm{Ci} / \mathrm{ml}\left[{ }^{3} \mathrm{H}\right]-$ cholesterol for 24 hours to label cells to equilibrium. The medium was then replaced by fresh DMEM containing $1 \mathrm{mg} / \mathrm{ml}$ BSA plus mif for BHK cells or 8-Br-cAMP or T0901317 for RAW cells as described above. For cholesterol efflux, cells were incubated for 2-6 hours at $37^{\circ} \mathrm{C}$ either with $5 \mu \mathrm{g} / \mathrm{ml}$ apoA-I in DMEM/BSA for efflux to apoA-I or without apoA1 for apoA-I independent efflux. Also, a variety of reagents (ATP, ADP, AMP, Apyrase, st-Ht-31 and P2 modulators) were added to the medium containing apoA-I to measure their effects on cholesterol efflux. For the apyrase washout experiment, cells were incubated with $10 \mathrm{U} / \mathrm{ml}$ apyrase for 2 hours then washed with PBS two times. Cells were then allowed to efflux to apoA-I for 2 hours. At the end of the efflux period, the medium was collected and centrifuged at $500 \times g$ to remove detached cells and cell debris. The cell-free supernatant was then combined with scintillation liquid. The amount of $\left[{ }^{3} \mathrm{H}\right]$-cholesterol in the medium was determined with scintillation counter (Beckman LS 6500) as counts per minute (cpm). The remaining adherent cells were lysed in $1 \mathrm{~N} \mathrm{NaOH}$ overnight and the total cpm of the lysate was measured. Efflux was expressed as the percent $\left[{ }^{3} \mathrm{H}\right]$-cholesterol in the medium over total $\left[{ }^{3} \mathrm{H}\right]$-cholesterol cholesterol (medium and cell). In some experiments, cholesterol efflux was expressed as a percentage relative to the positive controls (with apoA-I alone).

\subsection{CD39 transient transfection}

To transfect BHK cells with a plasma membrane protein, CD39, transfection mixture containing $1 \mu \mathrm{g}$ of plasmid DNA (hCD39Flag-pAPuro, or pEYFP-N1 as control vector), and $6 \mu \mathrm{l}$ of Lipofectamine 2000 in total volume of $200 \mu \mathrm{l}$ of OPTI-MEM was incubated in room 
temperature for $20 \mathrm{~min}$. BHK cells were seeded in a $35 \mathrm{~mm}$ dish containing DMEM and FBS without antibiotics. The transfection mixture was added to the suspended cells, immediately seeded in the dish and incubated at $37^{\circ} \mathrm{C}$ with $5 \% \mathrm{CO}_{2}$ for 18 hours. Cells were then washed with 1X PBS, trypsinized and re-seeded onto another plate or dish in growth medium for 24 hours for different experiments (e.g. immunofluorescence staining, western blot). For the cholesterol efflux experiment, transfected cells were labeled with $1 \mu \mathrm{Ci} / \mathrm{ml}\left[{ }^{3} \mathrm{H}\right]$-cholesterol before the cells were re-seeded.

RAW cells were transfected with FuGENE HD. $1 \mu \mathrm{g}$ of plasmid DNA was diluted in $100 \mu \mathrm{l}$ of OPTI-MEM and $6 \mu \mathrm{l}$ of FuGENE HD. The mixture was incubated for $15 \mathrm{~min}$ at room temperature and added directly to the newly seeded RAW cells $\left(2.5 \times 10^{5}\right.$ cells in a 35 mm dish containing 10\% FBS/low glucose DMEM without P/S). Cells were re-seeded the same way as BHK cells next day. The transfection efficiency was estimated using parallel YFP transfected cells. YFP transfected cells also serve as a positive control in efflux experiments.

\subsection{CD39 stable clone generation}

The following day of transient transfection of CD39 construct, the cells were re-seeded onto a $20 \mathrm{~cm}$ dish and the standard media was replaced with media containing $3 \mu \mathrm{g} / \mathrm{ml}$ puromycin. The puromycin concentration required to kill off untransfected cells were determined using a kill curve. The media was changed every 1-2 days until all of the untransfected cells were killed and only the colonies of stable cells were left behind. To pick colonies, the cells were washed with $1 \mathrm{X}$ PBS and then warm 1X PBS containing 5\% trypsin was added to the dish. The colonies of interest were scraped off, transferred into the prepared wells and grown in the medium containing $1 \mu \mathrm{g} / \mathrm{ml}$ puromycin until confluent. Cells were 
transferred into $10 \mathrm{~cm}$ dishes to further expand and generate frozen stocks. All clones were screened for CD39 expressions.

\subsection{Immunofluorescence staining of Flag}

BHK and RAW cells were plated in $35 \mathrm{~mm}$ glass-coverslip-bottom microscopy dishes, then transfected with CD39 construct and induced as described above. For immunofluorescence staining, cells were washed with PBS then fixed with 4\% paraformaldehyde in PBS for $10 \mathrm{~min}$, followed by permeabilization with $0.5 \mathrm{mg} / \mathrm{ml}$ saponin in PBS for 30 min. Cells were blocked with $5 \%$ calf serum and $50 \mathrm{mM} \mathrm{NH}_{4} \mathrm{Cl}$ in $\mathrm{PBS}$ for 20 min. For Flag staining, primary monoclonal antibody against Flag was added at a concentration of $15 \mu \mathrm{g} / \mathrm{ml}$ in a solution of $5 \%$ calf serum/PBS for $30 \mathrm{~min}$. After washing with PBS and incubating with 5\% calf serum/PBS for $20 \mathrm{~min}$, secondary antibody (Alexa Fluor 488 goat anti-mouse $\mathrm{IgG}$ ) was then added at a concentration of 1:300 for $30 \mathrm{~min}$, followed by $45 \mathrm{~min}$ incubation in $5 \%$ calf serum/PBS. The fluorescent images were visualized and taken with a 60x/1.4NA oil-immersion objective on an inverted Nikon fluorescent microscope (TE2000-E) equipped with a CCD camera and MetaMorph software. Images from non-transfected and transfected cells were taken using identical settings.

\subsection{Cell lysis}

Cells were placed on ice, media was aspirated, and cells were washed twice with cold PBS. Cells were lysed with SDS buffer (50 mM Tris-Cl pH 6.8, $100 \mathrm{mM}$ dithiothreitol, 2\% SDS, $10 \%$ glycerol, and 1 tablet protease inhibitor per $10 \mathrm{~mL}$ buffer). A volume of $150 \mu 1$ lysis buffer was used in each of $60 \mathrm{~mm}$ dishes. Cells were immediately scraped off the plates and transferred to microcentrifuge tubes on ice. Lysates were sonicated for 10-15 seconds to 
shear DNA and then heated to $75^{\circ} \mathrm{C}$ for $5 \mathrm{~min}$. Lysates were centrifuged for $1 \mathrm{~min}$ at 13,000 $\mathrm{g}$ and protein levels were measured as described below.

\subsection{SDS Polyacrylamide gel electrophoresis (SDS-PAGE) and Immunoblotting}

Loading samples were prepared by adding 4X SDS loading buffer (200 mM Tris $\mathrm{HCl}$, $\mathrm{pH} 6.8,400 \mathrm{mM}$ dithiothreitol, $8 \%$ SDS, $40 \%$ glycerol, $0.4 \%$ bromophenol blue) to 15-25 $\mu \mathrm{g}$ of cell lysates. Samples were loaded onto $10 \%$ acrylamide resolving gels (10\% acrylamide mix $(9.67 \%$ acrylamide, $0.33 \%$ bis), $375 \mathrm{mM}$ Tris (pH 8.8), $1 \%$ SDS, $1 \%$ ammonium persulfate, $0.04 \%$ TEMED) and separated at $180 \mathrm{~V}$ for $60 \mathrm{~min}$. Separated proteins were transferred to PVDF membranes at $70 \mathrm{~V}$ for $150 \mathrm{~min}$. PVDF membranes were blocked with TBS-T (50 mM Tris HCl, pH 7.4, $150 \mathrm{mM} \mathrm{NaCl,} \mathrm{0.1 \%} \mathrm{Tween-20)} \mathrm{containing}$ $2.5 \%$ BSA for $30 \mathrm{~min}$. Membranes were incubated with primary antibody (1:1000 or 1:2000) with gentle agitation overnight at $4{ }^{\circ} \mathrm{C}$. Membranes were than washed with TBS-T three times for $5 \mathrm{~min}$ each. Then, membrane was incubated and gently agitated for 2 hours in either anti-mouse or anti-rabbit secondary antibody (1:2000) diluted in TBS-T with 1\% BSA. Membranes were washed three times again for 5 min each with TBS-T. PVDF membranes were incubated for 1 minute with $1 \mathrm{ml}$ chemiluminescent substrate and covered in plastic wrap. In a dark room, membranes were exposed to x-ray film for appropriate exposure time and then processed using Raytech Medical Film Processor SRX-101A.

\subsection{Protein assay}

$200 \mu \mathrm{l}$ of Bradford protein assay dye reagent was added to an $800 \mu$ l solution containing water and 2-20 $\mu \mathrm{l}$ of cell lysates. Mixture was placed in $10 \mathrm{~mm}$ disposable cuvets (Fisher) and absorbance was measured at $595 \mathrm{~nm}$ using the UltrospecTM 3100 pro 
UV/visible spectrophotometer. Protein levels were calculated from a standard curve of 0-25 $\mu \mathrm{g} / \mu \mathrm{lBSA}$.

\subsection{ATP luciferin/luciferase Assay}

BHK and RAW cells were induced for $18-20$ hours in DMEM plus $1 \mathrm{mg} / \mathrm{ml}$ BSA at $37{ }^{\circ} \mathrm{C}$ and $5 \% \mathrm{CO}_{2}$ and various reagents were added directly to the inducing medium for 2 hours on the day of ATP measurement. Samples of the medium $(0.2 \mathrm{ml})$ were carefully collected on ice with minimum disturbances. Also the medium from a set of empty wells (without cells) were taken as background. The medium was then centrifuged to remove potentially detached cells or cell debris, and boiled for $1 \mathrm{~min}$. The appropriate dilution of the assay mix from the ATP Bioluminescent Assay Kit was prepared according to the manufacturer's instruction. Then, $25 \mu \mathrm{l}$ of each sample and $25 \mu \mathrm{l}$ of the assay mix were loaded into a 96-well plate and mixed. The luciferin-luciferase activity was quantified using FLUOstar galaxy multidetection microplate reader (BMG Labtechnologies Ltd. Germany). The luminescence intensity was compared with an ATP standard curve generated in parallel in each individual experiment. To generate the standard curve, standard ATP was diluted in the same buffer and processed identically as cell medium samples. To measure the eATP concentration in different confluencies of cells, cells were seeded at $45 \%$ and $90 \%$ confluency in a 24-well plate. eATP is represented as absolute ATP concentration.

\subsection{ATP degradation assay}

Mock, ABCA1, and A937V mutant cells were induced with $150 \mathrm{nM}$ of exogenous ATP, then $30 \mu \mathrm{l}$ of media was collected at 10,20 , and $80 \mathrm{~min}$ to measure eATP concentrations. The cells were kept at $37{ }^{\circ} \mathrm{C}$ and $5 \% \mathrm{CO}_{2}$ after the media was collected at each time point. At the end of the experiments, cells were lysed with $200 \mu \mathrm{l}$ of $1 \mathrm{~N} \mathrm{NaOH}$ 
and protein mass was determined. The results are represented as ATP degraded (subtracting the measured ATP concentration from $150 \mathrm{nM}$ ) by $\mu \mathrm{g}$ protein (nmol/ $\mu \mathrm{g}$ protein). To measure the hydrolysis capacity of CD39 stable cells, different concentrations of exogenous ATP (100 nM-10 $\mu \mathrm{M})$ were added to untransfected and CD39 stable RAW cells and were incubated for $10 \mathrm{~min}$. After $10 \mathrm{~min}$, medium was collected to measure ATP using the luciferin/luciferase assay described above.

\subsection{Statistical Analyses}

Statistical comparisons between groups were performed with PRISM software (GraphPad InStat v3.05). Data for western blot analyses are presented as the mean \pm the standard error of the mean (SEM). All other data are presented as mean \pm standard deviation (SD). The statistical significance of differences between groups was analyzed by Student's $t$ -test. Differences were considered significant at a $P$ value $<0.05$. 


\section{Chapter III: Results}

\subsection{ABCA1 is expressed and functional in BHK and RAW cells}

To determine whether functional ABCA1 influences eATP levels in both BHK and RAW cells, we first expressed ABCA1 in these cell lines. BHK cells are stable cell lines transfected with an inducible vector containing inserts for WT human ABCA1 (ABCA1), mutant ABCA1 (A937V) or vector alone (Mock). ABCA1 mutant A937V cells are comprised of a naturally occurring alanine to valine mutation within the first NBD of the transporter, which renders this transporter defective in apoA-I-mediated cholesterol efflux ${ }^{168}$. Mock cells contain the same induction system and therefore provide control for any mifinduced effects. BHK cells do not express endogenous ABCA1; hence no ABCA1 is expressed without induction (Figure 3.1 A, left 3 lanes). Upon 18-20 hour of mif induction, ABCA1 and A937V cells express ABCA1 or ABCA1 ${ }^{\mathrm{A} 937 \mathrm{~V}}$, respectively, but not Mock cells (Figure $3.1 \mathrm{~A}$, right 3 lanes). We have shown previously using immunofluorescence staining that $\mathrm{ABCA} 1^{\mathrm{A} 937 \mathrm{~V}}$ expresses and targets to the plasma membrane correctly, resembling the WT ABCA1 ${ }^{89}$. Importantly, the expression level and distribution of A937V cells were indistinguishable from ABCA1 cells.

Cholesterol efflux to apoA-I is one of the most important functions of ABCA1. We thus quantified the level of cholesterol efflux from these cells. Cholesterol efflux is measured using a widely used protocol. Specifically, cells were labeled with radioactive cholesterol $\left({ }^{3} \mathrm{H}\right.$-cholesterol) in growth medium (DEME plus 10\% FBS) for 1-2 days, washed and incubated overnight in DMEM/BSA without ${ }^{3} \mathrm{H}$-cholesterol. This last step is to allow ${ }^{3} \mathrm{H}$ cholesterol equilibrium into all cellular cholesterol pools. On the day of cholesterol efflux, 


\section{Figure 3.1}

Characterization of BHK cells with inducible ABCA1 expression. A) Mock, ABCA1 and ABCA1 mutant, A937V cells were either induced with mif $(10 \mathrm{nM})$ or without overnight, lysed and immuno-blotted for ABCA1 expression. Hsp70 was also blotted as loading control. B) $\mathrm{BHK}$ cells were labeled with $\left[{ }^{3} \mathrm{H}\right]$ cholesterol for 1 day and induced with $10 \mathrm{nM}$ mif overnight. Cholesterol efflux was measured as the percentage of $\left[{ }^{3} \mathrm{H}\right]$ cholesterol in the medium after 2 hours incubation with BSA $(1 \mathrm{mg} / \mathrm{ml})$ or BSA plus apoA-I $(5 \mu \mathrm{g} / \mathrm{ml})$. The results are presented as cholesterol efflux to apoA-I, i.e. efflux to BSA/apoA-I minus efflux to BSA alone. Results were presented as the average of triplicate wells with SD and are representative of at least three independent experiments. $* * *=p<0.001$. 
A

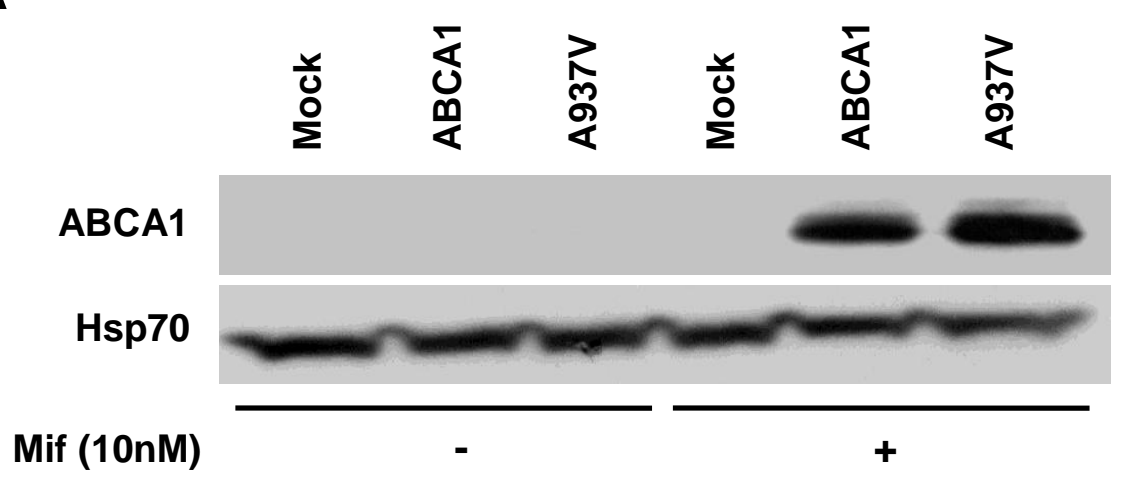

B

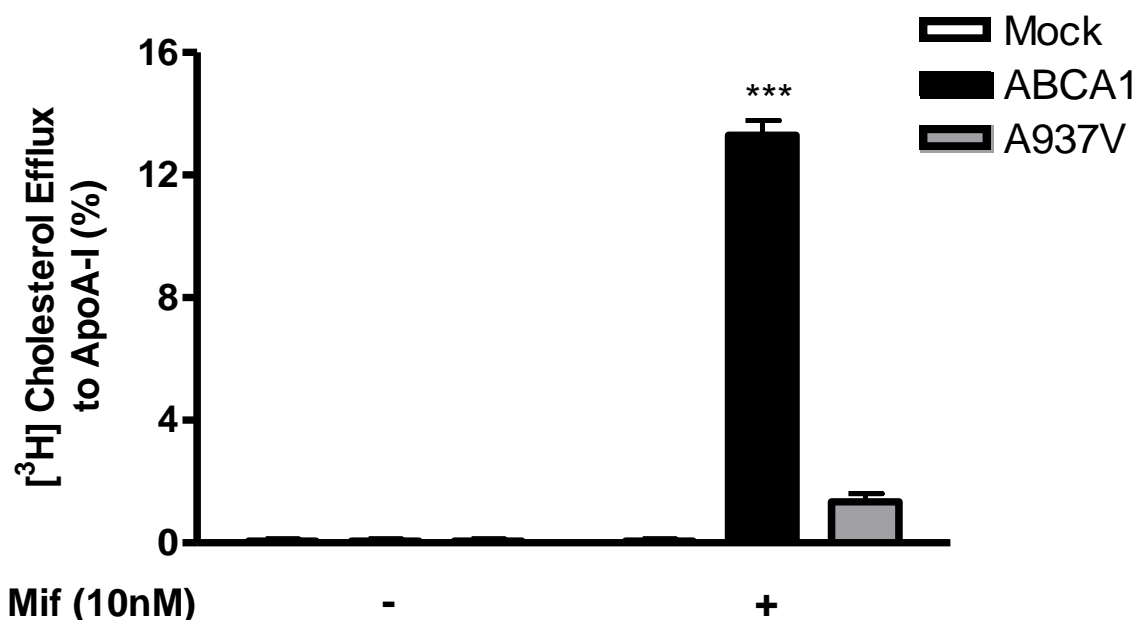


fresh DMEM/BSA was added to the cells with or without apoA-I for 2-6 hours. ${ }^{3} \mathrm{H}-$ cholesterol in the medium was then analyzed and ratioed to cell associated ${ }^{3} \mathrm{H}$-cholesterol to give percentage of cholesterol efflux. ApoA-I specific cholesterol efflux was obtained by subtracting the amount of efflux to BSA alone. As shown in Figure 3.1 B, cholesterol efflux to apoA-I is entirely dependent on functional ABCA1. Once ABCA1 expression was induced, ABCA1 cells efficiently released cholesterol to apoA-I. On the other hand, neither Mock nor A937V cells could generate significant cholesterol efflux to apoA-I in 2 hours (Figure 3.1 B).

RAW macrophages were either induced with a LXR-agonist, T0901317 or a cAMP analogue, 8-Br-cAMP overnight to express ABCA1 (Figure $3.2 \mathrm{~A}$ ). The cholesterol efflux from RAW macrophages depends on the expression levels of ABCA1 as shown by the western blot (Figure 3.2 B). T0901317 and 8-Br-cAMP were able to efflux out approximately $2.5 \%$ and $5 \%$, respectively, during 2 hours in the presence of apoA-I. These results together indicate that expression of WT ABCA1 protein in both cell types lead to proper ABCA1 function.

\subsection{Functional ABCA1 expression raises steady state extracellular ATP}

We then analyzed eATP concentrations in the medium of BHK and RAW cells. This is achieved by a luciferase-luciferin assay. The luciferase-luciferin assay is a commonly used and highly sensitive method for quantification of ATP. In this reaction, luciferase in the presence of magnesium catalyzes the oxidation of D-luciferin, which reacts with oxygen to hydrolyze ATP and forms oxyluciferin in an excited state. The light emitted from this reaction is quantitatively proportional to the amount of ATP present. For BHK cells, cells were incubated with mif overnight and $200 \mu \mathrm{l}$ of medium was carefully collected with little mechanical disturbance. Mechanical disturbance is known to provoke cells to transiently 


\section{Figure 3.2}

\section{Characterization of RAW 264.7 macrophages with ABCA1 expression. A) RAW}

macrophages were induced with or without 8-Br-cAMP $(50 \mu \mathrm{M})$ and T0901317 $(10 \mu \mathrm{M})$ overnight, lysed and immuno-blotted for ABCA1 expression. Hsp70 was also blotted as loading control. B) Cholesterol efflux to apoA-I was measured for 2 hours after overnight incubation with 8-Br-cAMP $(50 \mu \mathrm{M})$ and T0901317 $(10 \mu \mathrm{M})$. Results from $\mathbf{B}$ obtained from Loretta Ma. Results were presented as the average of triplicate wells with SD and representative of at least three independent experiments. $* * *=p<0.001$. 
A

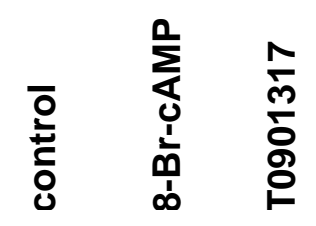

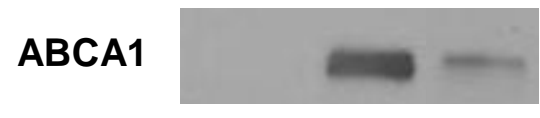

Hsp70

B

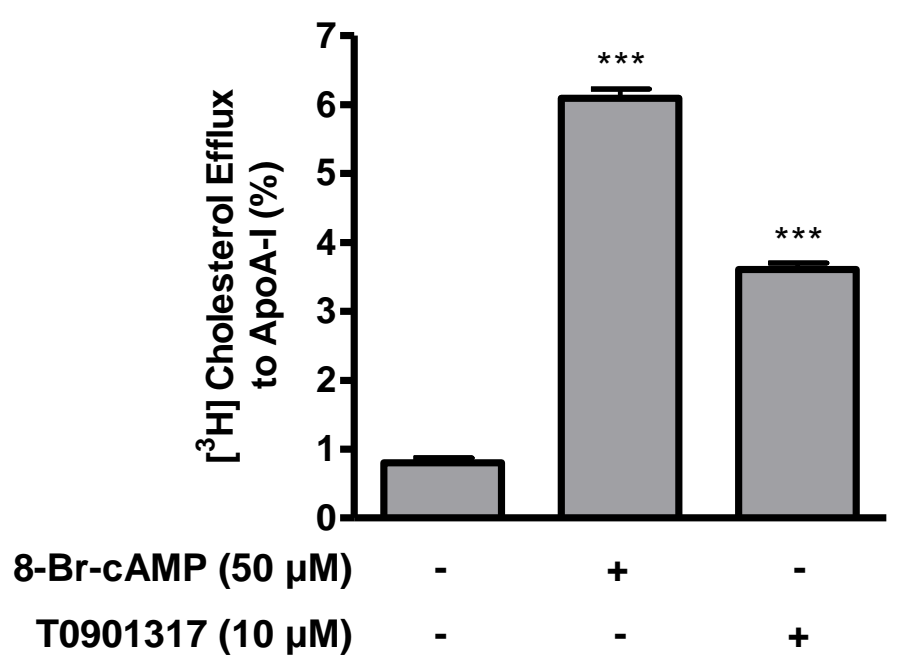


release $\mathrm{ATP}^{169}$. By collecting medium carefully, we however, can obtain relatively consistent readings from multi-wells and, importantly, from multiple experiments on different days, indicating minimal contributions from such mechanical perturbance. Once collected, the medium samples were heated at $80^{\circ} \mathrm{C}$ for $1 \mathrm{~min}$ to remove any enzymatic activities that may alter ATP concentration.

As shown in Figure 3.3 A, for BHK cells without mif induction, eATP concentration was about $20 \mathrm{nM}$, regardless of cell lines (Figure $3.3 \mathrm{~A}$, left 3 bars). The addition of mif in the medium made little difference in Mock cells in terms of eATP level. However, when ABCA1 cells were incubated with $10 \mathrm{nM}$ mif, there was a significant rise in eATP level up to $80 \mathrm{nM}(\mathrm{P}<0.001)$. Most importantly, this increase in eATP clearly requires functional ABCA1, because identical mif induction did not alter the eATP concentration in A937V cells (Figure $3.3 \mathrm{~A}$, right 3 bars), although $\mathrm{ABCA} 1^{\mathrm{A} 937 \mathrm{~V}}$ is similarly expressed as WT ABCA1. Furthermore, the elevation in eATP by ABCA1 is not confined to BHK cells. RAW macrophages also had significantly higher ATP concentration in the medium when expressing ABCA1 ( $\mathrm{P}<0.005)$ (Figure 3.3 B).

Although both BHK cells and RAW macrophages increased eATP concentrations once expressing ABCA1, BHK cells have higher eATP levels than that of RAW macrophages. This is likely due to the difference in ABCA1 expression levels. Indeed, when ABCA1 expression levels were compared, RAW macrophages expressed much lower levels of ABCA1 than BHK cells (Figure 3.4 A), which could potentially be the explanation for the smaller rise in eATP level. To confirm that there is a gene-dose relationship between ABCA1 and eATP, we induced ABCA1 cells with decreasing mif concentrations. This resulted in corresponding decrease of ABCA1 expression (Figure $3.4 \mathrm{~B}$ ). We found that eATP also decreased, which correlated with the decrease of ABCA1 expression (Figure 3.4 


\section{Figure 3.3}

Extracellular ATP levels in ABCA1 expressing BHK cells and RAW macrophages. A) BHK cells were either induced with mif $(10 \mathrm{nM})$ or without overnight. $25 \mu \mathrm{l}$ medium was taken from each well for ATP luciferase assay. B) RAW macrophages were incubated with 8 -Br-cAMP $(50 \mu \mathrm{M})$ or without overnight to induce ABCA1. The medium samples were then taken for ATP analysis. Results were presented as the average of triplicate wells with \pm $\mathrm{SD}$ and representative of at least three independent experiments. $* *=\mathrm{p}<0.005$, and $* * *=\mathrm{p}<$ 0.001 . 
A

BHK

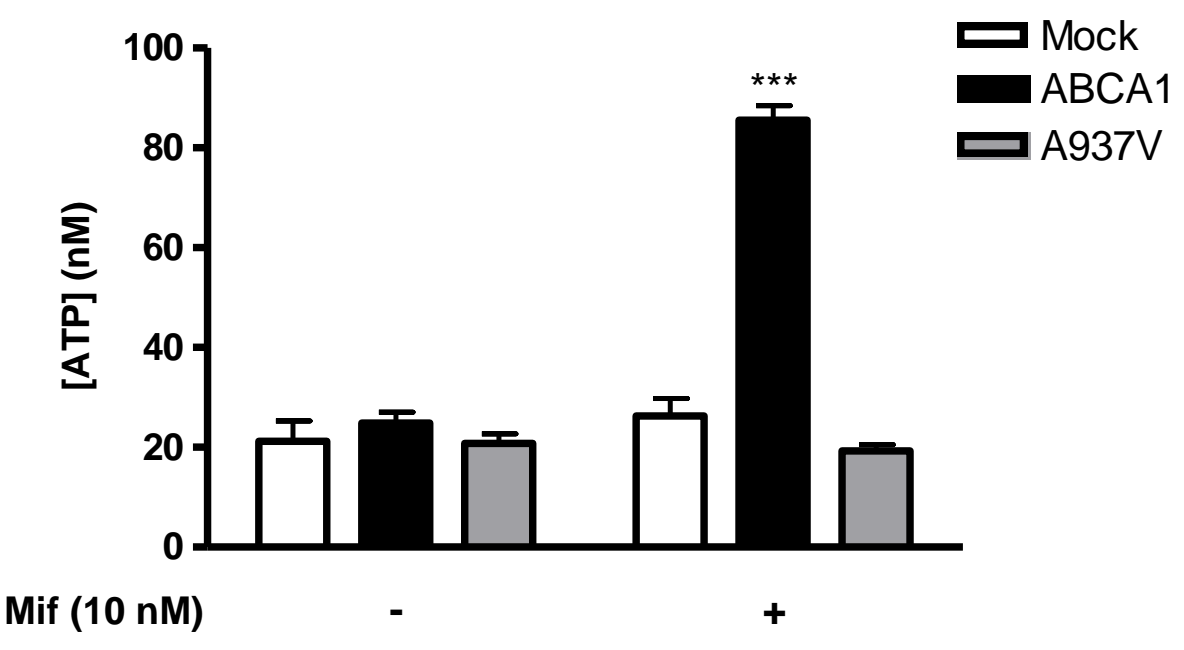

B

RAW 264.7 macrophages

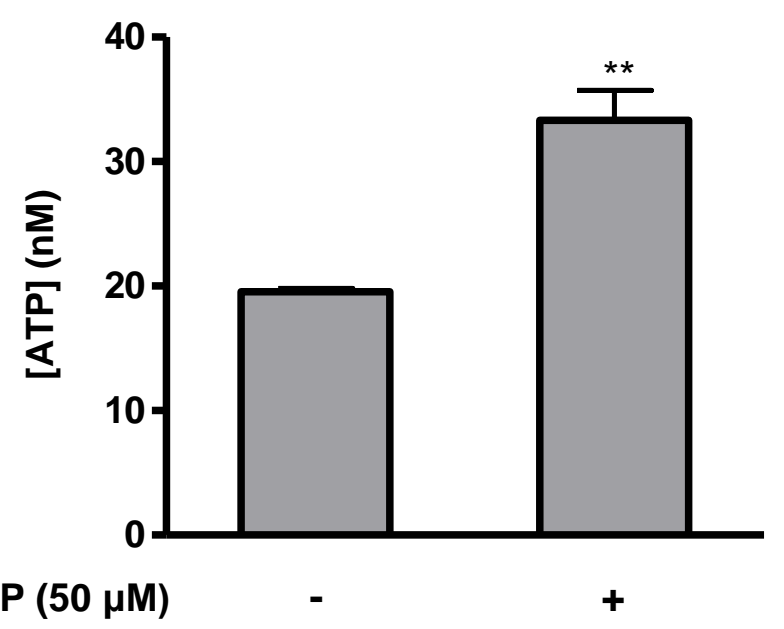




\section{Figure 3.4}

Various ABCA1 expressions on extracellular ATP secretion level. A) ABCA1 expression in BHK cells (Mock and ABCA1) and RAW macrophages with or without ABCA1 induction. B) Overnight incubation of mif (0.05-5 nM) dose-dependently increases ABCA1 expression in BHK-ABCA1 cells. C) Overnight incubation of mif dose-dependently increases eATP levels. All the bars represent the average of triplicate wells plus \pm SD. The results are representative of at least two independent experiments. $*=\mathrm{p}<0.05$, and $* * *=\mathrm{p}<$ 0.001 . 
A

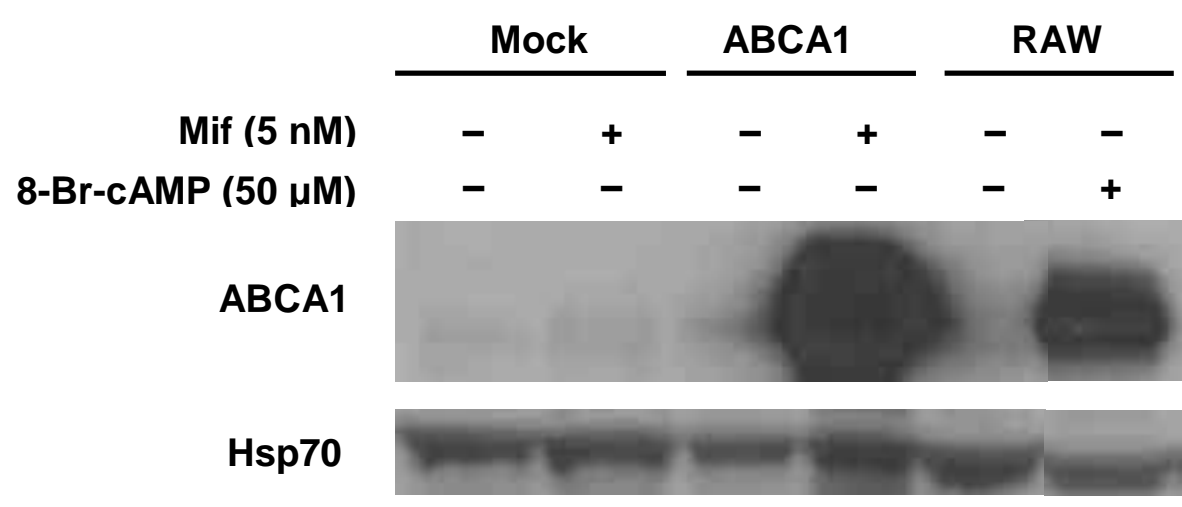

B

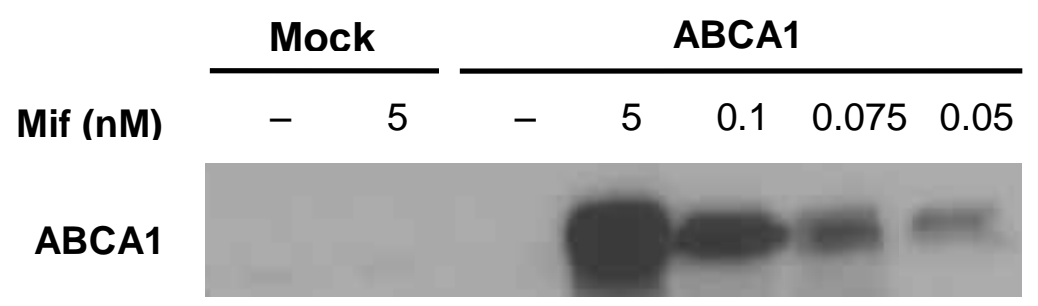

Hsp70

C

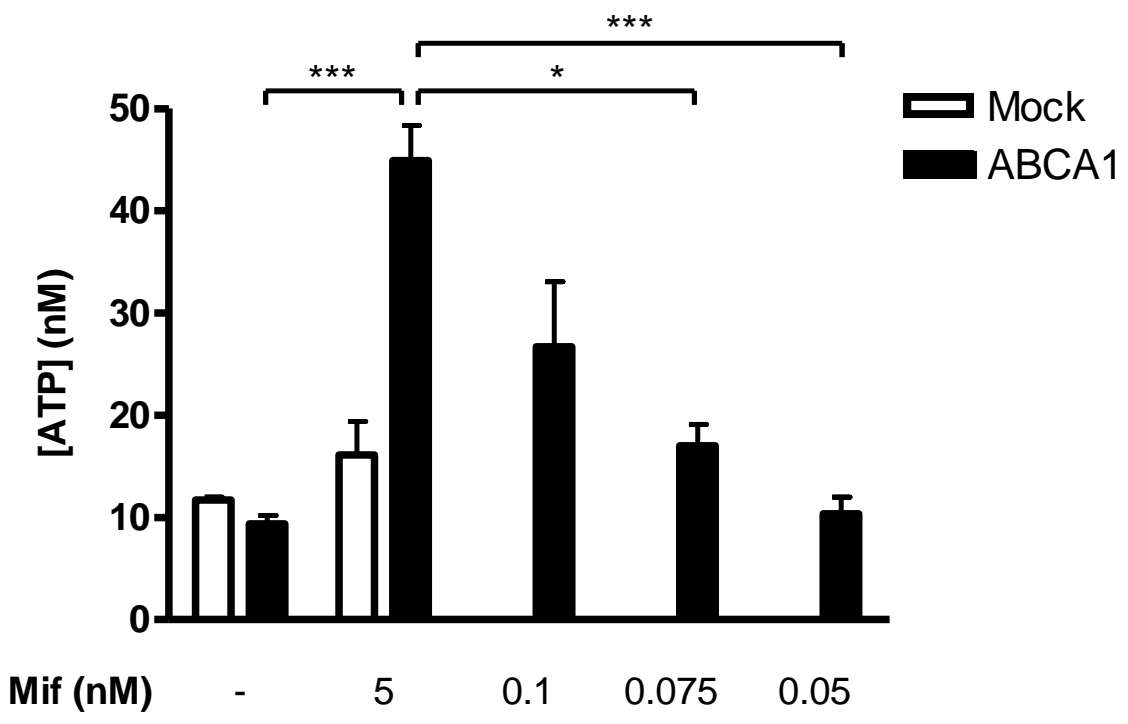


C). This demonstrates a positive correlation between ABCA1 expression level and eATP concentration, further supporting the role of ABCA1 in raising eATP levels.

The elevated eATP levels could be due to two possible factors: accelerated ATP release from cells or decreased ATP hydrolysis by cell surface ectonucleotidases. Ectonucleotidases are expressed on the plasma membrane and consist of various nucleotide metabolizing enzymes. These ectoenzymes function to control the concentration of extracellular nucleotides in concert with nucleotide releasing factors such as mechanical and chemical stimuli ${ }^{154}$. In order to determine the cause of elevated ATP concentration in the medium, we analyzed the capacity of BHK cells to hydrolyze eATP. This was achieved by adding a known amount of ATP $(150 \mathrm{nM})$ to the medium and then collecting the medium samples at 10, 20 and 80 min. The amount of ATP hydrolyzed is represented as nM of ATP degraded by equal number of cells ( $\mu$ g protein) shown in Figure $3.5 \mathrm{~A}$. We found that there were no significant differences among Mock, ABCA1 and A937V cells in their capacity to degrade eATP. In addition, we also observed that the rate of ATP hydrolysis was consistent at different time points. Based on these findings, we conclude that functional ABCA1 raises eATP level most likely by enhancing ATP release, not by slowing down hydrolysis.

Interestingly, eATP levels stayed relatively steady even when cell numbers varied within normal experimental conditions. We found that, when we set up cells in identical size of wells and same volume of medium but with either high (90\% confluency) or low density (45\% confluency), steady state eATP concentration was not influenced (Figure 3.5 B). This indicates that, at least within a range of cell density, cells are able to maintain a specific eATP concentration. This would allow eATP to activate a specific set of molecular targets. For example, some events may only be triggered at high eATP, i.e. by activation of receptors or channels with high Kd for ATP. These targets would be silenced at low nM eATP as in 


\title{
Figure 3.5
}

\begin{abstract}
ATP degradation assay and steady state extracellular ATP levels with different cell numbers. A) BHK cells were induced overnight with mif $(5 \mathrm{nM})$ and ATP was added to each well to a final concentration of $150 \mathrm{nM}$. Medium samples $(25 \mu \mathrm{l})$ were then taken from each well at 10, 20 and $80 \mathrm{~min}$, and analyzed for ATP. At the end of the experiment, cells were analyzed for protein. Results are presented as nM ATP degraded during indicated times per $\mu \mathrm{g}$ cellular protein. B) BHK cells were seeded at different densities and incubated with mif (10 nM) overnight. Medium ATP was analyzed as described above and presented as absolute ATP concentration. In all other experiments, we kept equal number of cells to be more consistent with the experimental conditions other than eATP. All the bars represent the average of triplicate wells \pm SD. The results are representative of at least two independent experiments.
\end{abstract}


A

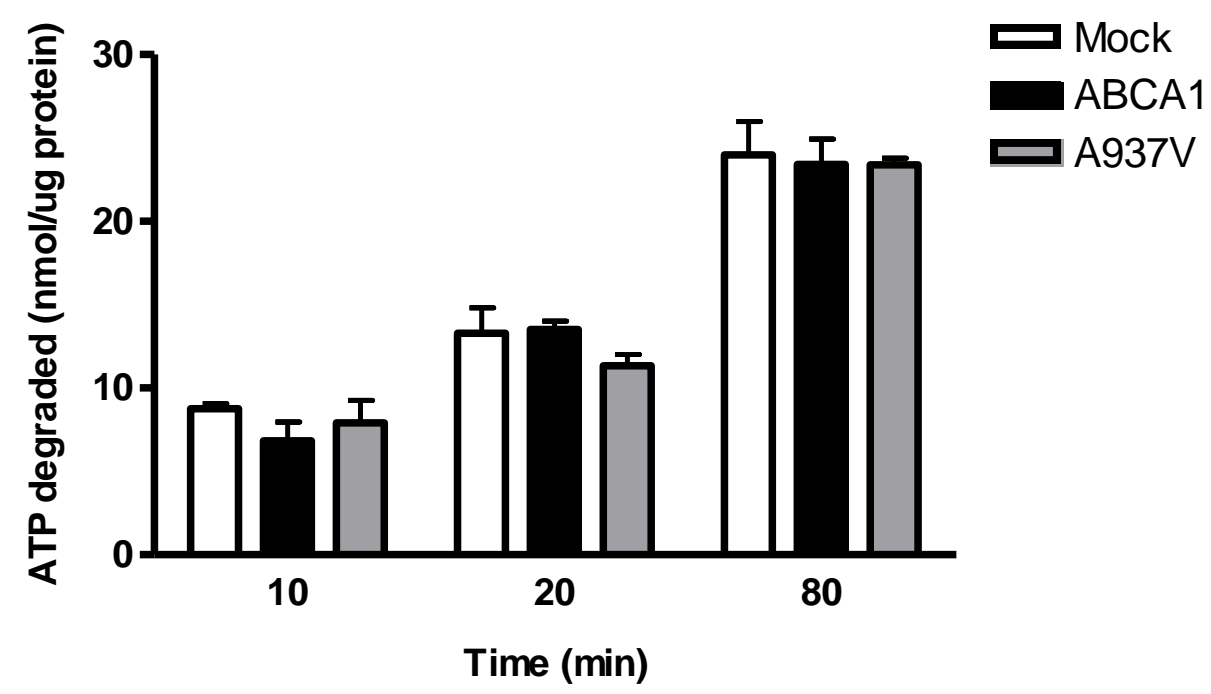

B

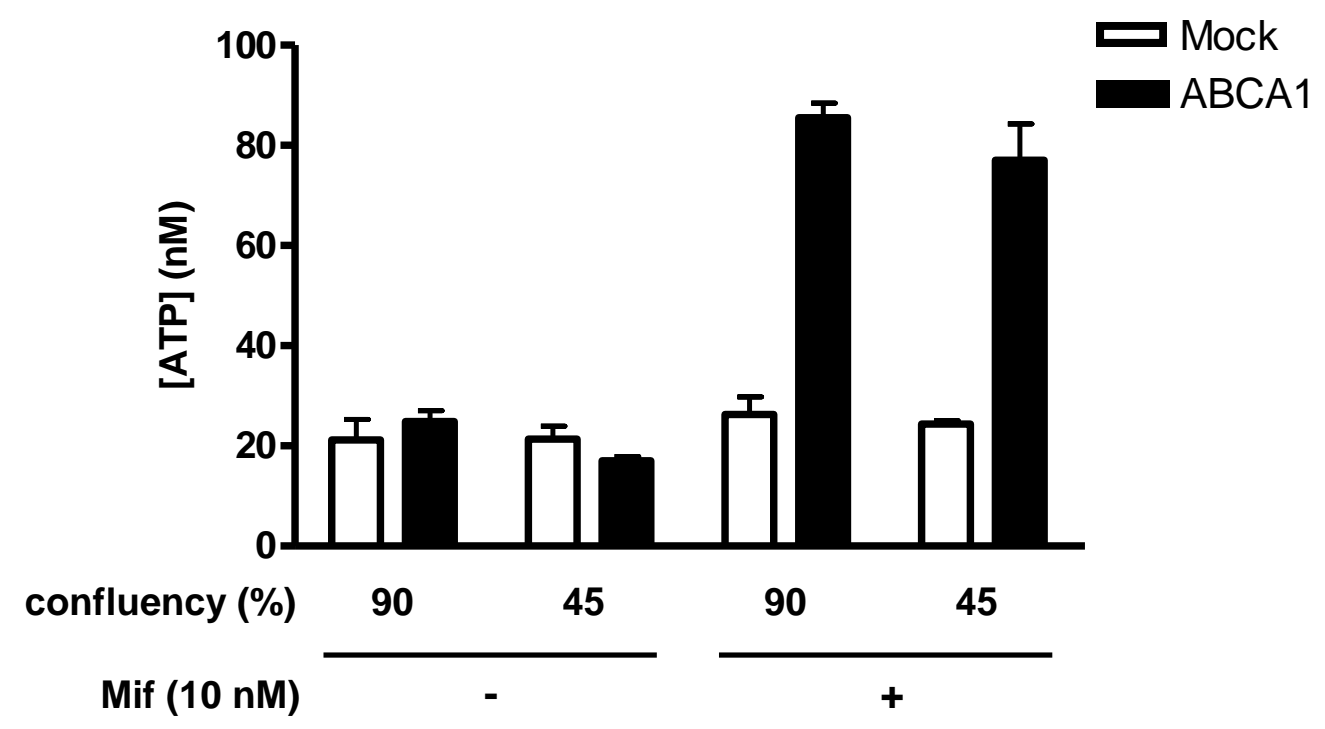


the absence of ABCA1 expression. For this reason, we have expressed our results as the absolute ATP concentration in the medium, instead of ATP/cellular protein. This also implies that eATP concentration is likely an intrinsic property of certain cell types, such as those expressing ABCA1. Therefore ABCA1-expressing cells can establish a signature steady state eATP levels (50-80 nM), largely independent of cell numbers.

\subsection{Increasing extracellular ATP results in a biphasic response in cholesterol efflux}

As described above, eATP is regulated by functional ABCA1 and thus likely an important factor in ABCA1 functions. To understand the role of eATP in ABCA1 functions, we next wanted to know whether such elevated eATP levels play physiological roles. In order to examine this, we first modulated eATP level by supplementing exogenous ATP in the medium and then analyzed ABCA1-mediated cholesterol efflux to apoA-I. We observed that when eATP levels were increased within the physiological range by adding ATP from $10 \mathrm{nM}$ to $1 \mu \mathrm{M}$, the level of cholesterol efflux to apoA-I from ABCA1 cells increased up to 40\% (Figure $3.6 \mathrm{~A}$ ). At higher concentrations (> $\mu \mathrm{M}$ ), exogenous ATP began to suppress cholesterol efflux to apoA-I. Increasing eATP to even higher concentration (> mM) completely inhibited cholesterol efflux and cells started lifting off from the plates (data not shown). We also found the same trend in RAW macrophages, shown in Figure $3.6 \mathrm{~B}$. Furthermore, we found no change in ABCA1 expression when we exposed BHK cells or RAW macrophages to exogenous ATP overnight (Figure $3.6 \mathrm{C}$, E). ApoA-I binding of ABCA1 is known to stabilize ABCA1 by inhibiting calpain/PEST-mediated degradation, and thus lengthening the short half-life of $\mathrm{ABCA} 1^{51,119,124}$. Indeed we found that overnight incubation of apoA-I increased ABCA1 expression by about 2-folds in RAW macrophages (Figure $3.6 \mathrm{E}, \mathrm{F}$ ). However, apoA-I did not change ABCA1 expression in BHK cells (Figure 


\section{Figure 3.6}

The influence of increased extracellular ATP on cholesterol efflux to apoA-I and ABCA1 expression. A) BHK cells were induced with $5 \mathrm{nM}$ of mif and B) RAW macrophages were induced overnight with 8-Br-cAMP $(50 \mu \mathrm{M})$. Cholesterol efflux (2 hours) was measured with or without apoA-I $(5 \mu \mathrm{g} / \mathrm{ml})$ in the presence of indicated concentrations of exogenous ATP $(10 \mathrm{nM}-100 \mu \mathrm{M})$. C) Mock, ABCA1, and A937V cells were induced with $10 \mathrm{nM}$ of mif and incubated overnight with or without apoA-I $(5 \mu \mathrm{g} / \mathrm{ml})$ and exogenous ATP $(500 \mathrm{nM})$ or both together for western analysis. D) Quantification of the western blot in C represented in ratio of ABCA1/hsp70 (A.U.). E) RAW macrophages were induced with 50 $\mu \mathrm{M}$ of 8-Br-cAMP and incubated overnight with or without apoA-I $(5 \mu \mathrm{g} / \mathrm{ml})$ and exogenous ATP $(10 \mathrm{nM})$ or both together. F) Quantification of the western blot in $\mathbf{E}$ represented in ratio of ABCA1/hsp70 (A.U.). Results present the average of triplicate wells with \pm SD and representative of at least two independent experiments, except $\mathbf{D}$ and $\mathbf{F}$ where data represent the means \pm SEM. $(\mathrm{n}=2) . * *=\mathrm{p}<0.005$. 
A

BHK-ABCA1

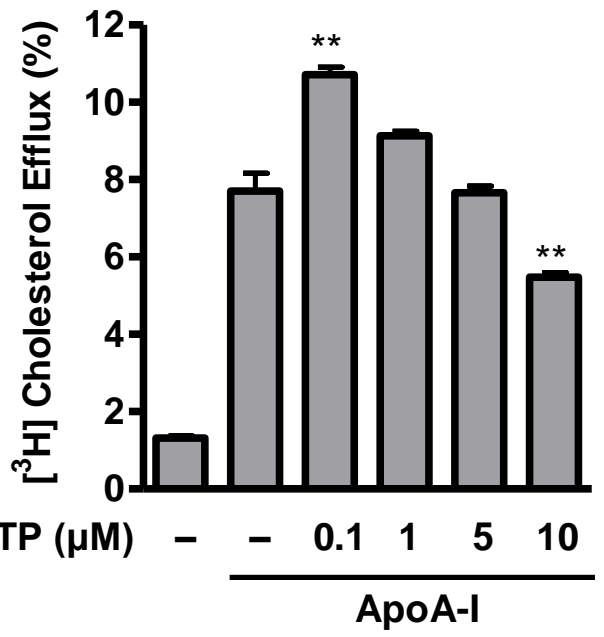

B

RAW 264.7 macrophages

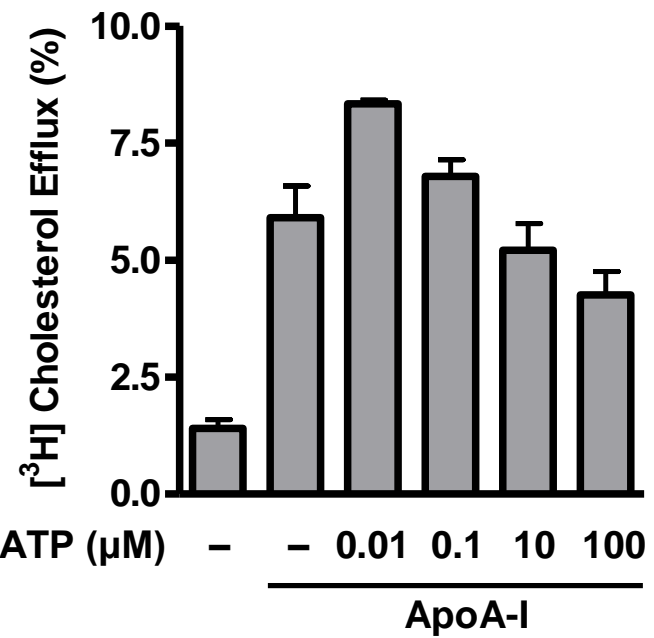

C

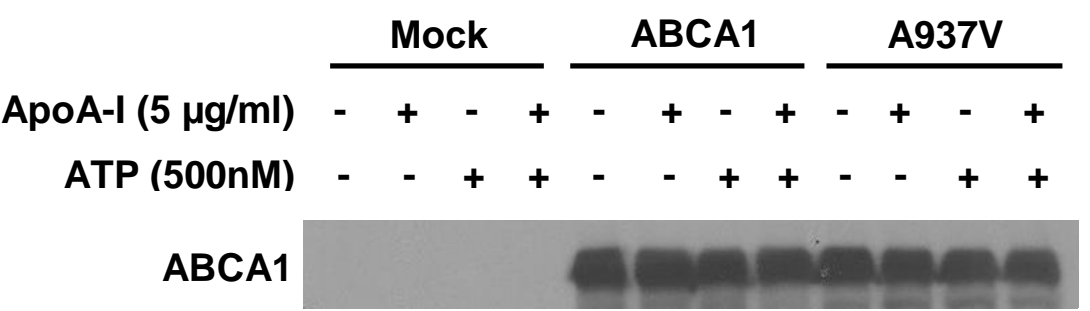

Hsp70

D

BHK

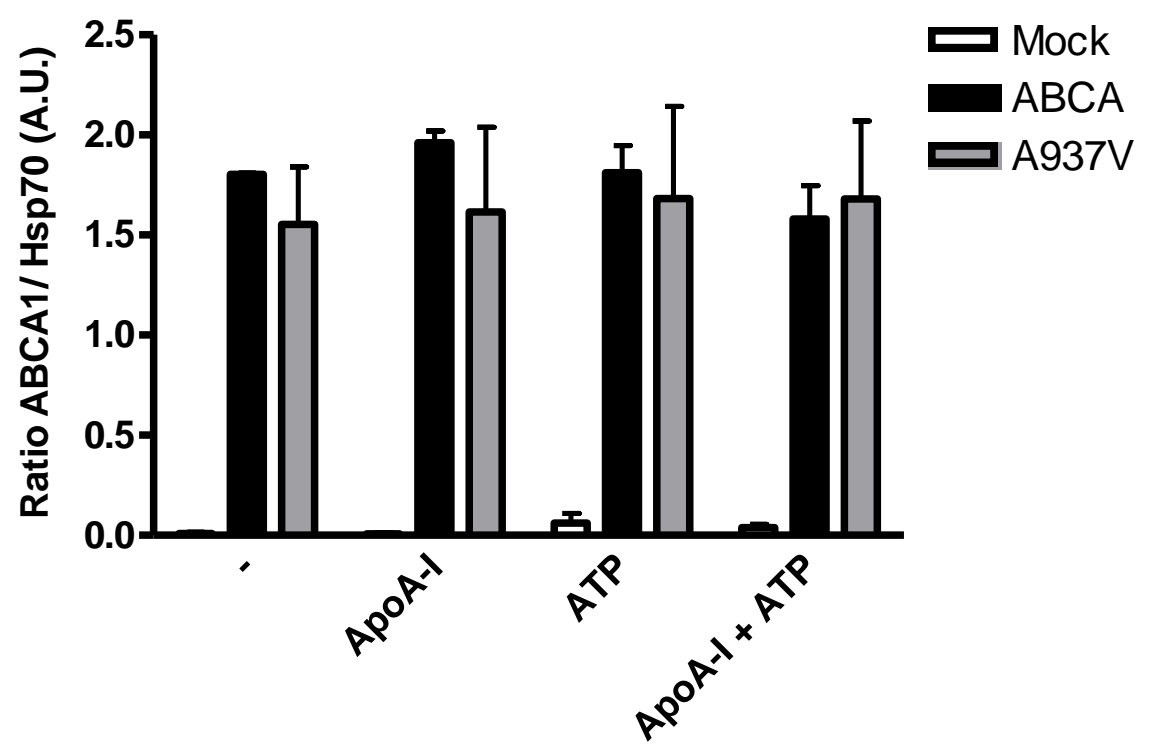


E

RAW 264.7 macrophages

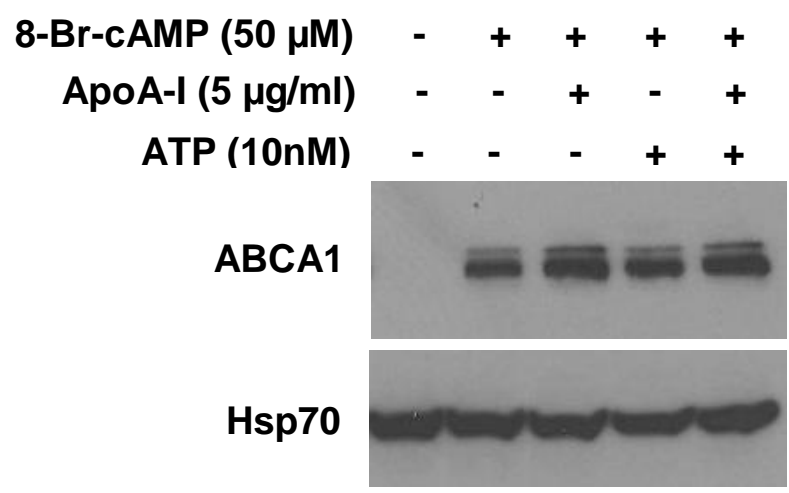

F

RAW 264.7 macrophages

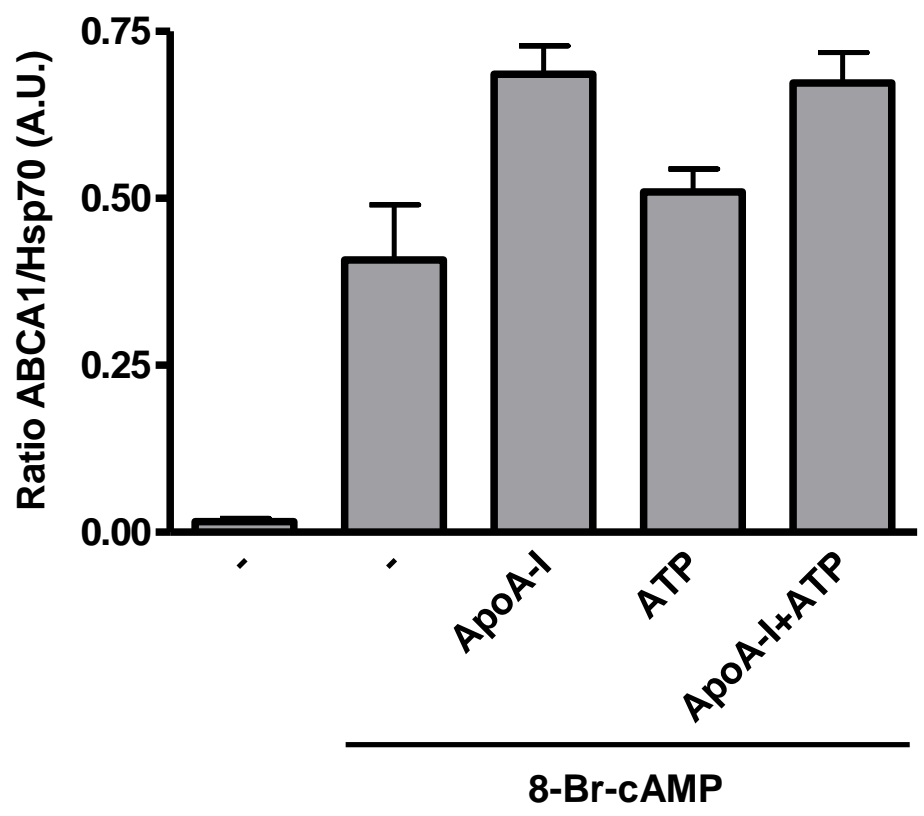


3.6 C, D), which may reflect the fact that BHK cells have limited degradation capacity, relative to macrophages. The turnover of ABCA1 in BHK cells is intrinsically much slower than in macrophages (data not shown), which makes them less sensitive to degradation protection by apoA-I. Importantly, we found that elevated eATP had no effect on the amount of ABCA1 protein in both cell types. Taken together, these results suggest that increase in eATP within normal physiological range is beneficial for HDL production by increasing efficiency of ABCA1 functions, but not expression. On the other hand, excess ATP can be toxic to cells and suppress cholesterol efflux.

\subsection{P2 receptors may not be involved in ABCA1-mediated cholesterol efflux}

One family of the molecular targets for eATP is the purinergic receptor. eATP is known to activate purinergic receptors such as $\mathrm{P} 2 \mathrm{X}$ and $\mathrm{P} 2 \mathrm{Y}$ receptors. Activated $\mathrm{P} 2 \mathrm{X}$ receptors can function as $\mathrm{Ca}^{2+}$ channels to allow $\mathrm{Ca}^{2+}$ influx ${ }^{170}$. However, $\mathrm{P} 2 \mathrm{X}$ is most effectively activated by $\mu \mathrm{M}$ to $\mathrm{mM}$ eATP ${ }^{154}$, the concentration range that actually suppresses cholesterol efflux to apoA-I. P2X receptor activation thus is not likely involved. Consistent with this notion, we found $\alpha, \beta$-MeATP, a selective agonist of $\mathrm{P} 2 \mathrm{X}$ receptors ${ }^{171}$, without any effect on the process (Figure 3.7 A). Furthermore, P2Y receptors in general are also effective in the $\mu \mathrm{M}$ range of eATP. We found that UTP, a potent P2Y activator ${ }^{172}$, was without any effect on cholesterol efflux (Figure 3.7 B). Also, several other P2Y inhibitors such as suramin (Figure $3.7 \mathrm{C}, \mathrm{D})$, PPADS and reactive blue ${ }^{172}$ (data not shown) were unable to influence the efflux process in both BHK cells and RAW macrophages. In addition, we tested ATP $\gamma \mathrm{S}$, which is a non-hydrolyzable ATP analog and general P2 receptor agonist ${ }^{173}$. Surprisingly, concentrations of ATP $\gamma \mathrm{S}$, similar to what we have used for ATP, did not 


\section{Figure 3.7}

Effects of $\mathrm{P2}$ receptor modulators on cholesterol efflux to apoA-I. BHK-ABCA1 cells and RAW macrophages were induced as in Figure 3.1 and $3.3 \mathrm{~B}$, respectively, and cholesterol efflux ( 2 hours) was measured with or without apoA-I in the presence of indicated concentrations of A) $\alpha, \beta-M e A T P$, B) UTP, C \& D) Suramin, and E \& F) ATP $\gamma$ S Results from $\mathbf{A}$ and $\mathbf{B}$ were obtained from Dr. Joel Karwatsky. Results present the average of triplicate wells with \pm SD and representative of at least three independent experiments. 
A

BHK-ABCA1

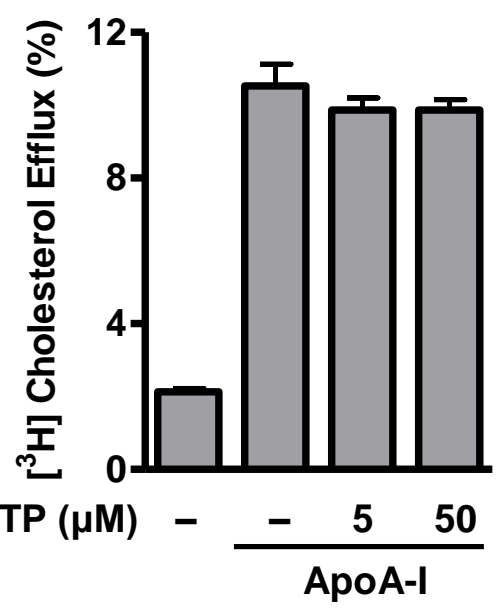

B

BHK-ABCA1

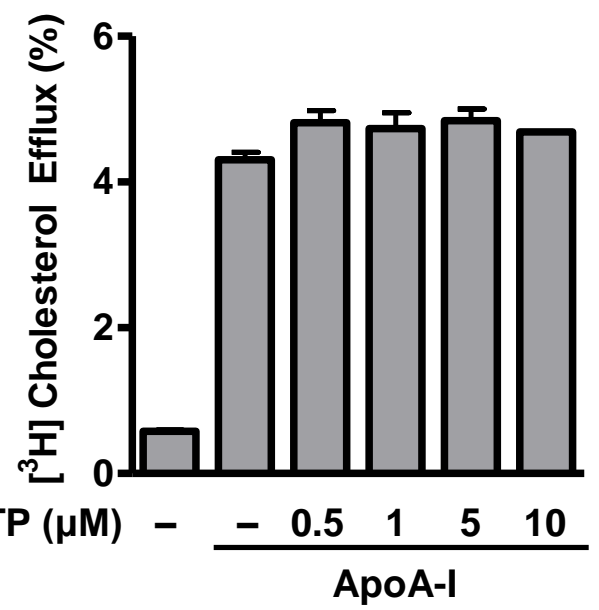

C

BHK-ABCA1

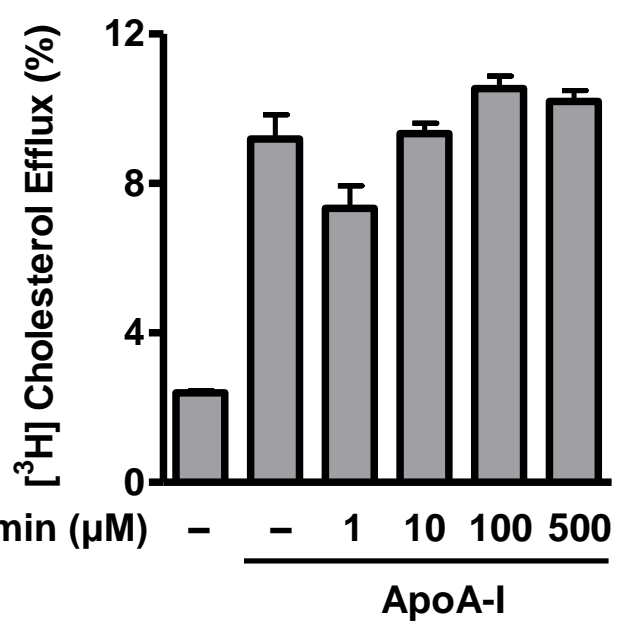

D

RAW 264.7 macrophages

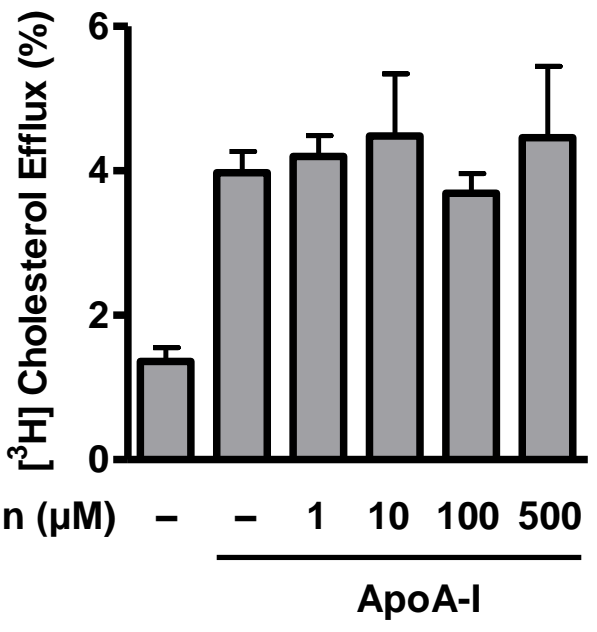


E

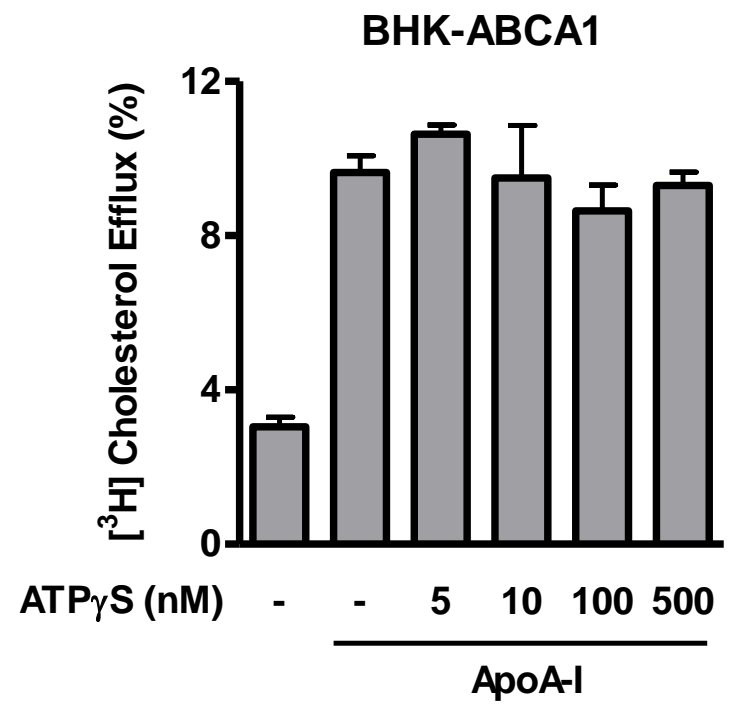

$\mathbf{F}$

RAW 264.7 macrophages

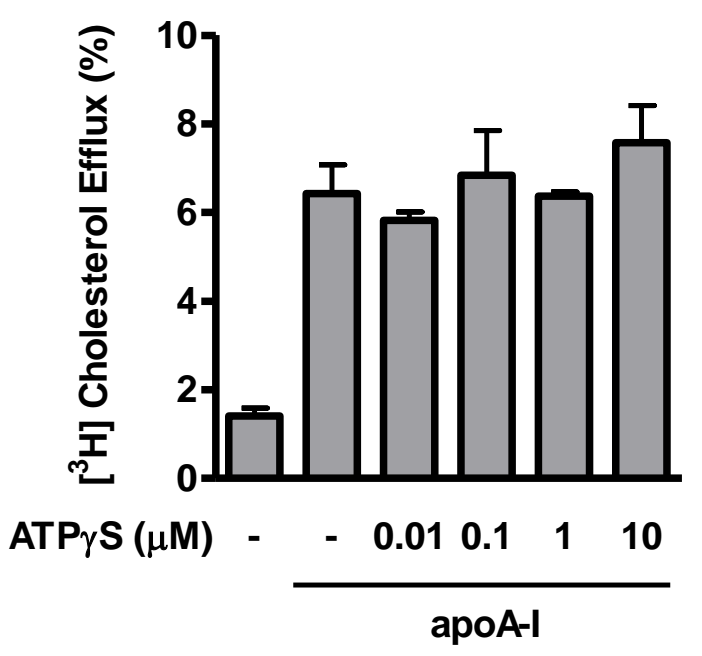


increase cholesterol efflux to apoA-I (Figure 3.7 E, F). This suggests that the presence of ATP itself does not enhance ABCA1's function. It may require hydrolysis of ATP as well.

ATP hydrolysis leads to the increase in ADP and AMP. AMP is further broken down to adenosine, which can be used by $\mathrm{P} 1$ receptors for various cellular signalling pathways. For this reason, eATP may influence cholesterol efflux through its metabolites. Hence, we tested the effects of ADP and AMP. However, neither had any effect on cholesterol efflux to apoAI (Figure 3.8 A, B). We could therefore conclude that it is unlikely that ABCA1-mediated efflux to apoA-I involves the activation of purinergic receptors. Also, the ATP hydrolysis step may be important in enhancing cholesterol efflux to apoA-I. However, ATP metabolites, ADP and AMP are not likely associated with ABCA1 functions.

\subsection{Hydrolyzing extracellular ATP by apyrase inhibit cholesterol efflux to apoA-I}

We next analyzed cholesterol efflux to apoA-I under conditions where eATP concentration was diminished. This was achieved first by supplementing exogenous apyrase to the medium during cholesterol efflux. Apyrase is a $\mathrm{Ca}^{2+}$ or $\mathrm{Mg}^{2+}$ activated enzyme that catalyzes hydrolysis of ATP and ADP to yield AMP and inorganic phosphates ${ }^{174}$. We first confirmed that apyrase was indeed effective in depleting ATP from the medium compared to untreated cells (Figure 3.9 A). Importantly, in both BHK-ABCA1 cells and RAW macrophages, apyrase dose-dependently suppressed cholesterol efflux to apoA-I (Figure 3.9 B, C). Significantly, cholesterol efflux from BHK-ABCA1 cells is inhibited by more than $80 \%$ at the highest concentration of apyrase tested $(25 \mathrm{U} / \mathrm{ml})(\mathrm{p}<0.001)$. In RAW macrophages, the effect of apyrase was less dramatic but still attained significance with 25 $\mathrm{U} / \mathrm{ml}(\mathrm{P}<0.005)$. 


\section{Figure 3.8}

ATP metabolites in cholesterol efflux to apoA-I. ABCA1 cells were induced as in Figure 3.1 and cholesterol efflux ( 2 hours) was measured with or without apoA-I in the presence of A) ADP $(10 \mathrm{nM}-100 \mu \mathrm{M})$, and B) AMP $(10 \mathrm{nM}-100 \mu \mathrm{M})$. Results present the average of triplicate wells with \pm SD and representative of at least three independent experiments. 
A

BHK-ABCA1

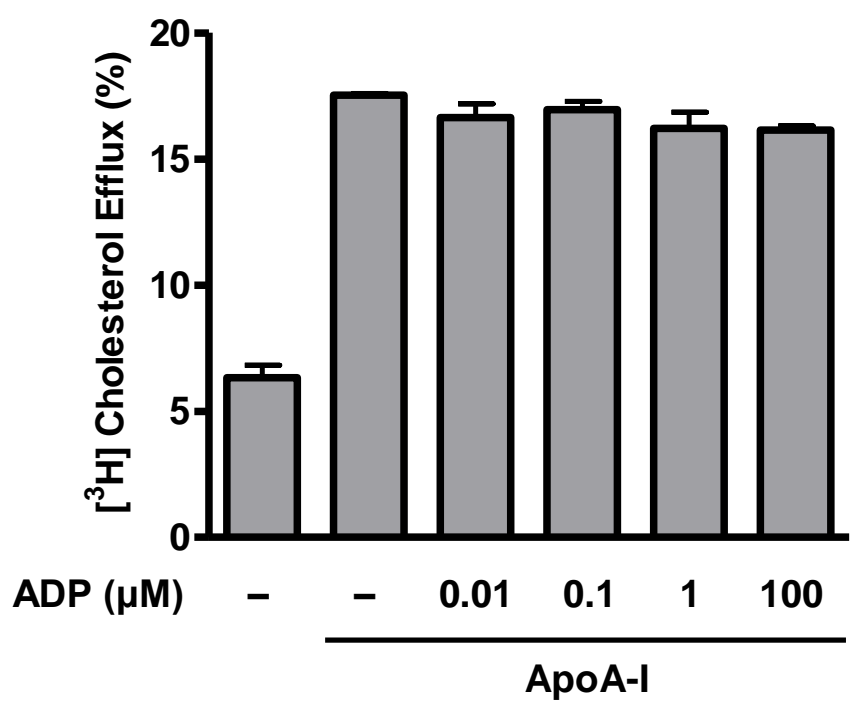

B

BHK-ABCA1

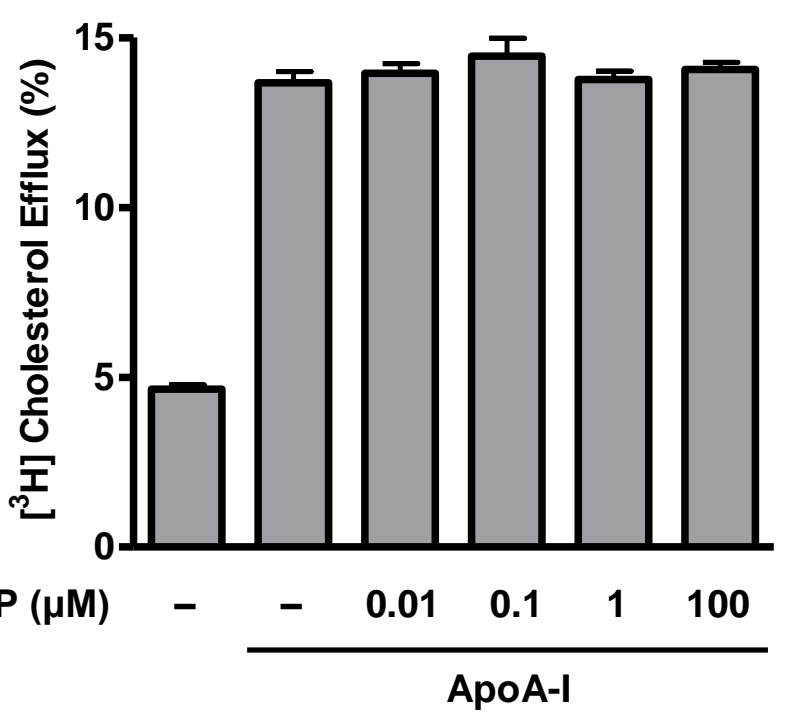




\section{Figure 3.9}

Analysis of ATP hydrolysis by apyrase. A) BHK cells were induced with $5 \mathrm{nM}$ mif and treated with apyrase for 2 hours. The medium was then analyzed for ATP. B) BHK-ABCA1 cells and C) RAW macrophages were labeled with $\left[{ }^{3} \mathrm{H}\right]$ cholesterol and induced as in Figure 3.1 and Figure 3.3 B, respectively. Cholesterol efflux to apoA-I $(5 \mu \mathrm{g} / \mathrm{ml})$ was analyzed in the presence of apyrase $(10$ and $25 \mathrm{U} / \mathrm{ml})$. D) BHK cells were treated with or without apyrase $(10 \mathrm{U} / \mathrm{ml})$ for apoA-I independent cholesterol efflux for 6 hours. E) Cholesterol efflux to apoA-I was analyzed as in $\mathbf{B}$, except that some of cells were treated with heat-inactivated apyrase. F) BHK-ABCA1 cells were pre-incubated with $10 \mathrm{U} / \mathrm{mL}$ apyrase for 2 hours and then washed off for cholesterol efflux to apoA-I for additional 2 hours. Results in $\mathbf{B}, \mathbf{C}, \mathbf{E}$ and $\mathbf{F}$ are presented as percentage of cholesterol efflux to apoA-I in the presence of apyrase, relative to the efflux without apyrase. G) Mif induced BHK-ABCA1 (5 nM) cells were incubated with apyrase $(10 \mathrm{U} / \mathrm{ml})$ alone or with apyrase and ATP $\gamma \mathrm{S}(500 \mathrm{nM})$ together for cholesterol efflux to apoA-I for 2 hours. Results present the average of triplicate wells with $\pm \mathrm{SD}$ and representative of at least two independent experiments. $*=\mathrm{p}<0.05, * *=\mathrm{p}<0.005$, and $* * *=\mathrm{p}<0.001$ 
A

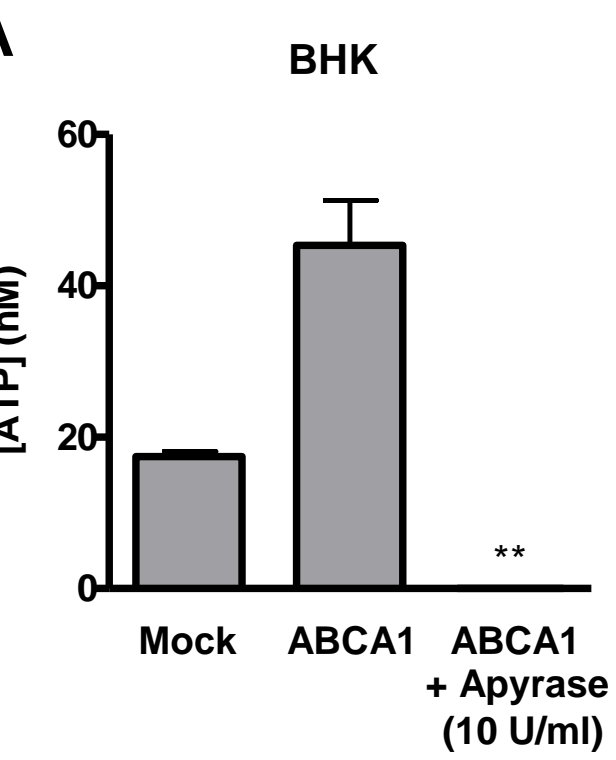

B

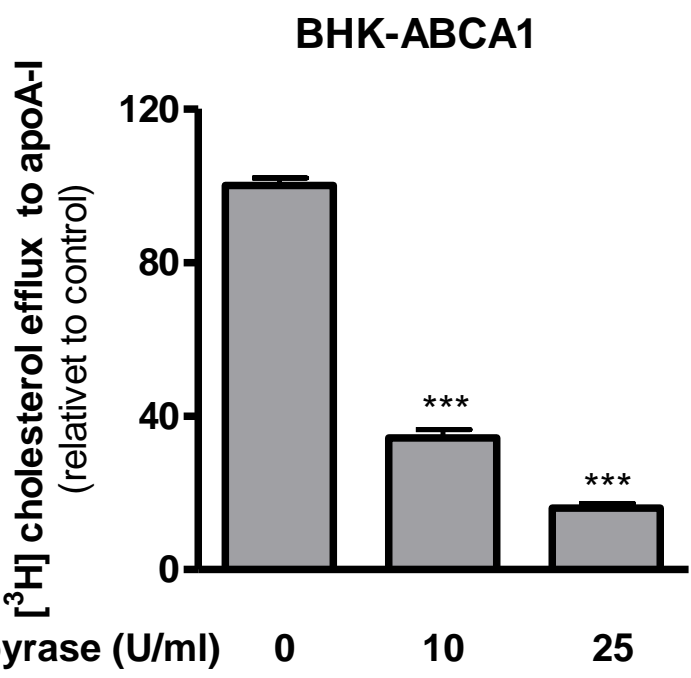

C

RAW 264.7 macrophages

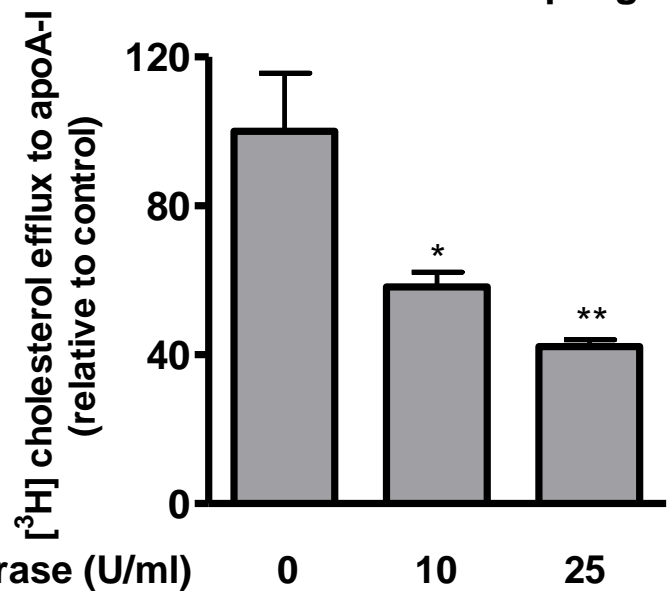

D

BHK

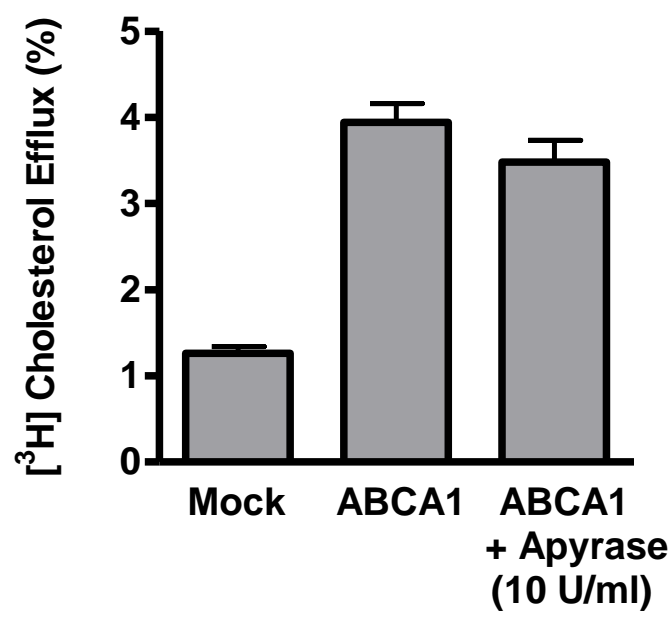



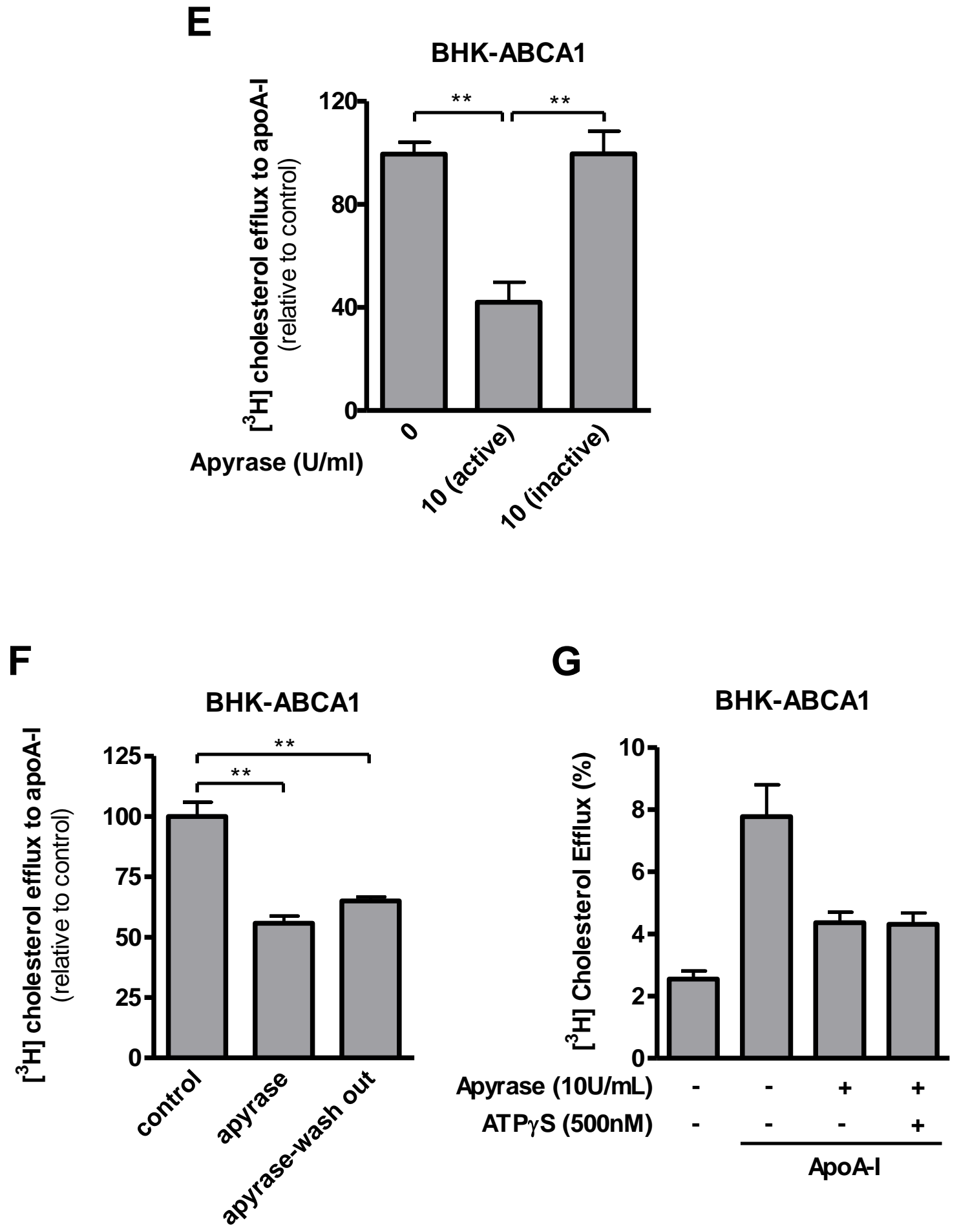
We have reported previously that ABCA1-expressing cells release cholesterol-rich non-HDL microparticles ${ }^{99}$, likely of exosomal origin ${ }^{138}$. This pathway is independent of apoA-I but still requires fully functional $\mathrm{ABCA} 1^{99}$. Interestingly, we found that apyrase is entirely without effect on this microparticle release (Figure 3.9 D), which is reminiscent of $\mathrm{Ca}^{2+}$ removal or calcineurin inhibition ${ }^{143}$. This implicates eATP in the same pathway as $\mathrm{Ca}^{2+} /$ calcineurin.

We next wanted to confirm whether the inhibitory effect on efflux is completely due to the enzymatic activity of apyrase. To test this, apyrase was heat-inactivated at $80^{\circ} \mathrm{C}$ and then its effect on efflux was verified along with functional apyrase. As shown in Figure 3.9 E, inactivation of apyrase completely abolished its inhibitory effects on efflux. Interestingly, we found that the inhibitory effect of apyrase persisted even when the active apyrase was washed out (Figure 3.9 F). This suggests that minor quantities of apyrase may remain associated with cells, preventing eATP levels from recovering after washing out. Alternatively, it may take much longer for eATP to recover. Lastly, we explored whether a non-hydrolyzable ATP analog, ATP $\gamma$ S, could replace ATP depleted by apyrase and possibly restore the lost function of cholesterol efflux by apyrase. We found no rescue by ATP $\gamma \mathrm{S}$ (Figure $3.9 \mathrm{G}$ ). This is consistent with our earlier observation that $\mathrm{ATP} \gamma \mathrm{S}$ had no enhancing effect on cholesterol efflux, contrary to ATP (Figure 3.7 E \& F). Thus, when eATP is removed by apyrase, ABCA1-mediated cholesterol efflux to apoA-I is abolished, implying that elevated eATP levels are essential for this process.

\subsection{CD39 overexpressed cells inhibit cholesterol efflux to apoA-I}

The results above clearly demonstrated the effectiveness of apyrase to remove eATP and to inhibit cholesterol efflux to apoA-I. However, we noted that fairly high concentrations 
(>10 U/ml) of apyrase were required to achieve effective inhibition. As described earlier, elevated eATP in ABCA1-expressing cells is likely caused by increased ATP release from cells. This raised the possibility that ATP may function through autocrine or paracrine mechanisms, where newly released ATP can find nearby targets before diffusing into the bulk medium. High concentrations of apyrase would then be necessary to capture newly released ATP near the cell surface in order to block cholesterol efflux to apoA-I.

We therefore expressed CD39, a plasma membrane anchored nucleotidase, on the cell surface to complement and confirm our observations with exogenous addition of apyrase. Overexpressing CD39 would allow a more efficient capture of ATP and hydrolyze, since it is directly located on the cell surface. To achieve this, we transiently transfected CD39 in both BHK-ABCA1 and RAW macrophages. BHK cells were transiently transfected with a control vector encoding YFP or Flag-tagged CD39 and then induced to express ABCA1. BHK-Mock cells and untransfected BHK-ABCA1 cells also served as controls. BHK-Mock and -ABCA1 cells expressed similar amounts of endogenous CD39, and overexpression with Flag-CD39 increased total CD39 expression by a few folds (Figure 3.10 A). Also, CD39 expression did not alter ABCA1 expression levels in these cells (Figure 3.10 A). In addition, Flag-CD39 is primarily localized on the plasma membrane as expected, shown by cells immunostained with a monoclonal antibody against Flag (Figure 3.10 B). CD39 overexpressing cells showed that Flag was decorating the general area of the plasma membrane, while non-transfected cells produced little staining, confirming the specificity of the antibody. We found that CD39 overexpression, but not control vector (YFP), significantly lowered ATP concentration in the medium of BHK-ABCA1 cells, which is now comparable to the ATP level in the medium of BHK-Mock cells (Figure 3.10 C). Importantly, this ATP lowering by CD39 protein results in a complete inhibition of cholesterol efflux from these cells to apoA-I (Figure 3.10 D, 


\section{Figure 3.10}

CD39 overexpression in BHK cells. A) BHK-ABCA1 cells were transiently transfected with Flag-CD39 or YFP and induced with mif $(10 \mathrm{nM})$ overnight before western analysis. Non-transfected BHK-ABCA1 and -Mock cells were treated similarly as control. Hsp70 was used as loading control. B) Flag-CD39 transfected BHK-ABCA1 cells were immuno-stained with Flag antibody to detect the cellular distribution of Flag-CD39. The fluorescent micrographs were taken under identical conditions. C) Flag-CD39 or YFP transfected BHKABCA1 cells were induced overnight with mif $(10 \mathrm{nM})$. The medium was collected and analyzed for ATP as in Figure 3.3. None-transfected BHK-ABCA1 and-Mock cells were analyzed similarly as control. D) Flag-CD39 or YFP transfected BHK-ABCA1 cells were labeled with $\left[{ }^{3} \mathrm{H}\right]$ cholesterol and induced with mif $(10 \mathrm{nM})$, followed by 2 hour cholesterol efflux assay with or without apoA-I. None-transfected BHK-ABCA1 and -Mock cells were analyzed as control. Results present the average of triplicate wells with \pm SD and are representative of three independent experiments. $* * *=p<0.001$. 
A

BHK cells

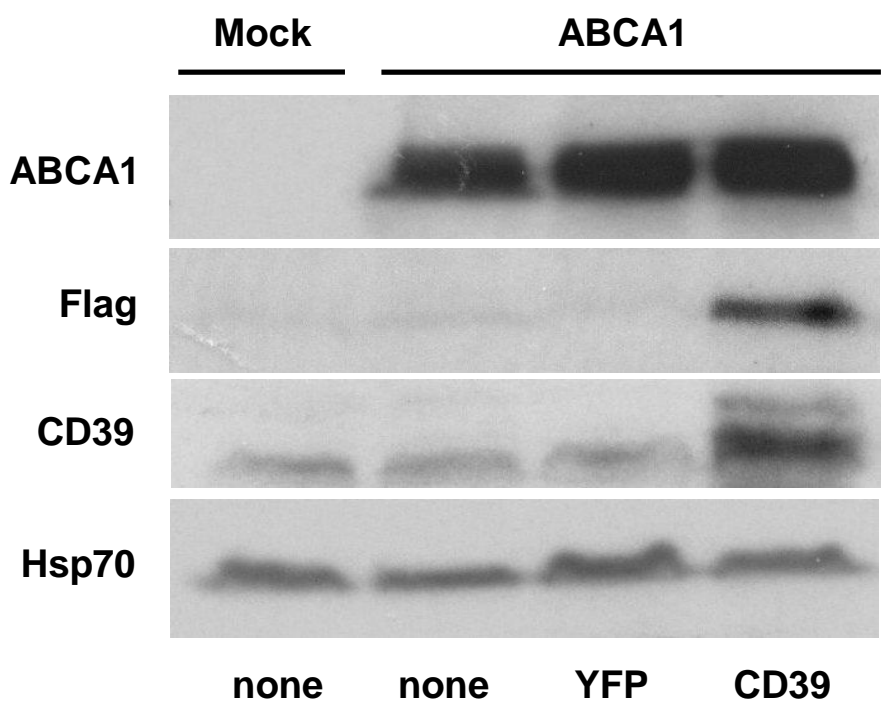

B

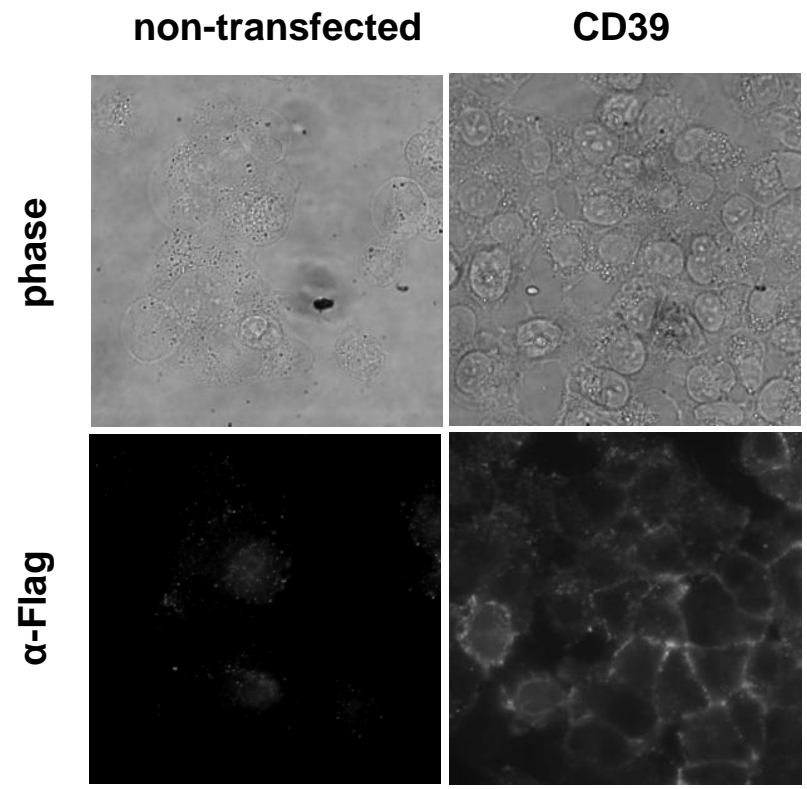


C
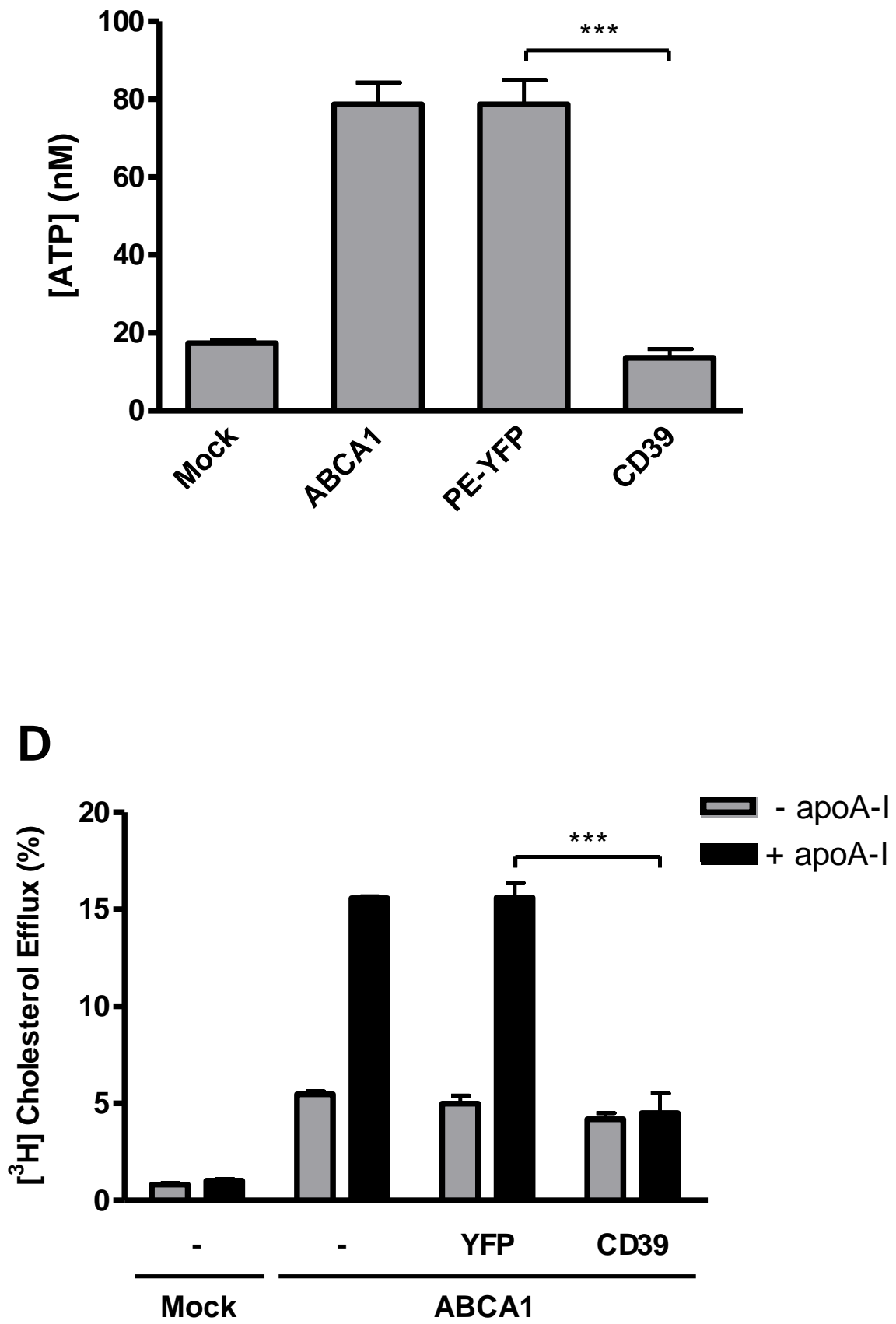
compare cholesterol efflux with or without apoA-I). Interestingly, manipulating eATP by CD39 has minimal effect on basal cholesterol efflux from ABCA1-expressing BHK cells, i.e. microparticle release independent of apoA-I (Figure 3.10 D, gray bars). ABCA1-expressing cells released substantial amounts of cholesterol in the form of microparticles (Figure 3.10 D, compare gray bars from Mock and ABCA1 cells). CD39 expression apparently has no effect on this component of cholesterol export, consistent with our earlier data that apyrase did not alter microparticle release (Figure 3.9 D).

Next, we performed identical experiments on RAW macrophages that express endogenous ABCA1. Similar to BHK cells, when Flag-CD39 was properly expressed and localized (Figure 3.11 A), we observed a significant inhibition of cholesterol efflux to apoA-I (Figure 3.11 B) ( $\mathrm{p}<0.005)$. Once again, basal cholesterol efflux (gray bars) was not affected by CD39. Based on these observations, we conclude that abolishing eATP by overexpressing CD39 specifically inhibits cholesterol efflux to apoA-I.

While we were confident that hydrolyzing eATP by transient transfection of CD39 abolishes ABCA1 function, we also attempted to explore whether cells stably expressing Flag-CD39 behaved similarly. Several stable clones of Flag-CD39 overexpressing RAW macrophages were established and the clone that had the highest expression of CD39 was used for immunoblotting (Figure 3.12 A) and its effect on eATP level was determined (Figure 3.12 B). These stable cells had much higher rate of hydrolyzing eATP than transiently transfected cells, as indicated by extremely low steady state eATP levels (Figure $3.12 \mathrm{~B})$. Also shown in Figure $3.12 \mathrm{C}$, CD39 stable cells were able to abolish all the exogenous ATP added into the medium up to $1 \mu \mathrm{M}$ within $10 \mathrm{~min}$. These cells even hydrolyzed about $90 \%$ of $10 \mu \mathrm{M}$ exogenous ATP during the same period. In terms of the functionality of these CD39 expressing cells, we observed a complete inhibition of 


\section{Figure 3.11}

CD39 overexpression in RAW macrophages. A) RAW macrophages were transiently transfected with Flag-CD39 and induced with 8-Br-cAMP $(50 \mu \mathrm{M})$ overnight.

Immunofluorescence staining was performed with anti-Flag antibody for CD39

overexpressing cells and non-transfected cells as control. The fluorescent micrographs were taken under identical conditions. B) YFP or Flag-CD39 transfected RAW macrophages were labeled with $\left[{ }^{3} \mathrm{H}\right]$ cholesterol, induced $(50 \mu \mathrm{M} 8$-Br-cAMP) and then incubated with or without apoA-I $(5 \mu \mathrm{g} / \mathrm{ml})$ for 2 hours. Results present the average of triplicate wells with SD and are representative of two independent experiments. $* *=p<0.005$. 
A

RAW 264.7 macrophages

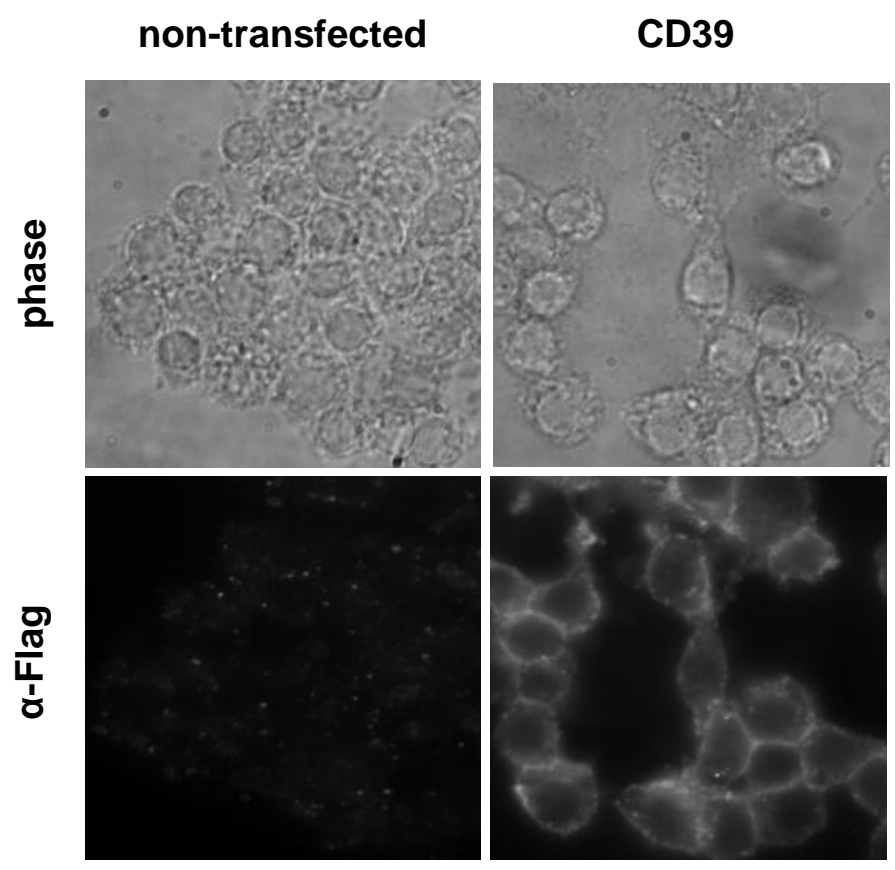

B

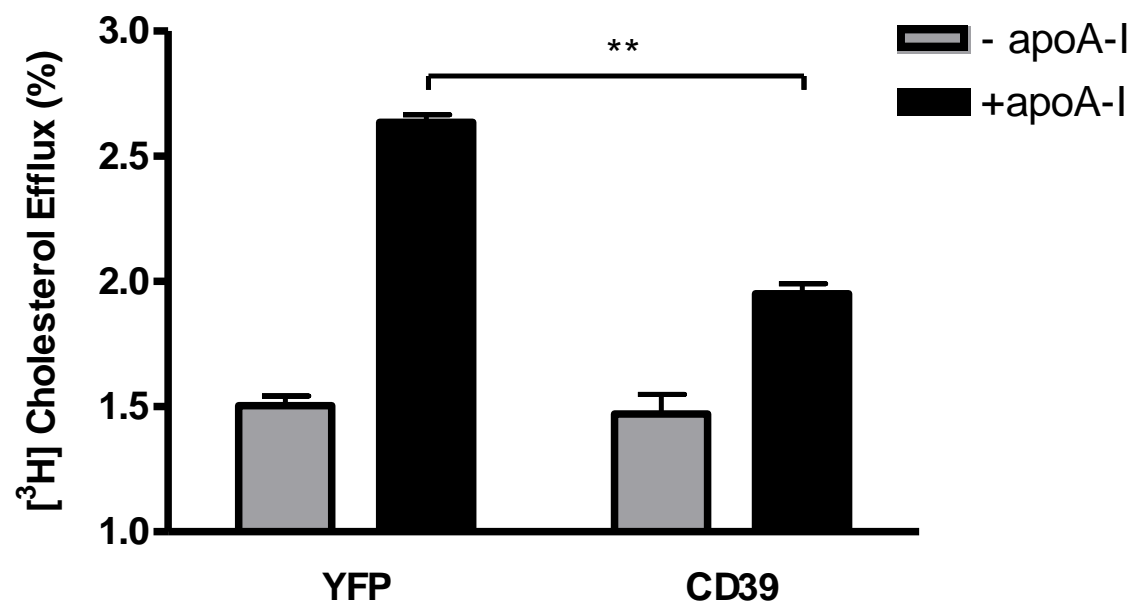




\section{Figure 3.12}

Stable overexpression of CD39 in ABCA1 induced RAW macrophages. Non-transfected and CD39 stable cells were: A) treated either with or without 8-Br-cAMP $(50 \mu \mathrm{M})$ for immunoblot of Flag expression to check CD39 expression level. The clone that contains highest Flag-CD39 expression is shown. Hsp70 was used as a loading control. B) treated either with or without 8-Br-cAMP $(50 \mu \mathrm{M})$ for ATP analysis. C) incubated with indicated concentrations of exogenous ATP for 10 min in fresh media. eATP levels were determined after media collection. D-F) checked for cholesterol efflux to apoA-I with induced and noninduced cells at passage $3(\mathbf{D})$, passage $8(\mathbf{E})$, and passage $15(\mathbf{F})$. Results present the average of triplicate wells with \pm SD and are representative of two independent experiments. 
A

RAW 264.7 macrophages

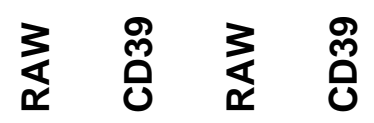

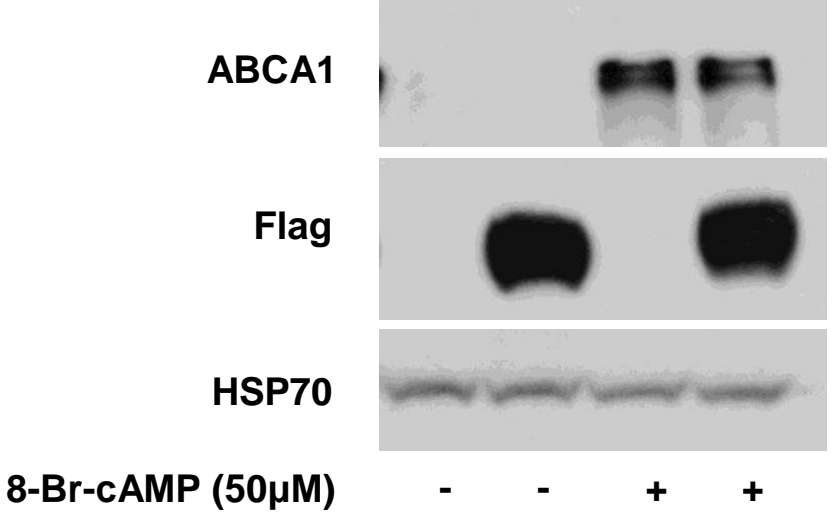

B

RAW 264.7 macrophages

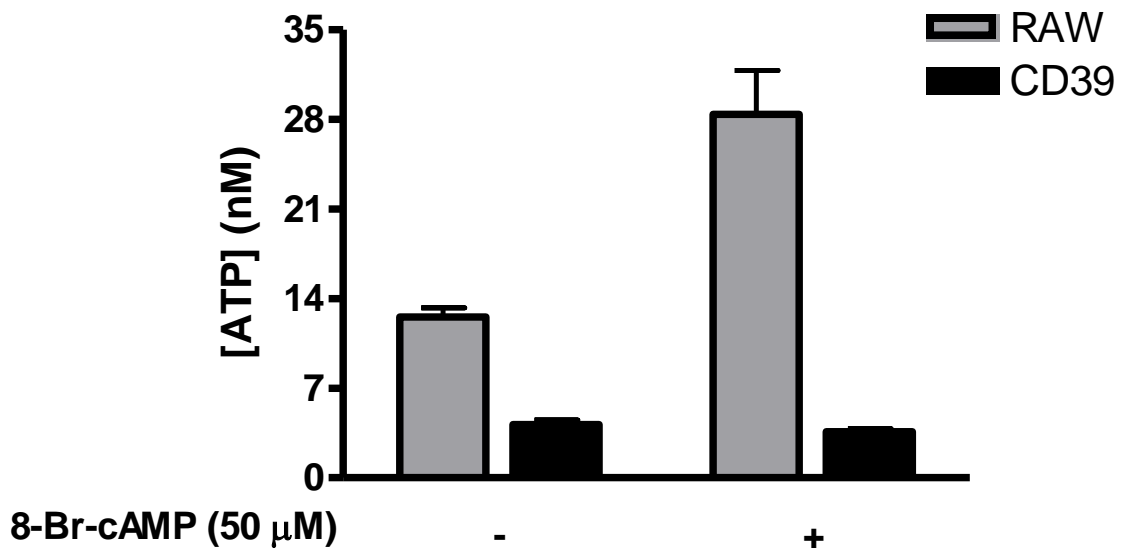

C

RAW 264.7 macrophages

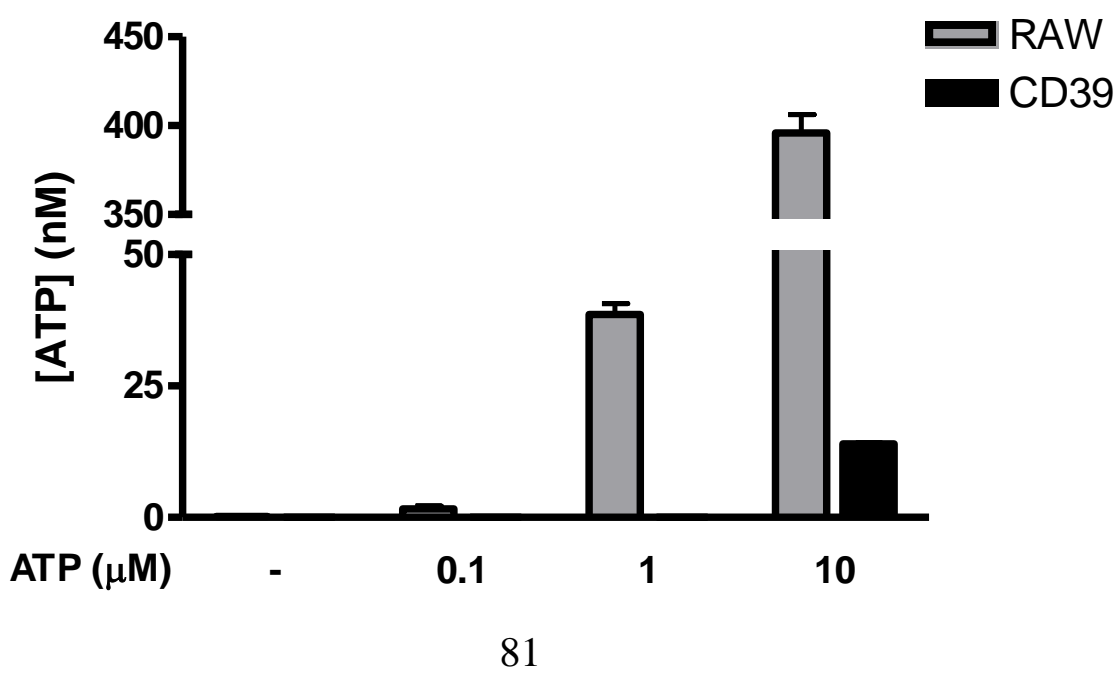


D

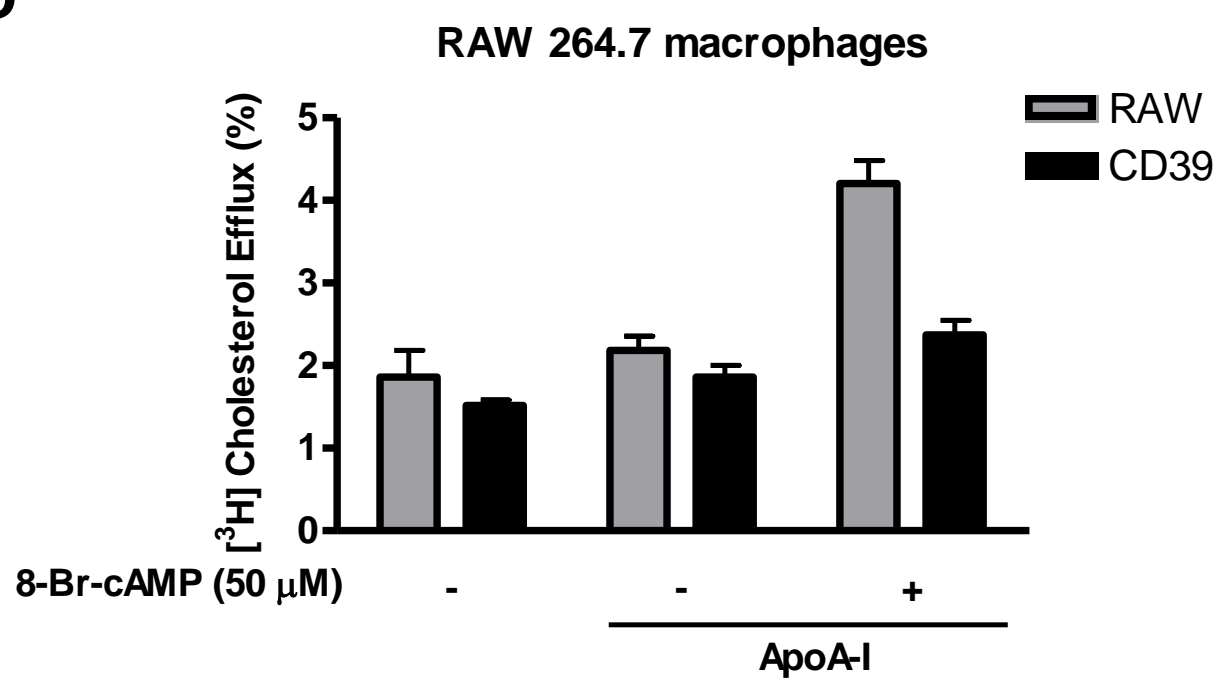

E

RAW 264.7 macrophages

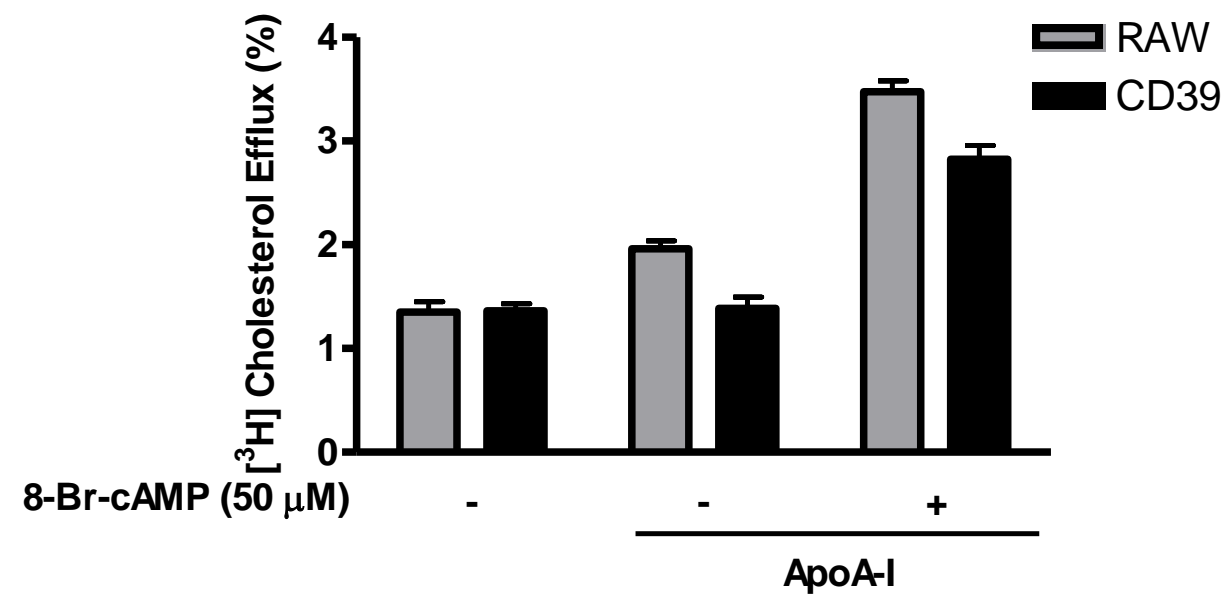

F

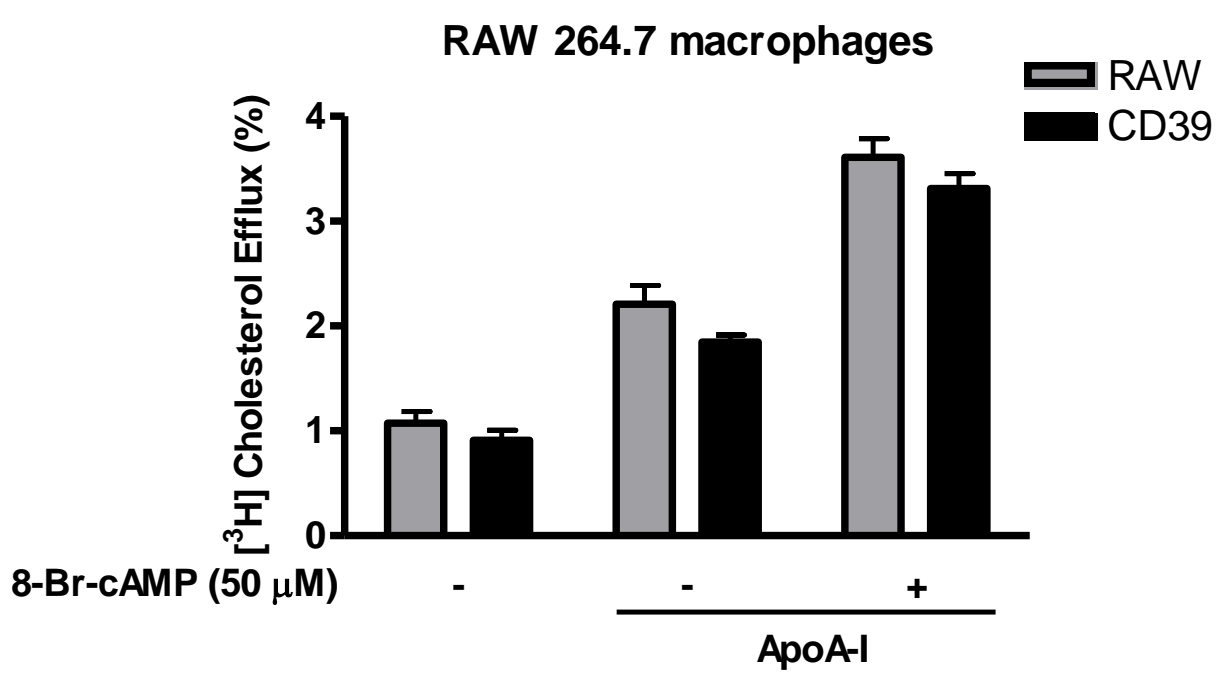


cholesterol efflux to apoA-I at early passages (Figure 3.12 D). However, after a month or so of passaging these cells, this inhibition effect was gradually deteriorated (Figure 3.12 E, F). We found that this cannot be due to decreased expression of CD39 as the level of CD39 expression remained unaltered (data not shown). Although it is not well understood, it is possible that complete absence of eATP during cell growth/cycle could transform cells, or activate some adaptive mechanisms to replace eATP signalling. Nevertheless, this limited our options of using these stable cells for further study. Regardless, our experiments using cells transiently expressing CD39 strongly support eATP as an essential component for ABCA1 to export cholesterol to apoA-I, consistent with apyrase data. On the other hand, ABCA1 can, however, still release microparticles in the absence of eATP.

\subsection{ATP release is independent of apoA-I and microparticle secretion}

Presently, we do not understand the mechanism by which ABCA1 facilitates ATP release. ABCA1 can actively export cholesterol to apoA-I, but apoA-I does not further enhance eATP levels in either BHK-ABCA1 cells or RAW macrophages (Figure 3.13 A, B).

Alternatively, the release of microparticles from ABCA1-expressing cells could bring ATP with them since intracellular ATP concentrations are in the $\mathrm{mM}$ range ${ }^{154}$. We therefore tested whether microparticle release is correlated with ATP release. We have shown recently that treating ABCA1-expressing cells with a small peptide, st-Ht31, can greatly boost microparticle release by several folds ${ }^{138}$. A representative experiment is shown in Figure 3.14 A, where st-Ht31 is able to enhance cholesterol efflux by several folds in BHK-ABCA1 cells in the absence of apoA-I. We however found that eATP level is not elevated during microparticle release (Figure 3.14 B). This effectively rules out the possibility that microparticles serve as ATP carriers. 


\section{Figure 3.13}

Effect of apoA-I binding on extracellular ATP levels in ABCA1-expressing BHK and RAW macrophages. A) BHK-ABCA1 and B) RAW macrophages were incubated overnight with or without mif $(5 \mathrm{nM})$ or 8 -Br-cAMP $(50 \mu \mathrm{M})$, respectively. ApoA-I $(5 \mu \mathrm{g} / \mathrm{ml})$ was added for 2 hours before medium ATP analysis. Results present the average of triplicate wells with \pm SD and are representative of three independent experiments. 
A

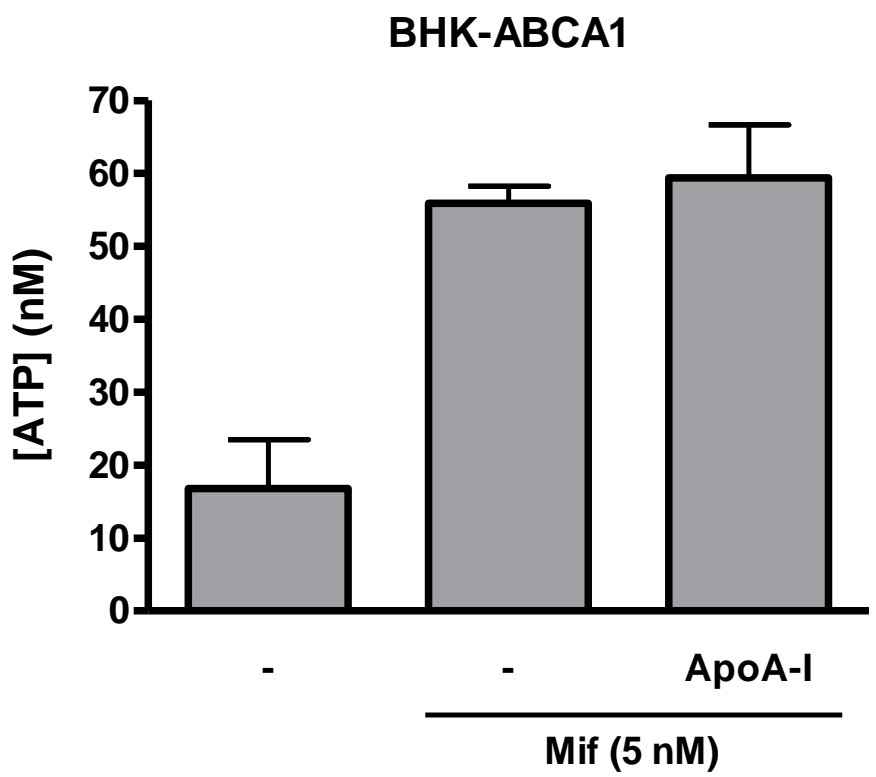

B

RAW 264.7 macrophages

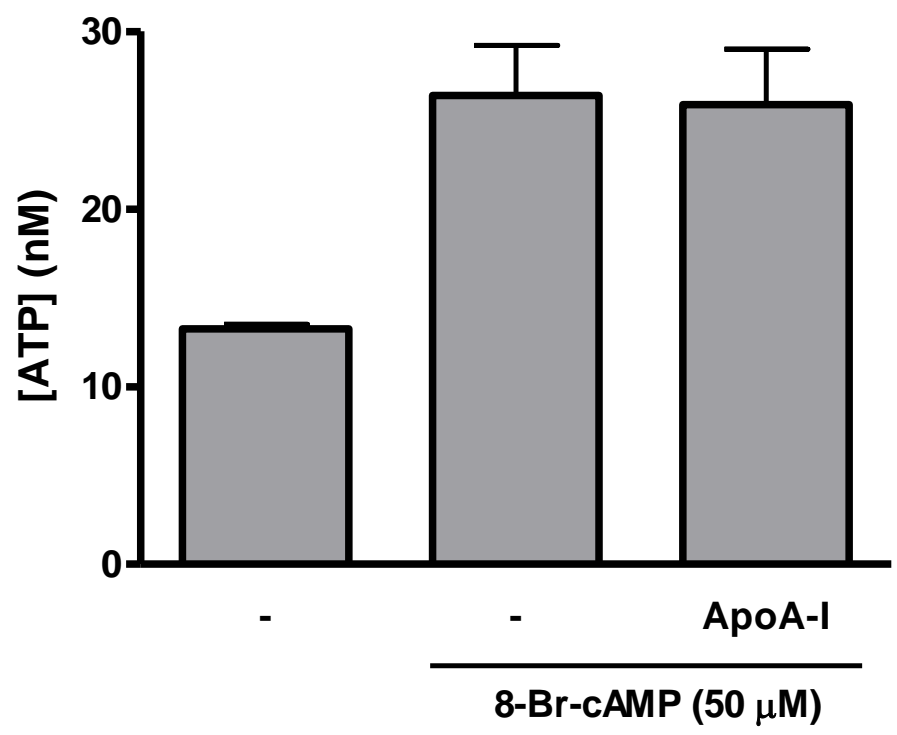




\section{Figure 3.14}

st-Ht31 stimulation in ATP secretion from ABCA1 expressing BHK cells. A) BHK cells were induced with mif $(10 \mathrm{nM})$ overnight then cholesterol efflux was analyzed by quantifying the percentage of cell-associated cholesterol appeared in the medium during a 2 hour period with or without st-Ht31 $(5 \mu \mathrm{M})$. B) Induced BHK-ABCA1 cells were incubated with st-Ht31 $(5 \mu \mathrm{M})$ for 2 hours before medium ATP analysis. The results from A obtained from Loretta Ma. Results present the average of triplicate wells with \pm SD and are representative of three independent experiments. $* * *=p<0.001$. 
A

\section{BHK}

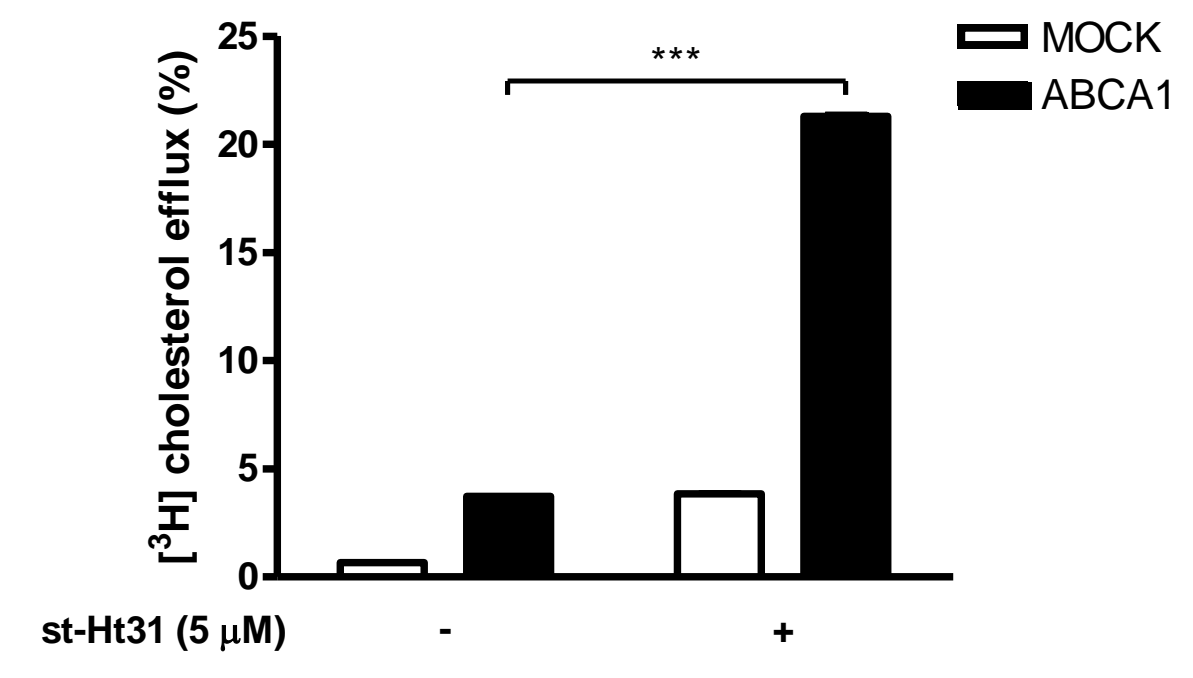

B

BHK-ABCA1

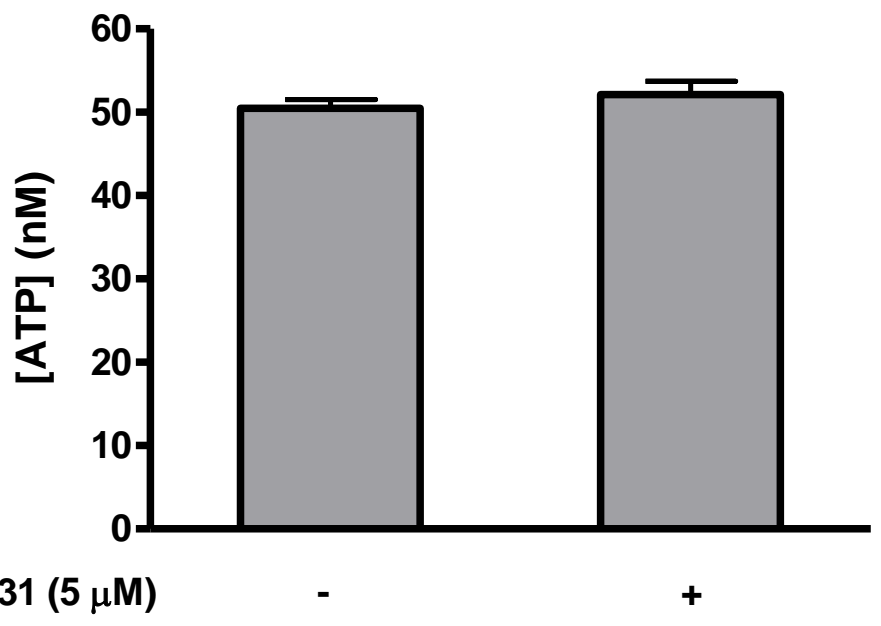


Given that elevated eATP is required for cholesterol efflux and ABCA1 ${ }^{\mathrm{A} 937 \mathrm{~V}}$ fails to raise eATP levels, we wondered whether supplying exogenous ATP to the medium could rescue cholesterol efflux to apoA-I in these mutant cells. We found that, although cholesterol efflux from these cells is slightly increased, exogenous ATP fails to fully rescue the efflux function in 2 hours (Figure $3.15 \mathrm{~A}$, compared to WT ABCA1). We also tried to add different concentrations of ATP (500 nM and $5 \mu \mathrm{M})$ for overnight, 2 hour pre-incubation, and with or without apoA-I during the normal 2 hour cholesterol efflux period (Figure $3.15 \mathrm{~B}$ ). In all cases, we failed to see significant differences in cholesterol efflux efficiency. ABCA1 ${ }^{\mathrm{A} 937 \mathrm{~V}}$ is known to be defective in apoA-I binding to $\mathrm{ABCA} 1^{140}$, an initial step required to trigger downstream signalling events including $\mathrm{Ca}^{2+}$ influx ${ }^{143}$. Perhaps in the absence of apoA-I binding, cholesterol efflux would not occur even if there is sufficient level of eATP. Taken together, eATP is not further enhanced by apoA-I or by microparticle release. As elevating eATP does not rescue cholesterol efflux to apoA-I in ABCA1 ${ }^{\text {A937V }}$ cells, we speculate that elevated eATP supports step(s) downstream of apoA-I binding. Further investigation is required to understand how ABCA1-expressing cells release ATP and how eATP promotes cholesterol efflux to apoA-I. 


\section{Figure 3.15}

Analysis of supplementing ATP to BHK-A937V cells. A) BHK cells were pre-incubated with mif $(5 \mathrm{nM})$ and with or without exogenous ATP $(100 \mathrm{nM}$ and $1 \mu \mathrm{M})$ for $30 \mathrm{~min}$. Cholesterol efflux was analyzed after adding apoA-I $(5 \mathrm{~g} / \mathrm{ml})$ with or without exogenous ATP for 2 hours. B) $500 \mathrm{nM}$ and $5 \mu \mathrm{M}$ of exogenous ATP were supplemented for overnight, 2 hour pre-incubation, and 2 hour incubation during cholesterol efflux to apoA-I. Results present the average of triplicate wells with \pm SD and are representative of three independent experiments. 
A

\section{BHK cells}

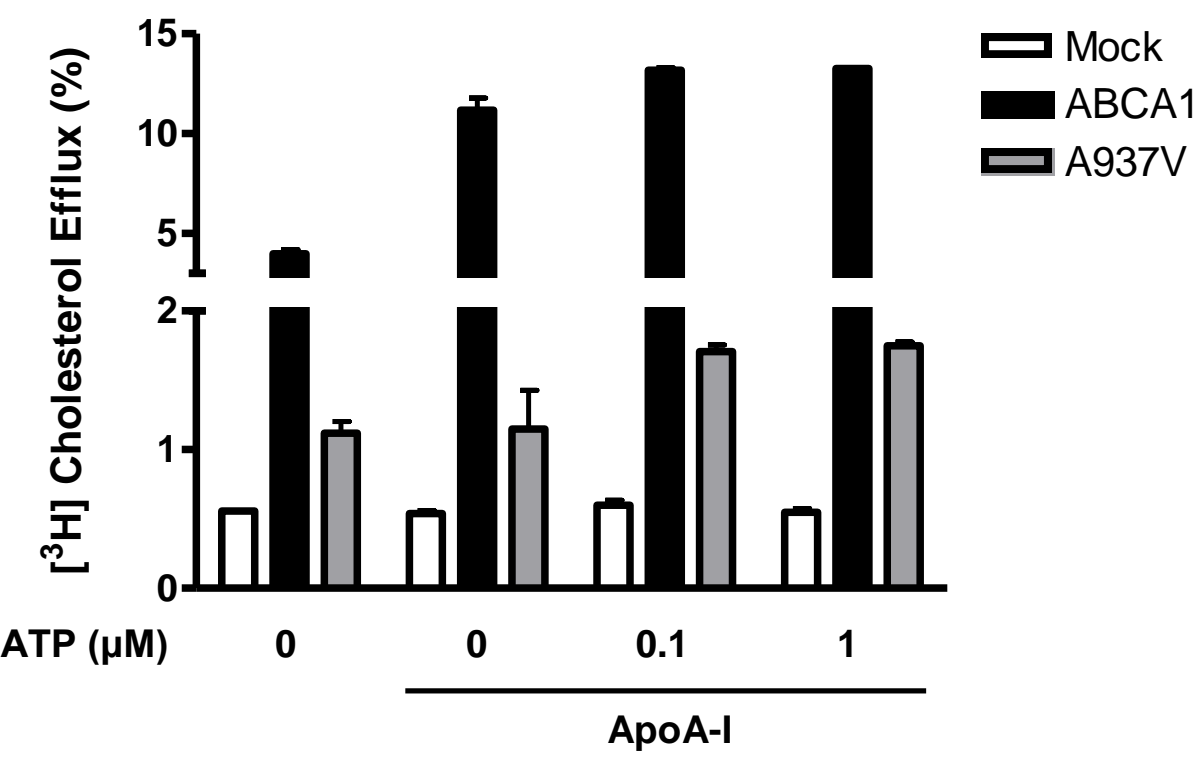

B

BHK-A937V

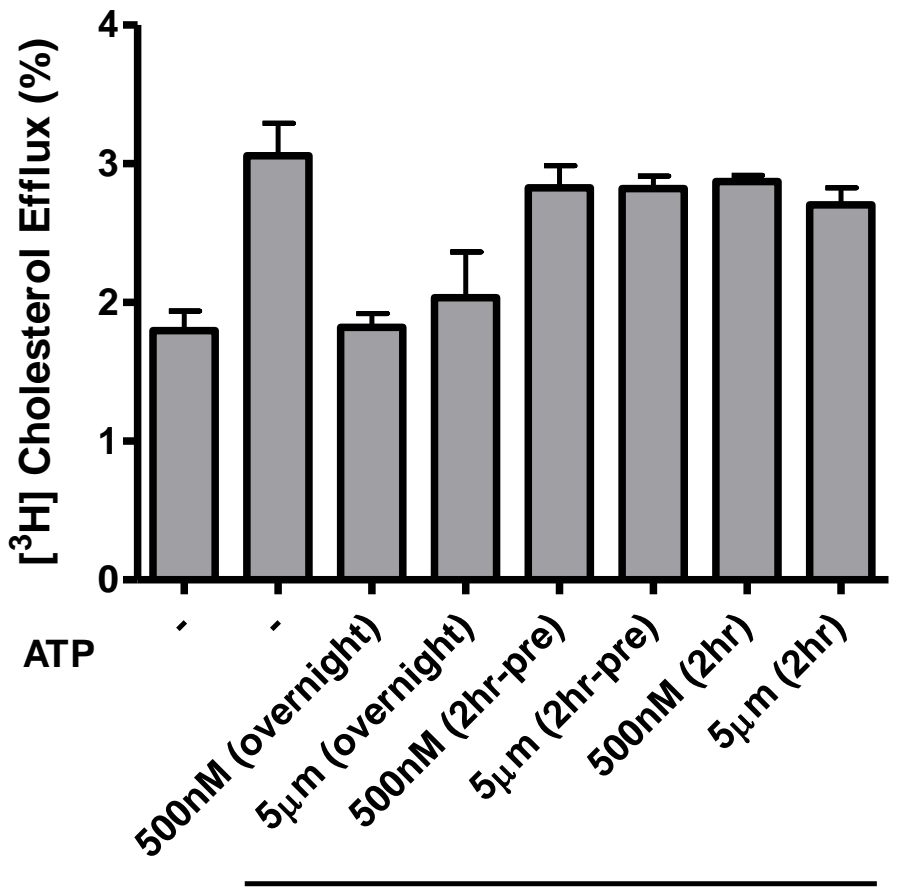

ApoA-I 


\section{Chapter IV: Discussion}

\subsection{Discussion}

Throughout this study, we provide multiple lines of evidence indicating that eATP is essential for functional ABCA1 to mediate apoA-I dependent cholesterol efflux. First of all, we observed that in both BHK cells and RAW macrophages, eATP concentration is elevated when cells express functional ABCA1. BHK cells expressing a functionally defective mutant, A937V, are unable to raise eATP levels. Furthermore, a dose-dependent effect of ABCA1 expression on eATP level was also demonstrated. Our results therefore strongly suggest that elevated eATP level is a direct consequence of ABCA1 function. Secondly, eATP at different concentrations have varying roles in controlling apoA-I mediated cholesterol efflux. Generally, increasing eATP concentrations within the range of $50 \mathrm{nM}$ to $1 \mu \mathrm{M}$ in the extracellular medium increases the efficiency of cholesterol efflux to apoA-I. However, this is dependent of apoA-I binding to cells as elevating eATP fail to fully rescue cholesterol efflux to apoA-I in ABCA1 ${ }^{\mathrm{A} 937 \mathrm{~V}}$ cells where apoA-I binding is defective. Furthermore, eATP concentrations either higher than $1 \mu \mathrm{M}$ or lower than $50 \mathrm{nM}$ inhibited cholesterol efflux, suggesting that the process is optimal under normal physiological conditions. Lastly, eATP does not seem to modulate basal cholesterol efflux i.e. microparticle release, which is independent of apoA-I.

ATP is mainly used as energy currency for cellular metabolism. Cytosolic concentrations of ATP are typically 3-10 mM, whereas its extracellular concentration is very low under normal physiological conditions, $<100 \mathrm{nM}^{154}$. Despite this huge concentration gradient, ATP and other nucleotides from the intracellular compartment cannot diffuse freely 
out of the plasma membrane. We have found that ABCA1 expressing cells likely release ATP from the intracellular pool of nucleotides. The extracellular accumulation of ATP reflects the balance between ATP release by cells and ATP hydrolysis by ectonucleotidases. Ectonucleotidases are found on the surface of virtually all mammalian cell types with distinct distribution patterns that determine the amount of ATP in the extracellular environment. As a common feature, these ectonucleotidases are capable of hydrolyzing nucleoside tri and/or diphosphates, but not monophosphates. They also require $\mathrm{Ca}^{2+}$ or $\mathrm{Mg}^{2+}$ for their activity, and are not sensitive to specific inhibitors of P-type, V-type and F-type ATPases ${ }^{175}$. The prototypic member of the ectonucleotidases is CD39, also known as ecto-nucleoside triphosphate diphosphohydrolase, an integral membrane protein which has been cloned, sequenced and identified as a cell activation antigen and a putative B-cell activation marker ${ }^{176}$. Other experiments have confirmed that there is a significant homology of apyrase from potato tubers to human CD39, explaining their similar functions in our results ${ }^{177}$. Both BHK cells and RAW macrophages express endogenous CD39. However, there is no downregulation of CD39 with ABCA1 expression. We have also established that the elevated eATP levels in ABCA1-expressing cells is not from ATP hydrolysis, because cells that do not express ABCA1 had the identical ability to hydrolyze eATP as cells expressing ABCA1 (Figure 3.3 A and 3.5 A). Thus, eATP hydrolysis capacity is apparently not altered by ABCA1 expression. Therefore, we speculate that the elevation of eATP is the consequence of increased ATP release from ABCA1-expressing cells.

ATP release by ABCA1 is actually in line with another ABC transporter protein, CFTR. CFTR is known to facilitate ATP release under constitutive and hypotonic conditions for autocrine control of cell volume regulation ${ }^{166}$. The precise mechanism by which CFTR releases ATP remains unclear. Some studies show that CFTR release ATP directly ${ }^{155}$. 
However, more recent research supports the notion that CFTR does not conduct ATP directly but regulates a closely associated anion channel that releases ATP, such as outwardly rectifying $\mathrm{Cl}^{-}$channel ${ }^{178}$. In the case of $\mathrm{ABCA} 1$, we do not fully understand the reason for ATP release, except that it is physiologically relevant for lipidation of apoA-I. Interestingly, numerous studies documented glyburide, a general blocker of $\mathrm{ABC}$ transporters including ABCA1, is able to abolish ATP release ${ }^{179,180}$. It remains to be determined if glyburide can indeed block ATP release from ABCA1-expressing cells. In addition, we do not understand the mechanism of ATP release in ABCA1. ABCA1 may act similar to CFTR and regulate ion channels to conduct ATP release or it may pump ATP across the plasma membrane directly. Interestingly, besides mediating cholesterol release, ABCA1 has an established function in lipid packing of the plasma membrane, such that there is an increased non-raft fraction at the expense of rafts ${ }^{89}$. Relatively "loosely-packed" plasma membrane could broadly influence membrane proteins including channels and modulate ionic permeability. Indeed, $\mathrm{ABCA} 1$ expression in Xenopus oocytes was shown to influence ion flux, although ATP conductance was not analyzed ${ }^{181}$. However, in order to find the definitive answer to this question, we will have to completely reconstitute purified ABCA1 into liposomes, a task proven to be extremely difficult for mammalian $\mathrm{ABC}$ transporters presently.

In this study, we have explored several potential ATP releasing mechanisms. The first possibility was that apoA-I binding to ABCA1 can somehow bring out ATP from their intracellular storage while effluxing out cholesterol. Binding of apoA-I is known to stimulate many signalling pathways such as JAK2/STAT3 ${ }^{140}$ and $\mathrm{Cdc} 42 / \mathrm{JNK}^{142}$ activation. We thought that perhaps apoA-I can modulate a novel signalling process that exports ATP. However, we observed that adding apoA-I to the extracellular medium of ABCA1 expressing cells did not further enhance eATP levels (Figure 3.13). We also questioned whether apoA-I 
independent secretion of microparticles could release intracellular ATP from ABCA1 expressing cells. Microparticles have been detected in the medium of ABCA1-expressing cells and extensively characterized by several groups including ours ${ }^{49,99,182}$. These non-HDL microparticles are known to be cholesterol/phospholipid-rich and are approximately $24 \mathrm{~nm}$ in size, which is smaller than immune-microparticles, but slightly larger than HDL. Several lines of evidence demonstrate that these microparticles are generated by intrinsic functions of $\mathrm{ABCA} 1^{99}$. These include the observations that only ABCA1-expressing cells could produce microparticles, independent of apoA-I, and that an ABCA1 mutant, A937V, was defective in producing microparticles. Moreover, PKI, an inhibitor of PKA, not only inhibited cholesterol efflux to apoA-I but also abolished microparticle formation. This also indicates that microparticle formation relies on phosphorylation of ABCA1 by PKA, similar to other functions of ABCA1 $1^{128,130}$. Furthermore, our laboratory has previously discovered a small peptide, st-Ht31, which functions as PKA-anchoring inhibitor and greatly boosts up microparticle secretion. If microparticles bring ATP with them to the extracellular medium, we should see higher eATP during st-Ht31 treatment. However, eATP was not altered by stHt31 (Figure 3.14 B). Therefore, the secretion of microparticles could not be the reason for the ATP release in ABCA1 expressing cells. Currently, the mechanism of ATP release by ABCA1-expressing cells remains unknown.

We also observed that increasing medium ATP within normal physiological range enhances cholesterol efflux to apoA-I, whereas decreasing medium ATP by two independent approaches abolishes the efflux. Remarkably, the eATP concentration positively correlated with the efficiency of cholesterol efflux to apoA-I only within the normal physiological range, i.e., $50 \mathrm{nM}$ to low $\mu \mathrm{M}$. Moreover, eATP apparently does not modulate ABCA1 
expression. When both BHK cells and RAW macrophages were incubated overnight with exogenous ATP to elevate eATP, it enhanced efflux but did not increase the expression of ABCA1 (Figure 3.6 C-F). Thus, it appears that change in eATP level does not affect the amount of $\mathrm{ABCA} 1$ protein but makes ABCA1 function more efficient through currently unknown mechanisms. We have also observed that apoA-I overnight incubation increased ABCA1 protein in RAW macrophages (Figure 3.6 E, F), likely by limiting degradation as documented by others ${ }^{127,}{ }^{126}$. In BHK cells, however, we could not detect this increase in ABCA1 expression by apoA-I incubation. This could be partially due to the fact that BHK cells are forced to artificially express ABCA1 with the induction system and, unlike macrophages, do not have high capacity for degradation. This allows a more stable expression of ABCA1 in the plasma membrane and therefore would not further increase the expression with apoA-I binding.

We also reported here that eATP at higher concentrations $(>10 \mu \mathrm{M})$ dose dependently suppressed the cholesterol efflux to apoA-I. At highest concentration tested $(1 \mathrm{mM})$, cells started to lift off the plates and eventually all died. Presently, we do not understand the mechanism for this suppression. It is very tempting to speculate that this decrease in efflux and apoptosis of cells is due to ATP acting as a "danger signal" at such a high concentration. For example, after cell damage, concentration of eATP rises. This leads to both activation of a pro-inflammatory response and apoptosis through $\mathrm{P} 2 \mathrm{X}_{7}$ receptor. In particular, activation of $\mathrm{P}_{2} \mathrm{X}_{7}$ receptor recruits pannexin-1 channel and allows the assembly of the NALP3 inflammasome and also activation of caspase- $1^{158}$. This stimulates inflammatory response and eventually leads to apoptosis. $\mathrm{P} 2 \mathrm{X}_{7}$ receptor is activated relatively at higher concentrations of eATP $(>1 \mathrm{mM})$, while other P2XRs are stimulated at $\mu \mathrm{M}$ range of concentrations $^{159}$. This may explain why we did not detect any involvement of purinergic 
signalling in cholesterol efflux to apoA-I under normal physiological conditions, i.e. eATP < $100 \mathrm{nM}$. We have tested agonists (ATP $\gamma \mathrm{S}$ ) and antagonists (Suramin) for $\mathrm{P}_{2} \mathrm{X}_{7}$ receptor, or $\alpha$, $\beta$-MeATP, UTP, PPADS and reactive blue for other P2 receptors. None of them had any impact on cholesterol efflux to apoA-I. We therefore conclude that purinergic receptors are not likely involved in this process. Interestingly, when we applied high concentrations of $\mathrm{ATP} \gamma \mathrm{S}(500 \mathrm{nM})$, cholesterol efflux to apoA-I was not inhibited. ATP $\gamma \mathrm{S}$ is known to efficiently activate purinergic receptors. This implies that the actual hydrolysis of eATP is required for effect of eATP on both enhancing and suppressing cholesterol efflux to apoA-I, and purinergic receptors may not be involved in the mechanisms by which high eATP concentrations suppress cholesterol efflux.

Hydrolysis of eATP can eventually lead to an increase in medium adenosine concentrations, which can initiate its own signalling pathway by stimulating P1 receptors ${ }^{159}$. eATP is broken down by CD39 to AMP, and another enzyme, CD73, then hydrolyzes AMP to adenosine ${ }^{183}$. Interestingly, at least in neutrophils, adenosine can activate $\mathrm{P} 1$ receptors, $\mathrm{A}_{3}$, and $\mathrm{A}_{2 \mathrm{~A}}{ }^{184,185}$. It remains possible that hydrolysis of eATP by apyrase or CD39, as in our experiments, significantly raised extracellular adenosine concentration such that these signalling pathways are activated, resulting in the inhibition of cholesterol efflux to apoA-I. We however did not test the effect of adenosine in the current thesis. This aspect would be of interest for future studies.

In our results, eATP concentration of ABCA1-expressing cells is around 30-100 nM. As indicated in Figure 3.4, the concentration varies, depending on different cell types and more significantly on the extent of ABCA1 expression. On the one hand, eATP under normal physiological conditions is extremely low, compared to many stimulated conditions. However, most of cells potently release eATP even with slight mechanical agitation. 
Although such eATP release is transient (usually return to baseline within minutes), it does impose technical difficulties to measure steady state eATP levels. For example, a slight tilting of the plate of cells or adding medium to the plate of cells can significantly stimulate this transient release of ATP and thus can trigger unwanted cellular signalling pathways ${ }^{186}$. In addition, many cells are capable of shedding enzymes including nucleotidase into the medium $^{187}$. In order to avoid some of these limitations, we carefully collected the medium near the top of the plate on ice and immediately heated samples to limit enzyme activities. Also, as a precaution, samples were analyzed by luciferase-luciferin assay immediately. As seen in the results, we were able to obtain relatively consistent reading from parallel samples (in triplicates) and repeats on different days.

It is also noteworthy that there are other alternative assays to detect ATP that have been developed more recently. It is technically difficult to estimate the dynamics of eATP, particularly within the proximity of the plasma membrane where the signalling process presumably occurs. Also, the eATP concentration near the plasma membrane may be much higher than in the bulk medium. For these reasons, many new methods allow direct visualization and quantification of ATP release by individual cells using luciferin-based fluorescence microscopy techniques ${ }^{188,189}$. There are also methods that can monitor ATP in real-time inside individual living cells using a fluorescence resonance energy transfer (FRET)-based indicators for ATP. For example, one of such indicators is composed of the $\varepsilon$ subunit of the bacterial $\mathrm{F}_{\mathrm{o}} \mathrm{F}_{1}$-ATP synthase together with cyan and yellow fluorescent proteins ${ }^{190}$. Variants of CFP and YFP were connected by the $\varepsilon$-subunit of bacterial $\mathrm{F}_{\mathrm{o}} \mathrm{F}_{1}$-ATP synthase. In the ATP-free form, extended and flexible conformations of the $\varepsilon$-subunit separate the two fluorescent proteins, resulting in low FRET efficiency. In the ATP-bound form, the $\varepsilon$-subunit retracts to bring the two fluorescent proteins close to each other, resulting 
in an increase in FRET efficiency. However, these methods in their present form are not perfect in that most of them are only capable of detecting higher concentrations (low $\mu \mathrm{M}$ to $\mathrm{mM}$ ). Nevertheless, the optical monitoring of eATP in real time may represent the future direction, if we were to understand the spatial and temporal ATP signalling process in further detail from ABCA1-expressing cells.

In this present study, we provide evidence that depleting eATP is effective in abolishing cholesterol efflux to apoA-I. For example, CD39 transient expression in BHK cells only partially depleted extracellular ATP, yet the efflux to apoA-I was nearly completely blocked (Figure 3.10). This indicates that ABCA1-mediated cholesterol efflux to apoA-I is most dynamically regulated by eATP under $100 \mathrm{nM}$, consistent with the notion that ABCA1 is a housekeeping protein maintaining cholesterol homeostasis in animal cells. In cells stably transfected with CD39, however, we initially see a complete inhibition of cholesterol efflux to apoA-I, but this inhibition was gradually diminished as cell passage number got higher in both BHK and RAW macrophages (Figure 3.12 D-F). Surprisingly, even though cholesterol efflux inhibition was lost, CD39 retained its ability to fully hydrolyze eATP. Currently, we do not understand this observation. One possibility is that total absence of eATP during cell growth/cycle was toxic to cells, which forced the cells to obtain a certain adaptive response. For instance, cells may overexpress other molecules or activate other signalling processes to compensate the lack of eATP to preserve important functions including cholesterol efflux to apoA-I. It would be of great interest to further study these stable cells and determine the signalling processes that facilitate cholesterol efflux to apoA-I in the absence of eATP.

We have reported previously that $\mathrm{Ca}^{2+}$ influx is triggered by apoA-I in ABCA1expressing cells and this $\mathrm{Ca}^{2+}$ influx is necessary to activate downstream targets including 
calcineurin for efficient cholesterol efflux to apoA- ${ }^{143}$. Purinergic receptors are known to function as $\mathrm{Ca}^{2+}$ channels to mediate $\mathrm{Ca}^{2+}$ influx. However, as discussed above, most purinergic receptors are not likely involved. The mechanism for $\mathrm{Ca}^{2+}$ influx is thus still unknown. In future studies, we need to investigate whether varying eATP at nM range influences $\mathrm{Ca}^{2+}$ influx and, particularly whether depleting eATP abolishes $\mathrm{Ca}^{2+}$ influx. If it does, it would place eATP upstream of $\mathrm{Ca}^{2+}$ influx. We also provide evidence here that eATP has little effect on basal cholesterol efflux, i.e. microparticle production. Coincidentally, the $\mathrm{Ca}^{2+}$ study mentioned above also established the same trend: modulating $\mathrm{Ca}^{2+}$ signalling including calcineurin activation only affect cholesterol efflux to apoA-I without any influence on microparticle release.

As a whole, our results support the notion that ABCA1 expression modulates cells in a two-tier fashion. The first tier is a fairly global change, independent of apoA-I. It includes a softer membrane through reorganizing the plasma membrane, i.e., fewer lipid rafts ${ }^{89,}{ }^{191}$, higher permeability to many molecules ${ }^{138}$, 192, higher ACAT activity ${ }^{168}$, and more microparticle release $\mathrm{e}^{99,138}$. It is likely that such a global change primes cells for the secondtier functions of ABCA1, of which cholesterol efflux to apoA-I is perhaps the most representative. In this process, apoA-I directly interact with ABCA1 and trigger a cascade of signalling events, such as ABCA1 phosphorylation through PKA ${ }^{128,138}$ and JAK2/STAT3 activation ${ }^{133}$. This apoA-I-dependent process can be completely inhibited by calcineurin antagonists or removal of extracellular $\mathrm{Ca}^{2+}$ without any detectable effect on tier 1 functions including microparticle release ${ }^{143,193}$. It is thus plausible that eATP participates in apoA-Iinduced signalling cascade to facilitate cholesterol efflux. 


\subsection{Summary}

In summary, we demonstrate for the first time that eATP is one of the key components required for ABCA1-mediated cholesterol efflux to apoA-I. Importantly, functional ABCA1expressing cells apparently release more ATP, and this elevated eATP is required for apoA-I to be lipidated. Within the physiological range, eATP but not ADP or AMP caused ABCA1 cells to enhance cholesterol efflux, while apyrase or CD39 that hydrolyze secreted eATP attenuated cholesterol efflux. Purinergic signalling may not control ABCA1 functions. We thus show that ABCA1 plays a role in ATP release and this participates in signalling events that facilitate cholesterol efflux to apoA1. Further studies of the mechanism linking eATP to ABCA1 functions may help to develop future therapeutics for the treatment of atherosclerosis, as well as other CVDs. 


\section{References}

1. World Health Organization. Global health risks: Mortality and burden of disease attributable to selected major risks. Switzerland: WHO Press; 2009.

2. Preventing chronic diseases: a vital investment. [Internet]; c2005 [cited 2011 August/1]. Available from:

http://www.who.int/chp/chronic_disease_report/contents/en/index.html.

3. Cardiovascular diseases [Internet]; c2011 [cited 2011 August/1]. Available from: http://www.who.int/mediacentre/factsheets/fs317/en/index.html.

4. Hansson GK, Libby P. The immune response in atherosclerosis: A double-edged sword. Nat Rev Immunol 2006 Jul;6(7):508-19.

5. Moore KJ, Tabas I. Macrophages in the pathogenesis of atherosclerosis. Cell 2011 Apr 29;145(3):341-55.

6. Woollard KJ, Geissmann F. Monocytes in atherosclerosis: Subsets and functions. Nat Rev Cardiol 2010 Feb;7(2):77-86.

7. Williams KJ, Tabas I. The response-to-retention hypothesis of atherogenesis reinforced. Curr Opin Lipidol 1998 Oct;9(5):471-4.

8. Steinberg D. Thematic review series: The pathogenesis of atherosclerosis: An interpretive history of the cholesterol controversy, part III: Mechanistically defining the role of hyperlipidemia. J Lipid Res 2005 Oct;46(10):2037-51.

9. Cybulsky MI, Gimbrone MA,Jr. Endothelial expression of a mononuclear leukocyte adhesion molecule during atherogenesis. Science 1991 Feb 15;251(4995):788-91.

10. Arnold L, Henry A, Poron F, Baba-Amer Y, van Rooijen N, Plonquet A, Gherardi RK, Chazaud B. Inflammatory monocytes recruited after skeletal muscle injury switch into antiinflammatory macrophages to support myogenesis. J Exp Med 2007 May 14;204(5):1057-69.

11. Greaves DR, Gordon S. The macrophage scavenger receptor at 30 years of age: Current knowledge and future challenges. J Lipid Res 2009 Apr;50 Suppl:S282-6.

12. Kunjathoor VV, Febbraio M, Podrez EA, Moore KJ, Andersson L, Koehn S, Rhee JS, Silverstein R, Hoff HF, Freeman MW. Scavenger receptors class A-I/II and CD36 are the principal receptors responsible for the uptake of modified low density lipoprotein leading to lipid loading in macrophages. J Biol Chem 2002 Dec 20;277(51):49982-8. 
13. Katz SS, Shipley GG, Small DM. Physical chemistry of the lipids of human atherosclerotic lesions. demonstration of a lesion intermediate between fatty streaks and advanced plaques. J Clin Invest 1976 Jul;58(1):200-11.

14. Boyle JJ, Weissberg PL, Bennett MR. Tumor necrosis factor-alpha promotes macrophage-induced vascular smooth muscle cell apoptosis by direct and autocrine mechanisms. Arterioscler Thromb Vasc Biol 2003 Sep 1;23(9):1553-8.

15. Fuster V, Moreno PR, Fayad ZA, Corti R, Badimon JJ. Atherothrombosis and highrisk plaque: Part I: Evolving concepts. J Am Coll Cardiol 2005 Sep 20;46(6):937-54.

16. Seo D, Ginsburg GS, Goldschmidt-Clermont PJ. Gene expression analysis of cardiovascular diseases: Novel insights into biology and clinical applications. J Am Coll Cardiol 2006 Jul 18;48(2):227-35.

17. Charo IF, Taub R. Anti-inflammatory therapeutics for the treatment of atherosclerosis. Nat Rev Drug Discov 2011 May;10(5):365-76.

18. Loubele ST, ten Cate H, Spronk HM. Anticoagulant therapy in critical organ ischaemia/reperfusion injury. Thromb Haemost $2010 \mathrm{Jul}$;104(1):136-42.

19. Attie AD. ABCA1: At the nexus of cholesterol, HDL and atherosclerosis. Trends Biochem Sci 2007 Apr;32(4):172-9.

20. Pike LJ. The challenge of lipid rafts. J Lipid Res 2009 Apr;50 Suppl:S323-8.

21. Dewick PM. Medicinal natural products. In: Third edition ed. United Kingdom: John Wiley \& sons Ltd; 2009. .

22. Smith LL. Another cholesterol hypothesis: Cholesterol as antioxidant. Free Radic Biol Med 1991;11(1):47-61.

23. Daniels TF, Killinger KM, Michal JJ, Wright RW,Jr, Jiang Z. Lipoproteins, cholesterol homeostasis and cardiac health. Int J Biol Sci 2009 Jun 29;5(5):474-88.

24. Donald Voet, Judith G. Voet, editor. Biochemistry. 3rd ed. Wiley; 2004. .

25. Brown MS, Goldstein JL. A receptor-mediated pathway for cholesterol homeostasis. Science 1986 Apr 4;232(4746):34-47.

26. Goldstein JL, Brown MS, Anderson RG, Russell DW, Schneider WJ. Receptormediated endocytosis: Concepts emerging from the LDL receptor system. Annu Rev Cell Biol 1985;1:1-39.

27. Bengoechea-Alonso MT, Ericsson J. SREBP in signal transduction: Cholesterol metabolism and beyond. Curr Opin Cell Biol 2007 Apr;19(2):215-22. 
28. Eberle D, Hegarty B, Bossard P, Ferre P, Foufelle F. SREBP transcription factors: Master regulators of lipid homeostasis. Biochimie 2004 Nov;86(11):839-48.

29. Horton JD, Goldstein JL, Brown MS. SREBPs: Activators of the complete program of cholesterol and fatty acid synthesis in the liver. J Clin Invest 2002 May;109(9):1125-31.

30. Brown MS, Goldstein JL. The SREBP pathway: Regulation of cholesterol metabolism by proteolysis of a membrane-bound transcription factor. Cell 1997 May 2;89(3):33140 .

31. Espenshade PJ. SREBPs: Sterol-regulated transcription factors. J Cell Sci 2006 Mar 15;119(Pt 6):973-6.

32. Adams CM, Reitz J, De Brabander JK, Feramisco JD, Li L, Brown MS, Goldstein JL. Cholesterol and 25-hydroxycholesterol inhibit activation of SREBPs by different mechanisms, both involving SCAP and insigs. J Biol Chem 2004 Dec 10;279(50):52772-80.

33. Goldstein JL, DeBose-Boyd RA, Brown MS. Protein sensors for membrane sterols. Cell 2006 Jan 13;124(1):35-46.

34. Gong Y, Lee JN, Lee PC, Goldstein JL, Brown MS, Ye J. Sterol-regulated ubiquitination and degradation of insig-1 creates a convergent mechanism for feedback control of cholesterol synthesis and uptake. Cell Metab 2006 Jan;3(1):15-24.

35. Chang TY, Li BL, Chang CC, Urano Y. Acyl-coenzyme A:Cholesterol acyltransferases. Am J Physiol Endocrinol Metab 2009 Jul;297(1):E1-9.

36. Anderson RA, Joyce C, Davis M, Reagan JW, Clark M, Shelness GS, Rudel LL. Identification of a form of acyl-CoA:Cholesterol acyltransferase specific to liver and intestine in nonhuman primates. J Biol Chem 1998 Oct 9;273(41):26747-54.

37. Cases S, Novak S, Zheng YW, Myers HM, Lear SR, Sande E, Welch CB, Lusis AJ, Spencer TA, Krause BR, Erickson SK, Farese RV,Jr. ACAT-2, a second mammalian acyl-CoA:Cholesterol acyltransferase. its cloning, expression, and characterization. J Biol Chem 1998 Oct 9;273(41):26755-64.

38. Cases S, Smith SJ, Zheng YW, Myers HM, Lear SR, Sande E, Novak S, Collins C, Welch CB, Lusis AJ, Erickson SK, Farese RV,Jr. Identification of a gene encoding an acyl CoA:Diacylglycerol acyltransferase, a key enzyme in triacylglycerol synthesis. Proc Natl Acad Sci U S A 1998 Oct 27;95(22):13018-23.

39. Rudel LL, Lee RG, Cockman TL. Acyl coenzyme A: Cholesterol acyltransferase types 1 and 2: Structure and function in atherosclerosis. Curr Opin Lipidol 2001 Apr;12(2):121-7. 
40. Kalbak K. Incidence of arteriosclerosis in patients with rheumatoid arthritis receiving long-term corticosteroid therapy. Ann Rheum Dis 1972 May;31(3):196-200.

41. Watanabe T, Suguro T, Kanome T, Sakamoto Y, Kodate S, Hagiwara T, Hongo S, Hirano T, Adachi M, Miyazaki A. Human urotensin II accelerates foam cell formation in human monocyte-derived macrophages. Hypertension 2005 Oct;46(4):738-44.

42. Yang L, Yang JB, Chen J, Yu GY, Zhou P, Lei L, Wang ZZ, Cy Chang C, Yang XY, Chang TY, Li BL. Enhancement of human ACAT1 gene expression to promote the macrophage-derived foam cell formation by dexamethasone. Cell Res 2004 Aug;14(4):315-23.

43. Castelli WP, Doyle JT, Gordon T, Hames CG, Hjortland MC, Hulley SB, Kagan A, Zukel WJ. HDL cholesterol and other lipids in coronary heart disease. the cooperative lipoprotein phenotyping study. Circulation 1977 May;55(5):767-72.

44. Prospective Studies Collaboration, Lewington S, Whitlock G, Clarke R, Sherliker P, Emberson J, Halsey J, Qizilbash N, Peto R, Collins R. Blood cholesterol and vascular mortality by age, sex, and blood pressure: A meta-analysis of individual data from 61 prospective studies with 55,000 vascular deaths. Lancet 2007 Dec 1;370(9602):182939.

45. Zannis VI, Cole FS, Jackson CL, Kurnit DM, Karathanasis SK. Distribution of apolipoprotein A-I, C-II, C-III, and E mRNA in fetal human tissues. time-dependent induction of apolipoprotein $\mathrm{E}$ mRNA by cultures of human monocyte-macrophages. Biochemistry 1985 Jul 30;24(16):4450-5.

46. Wang N, Silver DL, Thiele C, Tall AR. ATP-binding cassette transporter A1 (ABCA1) functions as a cholesterol efflux regulatory protein. J Biol Chem 2001 Jun 29;276(26):23742-7.

47. van der Velde AE. Reverse cholesterol transport: From classical view to new insights. World J Gastroenterol 2010 Dec 21;16(47):5908-15.

48. Phillips MC, Gillotte KL, Haynes MP, Johnson WJ, Lund-Katz S, Rothblat GH. Mechanisms of high density lipoprotein-mediated efflux of cholesterol from cell plasma membranes. Atherosclerosis 1998 Apr;137 Suppl:S13-7.

49. Vaughan AM, Oram JF. ABCA1 and ABCG1 or ABCG4 act sequentially to remove cellular cholesterol and generate cholesterol-rich HDL. J Lipid Res 2006 Nov;47(11):2433-43.

50. Krieger M. Scavenger receptor class B type I is a multiligand HDL receptor that influences diverse physiologic systems. J Clin Invest 2001 Sep;108(6):793-7. 
51. Wang N, Silver DL, Costet P, Tall AR. Specific binding of ApoA-I, enhanced cholesterol efflux, and altered plasma membrane morphology in cells expressing ABC1. J Biol Chem 2000 Oct 20;275(42):33053-8.

52. Wang N, Yvan-Charvet L, Lutjohann D, Mulder M, Vanmierlo T, Kim TW, Tall AR. ATP-binding cassette transporters G1 and G4 mediate cholesterol and desmosterol efflux to HDL and regulate sterol accumulation in the brain. FASEB J 2008 Apr;22(4):1073-82.

53. Gelissen IC, Harris M, Rye KA, Quinn C, Brown AJ, Kockx M, Cartland S, Packianathan M, Kritharides L, Jessup W. ABCA1 and ABCG1 synergize to mediate cholesterol export to apoA-I. Arterioscler Thromb Vasc Biol 2006 Mar;26(3):534-40.

54. Chajek T, Fielding CJ. Isolation and characterization of a human serum cholesteryl ester transfer protein. Proc Natl Acad Sci U S A 1978 Jul;75(7):3445-9.

55. Settasatian N, Duong M, Curtiss LK, Ehnholm C, Jauhiainen M, Huuskonen J, Rye KA. The mechanism of the remodeling of high density lipoproteins by phospholipid transfer protein. J Biol Chem 2001 Jul 20;276(29):26898-905.

56. Rigotti A, Trigatti BL, Penman M, Rayburn H, Herz J, Krieger M. A targeted mutation in the murine gene encoding the high density lipoprotein (HDL) receptor scavenger receptor class B type I reveals its key role in HDL metabolism. Proc Natl Acad Sci U S A 1997 Nov 11;94(23):12610-5.

57. Russell DW, Setchell KD. Bile acid biosynthesis. Biochemistry 1992 May 26;31(20):4737-49.

58. Berge KE, Tian H, Graf GA, Yu L, Grishin NV, Schultz J, Kwiterovich P, Shan B, Barnes R, Hobbs HH. Accumulation of dietary cholesterol in sitosterolemia caused by mutations in adjacent ABC transporters. Science 2000 Dec 1;290(5497):1771-5.

59. Graf GA, Yu L, Li WP, Gerard R, Tuma PL, Cohen JC, Hobbs HH. ABCG5 and ABCG8 are obligate heterodimers for protein trafficking and biliary cholesterol excretion. J Biol Chem 2003 Nov 28;278(48):48275-82.

60. Nofer JR, Remaley AT. Tangier disease: Still more questions than answers. Cell Mol Life Sci 2005 Oct;62(19-20):2150-60.

61. Schmitz G, Assmann G, Robenek H, Brennhausen B. Tangier disease: A disorder of intracellular membrane traffic. Proc Natl Acad Sci U S A 1985 Sep;82(18):6305-9.

62. Schmitz G, Assmann G, Rall SC,Jr, Mahley RW. Tangier disease: Defective recombination of a specific tangier apolipoprotein A-I isoform (pro-apo A-i) with high density lipoproteins. Proc Natl Acad Sci U S A 1983 Oct;80(19):6081-5. 
63. Law SW, Brewer HB,Jr. Tangier disease. the complete mRNA sequence encoding for preproapo-A-I. J Biol Chem 1985 Oct 15;260(23):12810-4.

64. Rust S, Rosier M, Funke H, Real J, Amoura Z, Piette JC, Deleuze JF, Brewer HB, Duverger N, Denefle P, Assmann G. Tangier disease is caused by mutations in the gene encoding ATP-binding cassette transporter 1. Nat Genet 1999 Aug;22(4):352-5.

65. Bodzioch M, Orso E, Klucken J, Langmann T, Bottcher A, Diederich W, Drobnik W, Barlage S, Buchler C, Porsch-Ozcurumez M, Kaminski WE, Hahmann HW, Oette K, Rothe G, Aslanidis C, Lackner KJ, Schmitz G. The gene encoding ATP-binding cassette transporter 1 is mutated in tangier disease. Nat Genet 1999 Aug;22(4):347-51.

66. Brooks-Wilson A, Marcil M, Clee SM, Zhang LH, Roomp K, van Dam M, Yu L, Brewer C, Collins JA, Molhuizen HO, Loubser O, Ouelette BF, Fichter K, AshbourneExcoffon KJ, Sensen CW, Scherer S, Mott S, Denis M, Martindale D, Frohlich J, Morgan K, Koop B, Pimstone S, Kastelein JJ, Genest J,Jr, Hayden MR. Mutations in $\mathrm{ABC} 1$ in tangier disease and familial high-density lipoprotein deficiency. Nat Genet 1999 Aug;22(4):336-45.

67. Chung S, Timmins JM, Duong M, Degirolamo C, Rong S, Sawyer JK, Singaraja RR, Hayden MR, Maeda N, Rudel LL, Shelness GS, Parks JS. Targeted deletion of hepatocyte ABCA1 leads to very low density lipoprotein triglyceride overproduction and low density lipoprotein hypercatabolism. J Biol Chem 2010 Apr 16;285(16):12197-209.

68. Dean M, Annilo T. Evolution of the ATP-binding cassette (ABC) transporter superfamily in vertebrates. Annu Rev Genomics Hum Genet 2005;6:123-42.

69. Stefkova J, Poledne R, Hubacek JA. ATP-binding cassette (ABC) transporters in human metabolism and diseases. Physiol Res 2004;53(3):235-43.

70. Dean M, Allikmets R. Evolution of ATP-binding cassette transporter genes. Curr Opin Genet Dev 1995 Dec;5(6):779-85.

71. Linton KJ, Higgins CF. Structure and function of ABC transporters: The ATP switch provides flexible control. Pflugers Arch 2007 Feb;453(5):555-67.

72. Tsybovsky Y, Molday RS, Palczewski K. The ATP-binding cassette transporter ABCA4: Structural and functional properties and role in retinal disease. Adv Exp Med Biol 2010;703:105-25.

73. Girodon-Boulandet E, Cazeneuve C, Goossens M. Screening practices for mutations in the CFTR gene ABCC7. Hum Mutat 2000;15(2):135-49. 
74. Singaraja RR, Brunham LR, Visscher H, Kastelein JJ, Hayden MR. Efflux and atherosclerosis: The clinical and biochemical impact of variations in the ABCA1 gene. Arterioscler Thromb Vasc Biol 2003 Aug 1;23(8):1322-32.

75. Joyce C, Freeman L, Brewer HB,Jr, Santamarina-Fojo S. Study of ABCA1 function in transgenic mice. Arterioscler Thromb Vasc Biol 2003 Jun 1;23(6):965-71.

76. Luciani MF, Denizot F, Savary S, Mattei MG, Chimini G. Cloning of two novel ABC transporters mapping on human chromosome 9. Genomics 1994 May 1;21(1):150-9.

77. Zarubica A, Trompier D, Chimini G. ABCA1, from pathology to membrane function. Pflugers Arch 2007 Feb;453(5):569-79.

78. Chang XB. Molecular mechanism of ATP-dependent solute transport by multidrug resistance-associated protein 1. Methods Mol Biol 2010;596:223-49.

79. Crowley E, Callaghan R. Multidrug efflux pumps: Drug binding--gates or cavity? FEBS J 2010 Feb;277(3):530-9.

80. Dean M, Hamon Y, Chimini G. The human ATP-binding cassette (ABC) transporter superfamily. J Lipid Res 2001 Jul;42(7):1007-17.

81. Oram JF, Heinecke JW. ATP-binding cassette transporter A1: A cell cholesterol exporter that protects against cardiovascular disease. Physiol Rev 2005 Oct;85(4):1343-72.

82. Von Eckardstein A, Langer C, Engel T, Schaukal I, Cignarella A, Reinhardt J, Lorkowski S, Li Z, Zhou X, Cullen P, Assmann G. ATP binding cassette transporter ABCA1 modulates the secretion of apolipoprotein $\mathrm{E}$ from human monocyte-derived macrophages. FASEB J 2001 Jul;15(9):1555-61.

83. Hamon Y, Luciani MF, Becq F, Verrier B, Rubartelli A, Chimini G. Interleukin-1beta secretion is impaired by inhibitors of the atp binding cassette transporter, ABC1. Blood 1997 Oct 15;90(8):2911-5.

84. Oram JF, Vaughan AM, Stocker R. ATP-binding cassette transporter A1 mediates cellular secretion of alpha-tocopherol. J Biol Chem 2001 Oct 26;276(43):39898-902.

85. Singaraja RR, Fievet C, Castro G, James ER, Hennuyer N, Clee SM, Bissada N, Choy JC, Fruchart JC, McManus BM, Staels B, Hayden MR. Increased ABCA1 activity protects against atherosclerosis. J Clin Invest $2002 \mathrm{Jul} ; 110(1): 35-42$.

86. Aiello RJ, Brees D, Francone OL. ABCA1-deficient mice: Insights into the role of monocyte lipid efflux in HDL formation and inflammation. Arterioscler Thromb Vasc Biol 2003 Jun 1;23(6):972-80. 
87. Zha X, Genest J,Jr, McPherson R. Endocytosis is enhanced in tangier fibroblasts: Possible role of ATP-binding cassette protein A1 in endosomal vesicular transport. J Biol Chem 2001 Oct 19;276(42):39476-83.

88. Luciani MF, Chimini G. The ATP binding cassette transporter ABC1, is required for the engulfment of corpses generated by apoptotic cell death. EMBO J 1996 Jan $15 ; 15(2): 226-35$

89. Landry YD, Denis M, Nandi S, Bell S, Vaughan AM, Zha X. ATP-binding cassette transporter A1 expression disrupts raft membrane microdomains through its ATPaserelated functions. J Biol Chem 2006 Nov 24;281(47):36091-101.

90. Neufeld EB, Remaley AT, Demosky SJ, Stonik JA, Cooney AM, Comly M, Dwyer NK, Zhang M, Blanchette-Mackie J, Santamarina-Fojo S, Brewer HB,Jr. Cellular localization and trafficking of the human ABCA1 transporter. J Biol Chem $2001 \mathrm{Jul}$ 20;276(29):27584-90.

91. Neufeld EB, Stonik JA, Demosky SJ,Jr, Knapper CL, Combs CA, Cooney A, Comly M, Dwyer N, Blanchette-Mackie J, Remaley AT, Santamarina-Fojo S, Brewer HB,Jr. The ABCA1 transporter modulates late endocytic trafficking: Insights from the correction of the genetic defect in tangier disease. J Biol Chem 2004 Apr 9;279(15):15571-8.

92. Chroni A, Liu T, Fitzgerald ML, Freeman MW, Zannis VI. Cross-linking and lipid efflux properties of apoA-I mutants suggest direct association between apoA-I helices and ABCA1. Biochemistry 2004 Feb 24;43(7):2126-39.

93. Fitzgerald ML, Morris AL, Chroni A, Mendez AJ, Zannis VI, Freeman MW. ABCA1 and amphipathic apolipoproteins form high-affinity molecular complexes required for cholesterol efflux. J Lipid Res 2004 Feb;45(2):287-94.

94. Fitzgerald ML, Morris AL, Rhee JS, Andersson LP, Mendez AJ, Freeman MW. Naturally occurring mutations in the largest extracellular loops of ABCA1 can disrupt its direct interaction with apolipoprotein A-I. J Biol Chem 2002 Sep 6;277(36):3317887.

95. Azuma Y, Takada M, Shin HW, Kioka N, Nakayama K, Ueda K. Retroendocytosis pathway of ABCA1/apoA-I contributes to HDL formation. Genes Cells 2009 Feb;14(2):191-204.

96. Faulkner LE, Panagotopulos SE, Johnson JD, Woollett LA, Hui DY, Witting SR, Maiorano JN, Davidson WS. An analysis of the role of a retroendocytosis pathway in ABCA1-mediated cholesterol efflux from macrophages. J Lipid Res 2008 Jun;49(6):1322-32. 
97. Denis M, Landry YD, Zha X. ATP-binding cassette A1-mediated lipidation of apolipoprotein A-I occurs at the plasma membrane and not in the endocytic compartments. J Biol Chem 2008 Jun 6;283(23):16178-86.

98. Vedhachalam C, Duong PT, Nickel M, Nguyen D, Dhanasekaran P, Saito H, Rothblat GH, Lund-Katz S, Phillips MC. Mechanism of ATP-binding cassette transporter A1mediated cellular lipid efflux to apolipoprotein A-I and formation of high density lipoprotein particles. J Biol Chem 2007 Aug 24;282(34):25123-30.

99. Nandi S, Ma L, Denis M, Karwatsky J, Li Z, Jiang XC, Zha X. ABCA1-mediated cholesterol efflux generates microparticles in addition to HDL through processes governed by membrane rigidity. J Lipid Res 2009 Mar;50(3):456-66.

100. Fielding PE, Nagao K, Hakamata H, Chimini G, Fielding CJ. A two-step mechanism for free cholesterol and phospholipid efflux from human vascular cells to apolipoprotein A-1. Biochemistry 2000 Nov 21;39(46):14113-20.

101. Gillotte KL, Davidson WS, Lund-Katz S, Rothblat GH, Phillips MC. Removal of cellular cholesterol by pre-beta-HDL involves plasma membrane microsolubilization. J Lipid Res 1998 Oct;39(10):1918-28.

102. Soro-Paavonen A, Westerbacka J, Ehnholm C, Taskinen MR. Metabolic syndrome aggravates the increased endothelial activation and low-grade inflammation in subjects with familial low HDL. Ann Med 2006;38(3):229-38.

103. Birjmohun RS, van Leuven SI, Levels JH, van 't Veer C, Kuivenhoven JA, Meijers JC, Levi M, Kastelein JJ, van der Poll T, Stroes ES. High-density lipoprotein attenuates inflammation and coagulation response on endotoxin challenge in humans. Arterioscler Thromb Vasc Biol 2007 May;27(5):1153-8.

104. Zhu X, Lee JY, Timmins JM, Brown JM, Boudyguina E, Mulya A, Gebre AK, Willingham MC, Hiltbold EM, Mishra N, Maeda N, Parks JS. Increased cellular free cholesterol in macrophage-specific Abca1 knock-out mice enhances pro-inflammatory response of macrophages. J Biol Chem 2008 Aug 22;283(34):22930-41.

105. Sun Y, Ishibashi M, Seimon T, Lee M, Sharma SM, Fitzgerald KA, Samokhin AO, Wang Y, Sayers S, Aikawa M, Jerome WG, Ostrowski MC, Bromme D, Libby P, Tabas IA, Welch CL, Tall AR. Free cholesterol accumulation in macrophage membranes activates toll-like receptors and p38 mitogen-activated protein kinase and induces cathepsin K. Circ Res 2009 Feb 27;104(4):455-65.

106. Yvan-Charvet L, Welch C, Pagler TA, Ranalletta M, Lamkanfi M, Han S, Ishibashi M, Li R, Wang N, Tall AR. Increased inflammatory gene expression in ABC transporterdeficient macrophages: Free cholesterol accumulation, increased signaling via toll-like receptors, and neutrophil infiltration of atherosclerotic lesions. Circulation 2008 Oct 28;118(18):1837-47. 
107. Wellington CL, Walker EK, Suarez A, Kwok A, Bissada N, Singaraja R, Yang YZ, Zhang LH, James E, Wilson JE, Francone O, McManus BM, Hayden MR. ABCA1 mRNA and protein distribution patterns predict multiple different roles and levels of regulation. Lab Invest 2002 Mar;82(3):273-83.

108. Schmitz G, Langmann T. Transcriptional regulatory networks in lipid metabolism control ABCA1 expression. Biochim Biophys Acta 2005 Jun 15;1735(1):1-19.

109. Tall AR, Costet P, Luo Y. 'Orphans' meet cholesterol. Nat Med 2000 Oct;6(10):1104-5.

110. Costet P, Luo Y, Wang N, Tall AR. Sterol-dependent transactivation of the ABC1 promoter by the liver X receptor/retinoid X receptor. J Biol Chem 2000 Sep $8 ; 275(36): 28240-5$.

111. Fitzgerald ML, Moore KJ, Freeman MW. Nuclear hormone receptors and cholesterol trafficking: The orphans find a new home. J Mol Med (Berl) 2002 May;80(5):271-81.

112. Repa JJ, Mangelsdorf DJ. Nuclear receptor regulation of cholesterol and bile acid metabolism. Curr Opin Biotechnol 1999 Dec;10(6):557-63.

113. Schwartz K, Lawn RM, Wade DP. ABC1 gene expression and ApoA-I-mediated cholesterol efflux are regulated by LXR. Biochem Biophys Res Commun 2000 Aug $11 ; 274(3): 794-802$.

114. Ou J, Tu H, Shan B, Luk A, DeBose-Boyd RA, Bashmakov Y, Goldstein JL, Brown MS. Unsaturated fatty acids inhibit transcription of the sterol regulatory elementbinding protein-1c (SREBP-1c) gene by antagonizing ligand-dependent activation of the LXR. Proc Natl Acad Sci U S A 2001 May 22;98(11):6027-32.

115. Chinetti G, Lestavel S, Bocher V, Remaley AT, Neve B, Torra IP, Teissier E, Minnich A, Jaye M, Duverger N, Brewer HB, Fruchart JC, Clavey V, Staels B. PPAR-alpha and PPAR-gamma activators induce cholesterol removal from human macrophage foam cells through stimulation of the ABCA1 pathway. Nat Med 2001 Jan;7(1):53-8.

116. Gan X, Kaplan R, Menke JG, MacNaul K, Chen Y, Sparrow CP, Zhou G, Wright SD, Cai TQ. Dual mechanisms of ABCA1 regulation by geranylgeranyl pyrophosphate. J Biol Chem 2001 Dec 28;276(52):48702-8.

117. Panousis CG, Zuckerman SH. Interferon-gamma induces downregulation of tangier disease gene (ATP-binding-cassette transporter 1) in macrophage-derived foam cells. Arterioscler Thromb Vasc Biol 2000 Jun;20(6):1565-71.

118. Langmann T, Porsch-Ozcurumez M, Heimerl S, Probst M, Moehle C, Taher M, Borsukova H, Kielar D, Kaminski WE, Dittrich-Wengenroth E, Schmitz G. Identification of sterol-independent regulatory elements in the human ATP-binding 
cassette transporter A1 promoter: Role of Sp1/3, E-box binding factors, and an oncostatin M-responsive element. J Biol Chem 2002 Apr 26;277(17):14443-50.

119. Oram JF, Lawn RM, Garvin MR, Wade DP. ABCA1 is the cAMP-inducible apolipoprotein receptor that mediates cholesterol secretion from macrophages. J Biol Chem 2000 Nov 3;275(44):34508-11.

120. Denis M, Bissonnette R, Haidar B, Krimbou L, Bouvier M, Genest J. Expression, regulation, and activity of ABCA1 in human cell lines. Mol Genet Metab 2003 Apr;78(4):265-74.

121. Le Goff W, Zheng P, Brubaker G, Smith JD. Identification of the cAMP-responsive enhancer of the murine ABCA1 gene: Requirement for CREB1 and STAT3/4 elements. Arterioscler Thromb Vasc Biol 2006 Mar;26(3):527-33.

122. Llaverias G, Lacasa D, Vazquez-Carrera M, Sanchez RM, Laguna JC, Alegret M. Cholesterol regulation of genes involved in sterol trafficking in human THP-1 macrophages. Mol Cell Biochem 2005 May;273(1-2):185-91.

123. Wang Y, Oram JF. Unsaturated fatty acids inhibit cholesterol efflux from macrophages by increasing degradation of ATP-binding cassette transporter A1. J Biol Chem 2002 Feb 15;277(7):5692-7.

124. Wang N, Chen W, Linsel-Nitschke P, Martinez LO, Agerholm-Larsen B, Silver DL, Tall AR. A PEST sequence in ABCA1 regulates degradation by calpain protease and stabilization of ABCA1 by apoA-I. J Clin Invest 2003 Jan;111(1):99-107.

125. Feng B, Tabas I. ABCA1-mediated cholesterol efflux is defective in free cholesterolloaded macrophages. mechanism involves enhanced ABCA1 degradation in a process requiring full NPC1 activity. J Biol Chem 2002 Nov 8;277(45):43271-80.

126. Yamauchi Y, Hayashi M, Abe-Dohmae S, Yokoyama S. Apolipoprotein A-I activates protein kinase $\mathrm{C}$ alpha signaling to phosphorylate and stabilize ATP binding cassette transporter A1 for the high density lipoprotein assembly. J Biol Chem 2003 Nov 28;278(48):47890-7.

127. Martinez LO, Agerholm-Larsen B, Wang N, Chen W, Tall AR. Phosphorylation of a pest sequence in ABCA1 promotes calpain degradation and is reversed by ApoA-I. J Biol Chem 2003 Sep 26;278(39):37368-74.

128. Haidar B, Denis M, Krimbou L, Marcil M, Genest J,Jr. cAMP induces ABCA1 phosphorylation activity and promotes cholesterol efflux from fibroblasts. J Lipid Res 2002 Dec;43(12):2087-94. 
129. Tang C, Vaughan AM, Anantharamaiah GM, Oram JF. Janus kinase 2 modulates the lipid-removing but not protein-stabilizing interactions of amphipathic helices with ABCA1. J Lipid Res 2006 Jan;47(1):107-14.

130. See RH, Caday-Malcolm RA, Singaraja RR, Zhou S, Silverston A, Huber MT, Moran J, James ER, Janoo R, Savill JM, Rigot V, Zhang LH, Wang M, Chimini G, Wellington CL, Tafuri SR, Hayden MR. Protein kinase A site-specific phosphorylation regulates ATP-binding cassette A1 (ABCA1)-mediated phospholipid efflux. J Biol Chem 2002 Nov 1;277(44):41835-42.

131. Nofer JR, Feuerborn R, Levkau B, Sokoll A, Seedorf U, Assmann G. Involvement of Cdc42 signaling in apoA-I-induced cholesterol efflux. J Biol Chem 2003 Dec 26;278(52):53055-62.

132. Roosbeek S, Peelman F, Verhee A, Labeur C, Caster H, Lensink MF, Cirulli C, Grooten J, Cochet C, Vandekerckhove J, Amoresano A, Chimini G, Tavernier J, Rosseneu M. Phosphorylation by protein kinase CK2 modulates the activity of the ATP binding cassette A1 transporter. J Biol Chem 2004 Sep 3;279(36):37779-88.

133. Tang C, Vaughan AM, Oram JF. Janus kinase 2 modulates the apolipoprotein interactions with ABCA1 required for removing cellular cholesterol. J Biol Chem 2004 Feb 27;279(9):7622-8.

134. Haidar B, Denis M, Marcil M, Krimbou L, Genest J,Jr. Apolipoprotein A-I activates cellular cAMP signaling through the ABCA1 transporter. J Biol Chem 2004 Mar 12;279(11):9963-9.

135. Pavan B, Biondi C, Dalpiaz A. Adenylyl cyclases as innovative therapeutic goals. Drug Discov Today 2009 Oct;14(19-20):982-91.

136. Gonzalez GA, Montminy MR. Cyclic AMP stimulates somatostatin gene transcription by phosphorylation of CREB at serine 133. Cell 1989 Nov 17;59(4):675-80.

137. Murata T, Shimizu K, Hiramoto K, Tagawa T. Phosphodiesterase 3 (PDE3): Structure, localization and function. Cardiovasc Hematol Agents Med Chem 2009 Jul;7(3):20611.

138. Ma L, Dong F, Denis M, Feng Y, Wang MD, Zha X. Ht31, a protein kinase A anchoring inhibitor, induces robust cholesterol efflux and reverses macrophage foam cell formation through ATP-binding cassette transporter A1. J Biol Chem 2011 Feb $4 ; 286(5): 3370-8$.

139. Kerr IM, Costa-Pereira AP, Lillemeier BF, Strobl B. Of JAKs, STATs, blind watchmakers, jeeps and trains. FEBS Lett 2003 Jul 3;546(1):1-5. 
140. Vaughan AM, Tang C, Oram JF. ABCA1 mutants reveal an interdependency between lipid export function, apoA-I binding activity, and janus kinase 2 activation. J Lipid Res 2009 Feb;50(2):285-92.

141. Tang C, Liu Y, Kessler PS, Vaughan AM, Oram JF. The macrophage cholesterol exporter ABCA1 functions as an anti-inflammatory receptor. J Biol Chem 2009 Nov 20;284(47):32336-43.

142. Nofer JR, Remaley AT, Feuerborn R, Wolinnska I, Engel T, von Eckardstein A, Assmann G. Apolipoprotein A-I activates Cdc42 signaling through the ABCA1 transporter. J Lipid Res 2006 Apr;47(4):794-803.

143. Karwatsky J, Ma L, Dong F, Zha X. Cholesterol efflux to apoA-I in ABCA1expressing cells is regulated by $\mathrm{Ca} 2+-$ dependent calcineurin signaling. J Lipid Res 2010 May;51(5):1144-56.

144. Chin ER. Role of Ca2+/calmodulin-dependent kinases in skeletal muscle plasticity. J Appl Physiol 2005 Aug;99(2):414-23.

145. Delbono O, Renganathan M, Messi ML. Regulation of mouse skeletal muscle L-type $\mathrm{Ca} 2+$ channel by activation of the insulin-like growth factor-1 receptor. J Neurosci 1997 Sep 15;17(18):6918-28.

146. Mukherjee R, Spinale FG. L-type calcium channel abundance and function with cardiac hypertrophy and failure: A review. J Mol Cell Cardiol 1998 Oct;30(10):1899916.

147. Finn BE, Forsen S. The evolving model of calmodulin structure, function and activation. Structure 1995 Jan 15;3(1):7-11.

148. Chin D, Means AR. Calmodulin: A prototypical calcium sensor. Trends Cell Biol 2000 Aug;10(8):322-8.

149. Klee CB, Ren H, Wang X. Regulation of the calmodulin-stimulated protein phosphatase, calcineurin. J Biol Chem 1998 May 29;273(22):13367-70.

150. Berridge MJ, Lipp P, Bootman MD. The versatility and universality of calcium signalling. Nat Rev Mol Cell Biol 2000 Oct;1(1):11-21.

151. Takahashi Y, Smith JD. Cholesterol efflux to apolipoprotein AI involves endocytosis and resecretion in a calcium-dependent pathway. Proc Natl Acad Sci U S A 1999 Sep 28;96(20):11358-63.

152. Novak I. ATP as a signaling molecule: The exocrine focus. News Physiol Sci 2003 Feb;18:12-7. 
153. Burnstock G, Fredholm BB, North RA, Verkhratsky A. The birth and postnatal development of purinergic signalling. Acta Physiol (Oxf) 2010 Jun;199(2):93-147.

154. Trautmann A. Extracellular ATP in the immune system: More than just a "danger signal". Sci Signal 2009 Feb 3;2(56):pe6.

155. Linsdell P, Hanrahan JW. Glutathione permeability of CFTR. Am J Physiol 1998 Jul;275(1 Pt 1):C323-6.

156. Pasyk EA, Foskett JK. Cystic fibrosis transmembrane conductance regulator-associated ATP and adenosine 3'-phosphate 5'-phosphosulfate channels in endoplasmic reticulum and plasma membranes. J Biol Chem 1997 Mar 21;272(12):7746-51.

157. Schenk U, Westendorf AM, Radaelli E, Casati A, Ferro M, Fumagalli M, Verderio C, Buer J, Scanziani E, Grassi F. Purinergic control of T cell activation by ATP released through pannexin-1 hemichannels. Sci Signal 2008 Sep 30;1(39):ra6.

158. Pelegrin P, Surprenant A. Pannexin-1 mediates large pore formation and interleukin1beta release by the ATP-gated P2X7 receptor. EMBO J 2006 Nov 1;25(21):5071-82.

159. Ralevic V, Burnstock G. Receptors for purines and pyrimidines. Pharmacol Rev 1998 Sep;50(3):413-92.

160. Kim M, Jiang LH, Wilson HL, North RA, Surprenant A. Proteomic and functional evidence for a P2X7 receptor signalling complex. EMBO J 2001 Nov 15;20(22):634758.

161. Suadicani SO, Brosnan CF, Scemes E. P2X7 receptors mediate ATP release and amplification of astrocytic intercellular Ca2+ signaling. J Neurosci 2006 Feb 1;26(5):1378-85.

162. Bean BP. Pharmacology and electrophysiology of ATP-activated ion channels. Trends Pharmacol Sci 1992 Mar;13(3):87-90.

163. Junger WG. Immune cell regulation by autocrine purinergic signalling. Nat Rev Immunol 2011 Mar;11(3):201-12.

164. al-Awqati Q. Regulation of ion channels by ABC transporters that secrete ATP. Science 1995 Aug 11;269(5225):805-6.

165. Guggino WB. The cystic fibrosis transmembrane regulator forms macromolecular complexes with PDZ domain scaffold proteins. Proc Am Thorac Soc 2004;1(1):28-32.

166. Braunstein GM, Roman RM, Clancy JP, Kudlow BA, Taylor AL, Shylonsky VG, Jovov B, Peter K, Jilling T, Ismailov II, Benos DJ, Schwiebert LM, Fitz JG, Schwiebert EM. Cystic fibrosis transmembrane conductance regulator facilitates ATP 
release by stimulating a separate ATP release channel for autocrine control of cell volume regulation. J Biol Chem 2001 Mar 2;276(9):6621-30.

167. Cantiello HF. Electrodiffusional ATP movement through CFTR and other ABC transporters. Pflugers Arch 2001;443 Suppl 1:S22-7.

168. Vaughan AM, Oram JF. ABCA1 redistributes membrane cholesterol independent of apolipoprotein interactions. J Lipid Res 2003 Jul;44(7):1373-80.

169. Yegutkin GG, Samburski SS, Jalkanen S, Novak I. ATP-consuming and ATPgenerating enzymes secreted by pancreas. J Biol Chem 2006 Oct 6;281(40):29441-7.

170. del Rey A, Renigunta V, Dalpke AH, Leipziger J, Matos JE, Robaye B, Zuzarte M, Kavelaars A, Hanley PJ. Knock-out mice reveal the contributions of P2Y and P2X receptors to nucleotide-induced Ca2+ signaling in macrophages. J Biol Chem 2006 Nov 17;281(46):35147-55.

171. Kim JH, Nam JH, Kim MH, Koh DS, Choi SJ, Kim SJ, Lee JE, Min KM, Uhm DY, Kim SJ. Purinergic receptors coupled to intracellular $\mathrm{Ca} 2+$ signals and exocytosis in rat prostate neuroendocrine cells. J Biol Chem 2004 Jun 25;279(26):27345-56.

172. von Kugelgen I. Pharmacological profiles of cloned mammalian P2Y-receptor subtypes. Pharmacol Ther 2006 Jun;110(3):415-32.

173. Suzuki-Kerr H, Lim JC, Donaldson PJ. Purinergic receptors in the rat lens: Activation of P2X receptors following hyperosmotic stress. Invest Ophthalmol Vis Sci 2010 Aug;51(8):4156-63.

174. Smith TM, Hicks-Berger CA, Kim S, Kirley TL. Cloning, expression, and characterization of a soluble calcium-activated nucleotidase, a human enzyme belonging to a new family of extracellular nucleotidases. Arch Biochem Biophys 2002 Oct 1;406(1):105-15.

175. Yegutkin GG. Nucleotide- and nucleoside-converting ectoenzymes: Important modulators of purinergic signalling cascade. Biochim Biophys Acta 2008 May;1783(5):673-94.

176. Maliszewski CR, Delespesse GJ, Schoenborn MA, Armitage RJ, Fanslow WC, Nakajima T, Baker E, Sutherland GR, Poindexter K, Birks C. The CD39 lymphoid cell activation antigen. molecular cloning and structural characterization. J Immunol 1994 Oct $15 ; 153(8): 3574-83$.

177. Handa M, Guidotti G. Purification and cloning of a soluble ATP-diphosphohydrolase (apyrase) from potato tubers (solanum tuberosum). Biochem Biophys Res Commun 1996 Jan 26;218(3):916-23. 
178. Jiang Q, Mak D, Devidas S, Schwiebert EM, Bragin A, Zhang Y, Skach WR, Guggino WB, Foskett JK, Engelhardt JF. Cystic fibrosis transmembrane conductance regulatorassociated ATP release is controlled by a chloride sensor. J Cell Biol 1998 Nov 2;143(3):645-57.

179. Sheppard DN, Robinson KA. Mechanism of glibenclamide inhibition of cystic fibrosis transmembrane conductance regulator cl- channels expressed in a murine cell line. $\mathrm{J}$ Physiol 1997 Sep 1;503 ( Pt 2)(Pt 2):333-46.

180. Sugita M, Yue Y, Foskett JK. CFTR cl- channel and CFTR-associated ATP channel: Distinct pores regulated by common gates. EMBO J 1998 Feb 16;17(4):898-908.

181. Becq F, Hamon Y, Bajetto A, Gola M, Verrier B, Chimini G. ABC1, an ATP binding cassette transporter required for phagocytosis of apoptotic cells, generates a regulated anion flux after expression in xenopus laevis oocytes. J Biol Chem 1997 Jan 31;272(5):2695-9.

182. Duong PT, Collins HL, Nickel M, Lund-Katz S, Rothblat GH, Phillips MC. Characterization of nascent HDL particles and microparticles formed by ABCA1mediated efflux of cellular lipids to apoA-I. J Lipid Res 2006 Apr;47(4):832-43.

183. Hunsucker SA, Mitchell BS, Spychala J. The 5'-nucleotidases as regulators of nucleotide and drug metabolism. Pharmacol Ther 2005 Jul;107(1):1-30.

184. Kohno Y, Sei Y, Koshiba M, Kim HO, Jacobson KA. Induction of apoptosis in HL-60 human promyelocytic leukemia cells by adenosine A(3) receptor agonists. Biochem Biophys Res Commun 1996 Feb 27;219(3):904-10.

185. Walker BA, Rocchini C, Boone RH, Ip S, Jacobson MA. Adenosine A2a receptor activation delays apoptosis in human neutrophils. J Immunol 1997 Mar 15;158(6):2926-31.

186. Insel PA, Ostrom RS, Zambon AC, Hughes RJ, Balboa MA, Shehnaz D, Gregorian C, Torres B, Firestein BL, Xing M, Post SR. P2Y receptors of MDCK cells: Epithelial cell regulation by extracellular nucleotides. Clin Exp Pharmacol Physiol 2001 Apr;28(4):351-4.

187. Corriden R, Insel PA. Basal release of ATP: An autocrine-paracrine mechanism for cell regulation. Sci Signal 2010 Jan 12;3(104):re1.

188. Sorensen CE, Novak I. Visualization of ATP release in pancreatic acini in response to cholinergic stimulus. use of fluorescent probes and confocal microscopy. J Biol Chem 2001 Aug 31;276(35):32925-32. 
189. Corriden R, Insel PA, Junger WG. A novel method using fluorescence microscopy for real-time assessment of ATP release from individual cells. Am J Physiol Cell Physiol 2007 Oct;293(4):C1420-5.

190. Imamura H, Nhat KP, Togawa H, Saito K, Iino R, Kato-Yamada Y, Nagai T, Noji H. Visualization of ATP levels inside single living cells with fluorescence resonance energy transfer-based genetically encoded indicators. Proc Natl Acad Sci U S A 2009 Sep 15;106(37):15651-6.

191. Yvan-Charvet L, Wang N, Tall AR. Role of HDL, ABCA1, and ABCG1 transporters in cholesterol efflux and immune responses. Arterioscler Thromb Vasc Biol 2010 Feb;30(2):139-43.

192. Tam SP, Mok L, Chimini G, Vasa M, Deeley RG. ABCA1 mediates high-affinity uptake of 25-hydroxycholesterol by membrane vesicles and rapid efflux of oxysterol by intact cells. Am J Physiol Cell Physiol 2006 Sep;291(3):C490-502.

193. Le Goff W, Peng DQ, Settle M, Brubaker G, Morton RE, Smith JD. Cyclosporin A traps ABCA1 at the plasma membrane and inhibits ABCA1-mediated lipid efflux to apolipoprotein A-I. Arterioscler Thromb Vasc Biol 2004 Nov;24(11):2155-61. 


\section{Contributions of Collaborators}

All experiments and results presented in this thesis are done by the author of the thesis, Jee Yeon Lee except for the following:

- Cholesterol efflux from RAW macrophages induced with 8-Br-cAMP and T0901317 at the same time was provided by Loretta Ma (Figure 3.2 B).

- Cholesterol efflux with $\alpha, \beta$-MeATP and UTP were performed by Dr. Joel Karwatsky (Figure 3.7 A, B).

- Cholesterol efflux with st-Ht31 was performed by Loretta Ma (Figure 3.14 A).

I would like to truly thank them for their contributions to this thesis. 


\title{
Curriculum Vitae
}

\author{
Jee Yeon Lee \\ Faculty of Medicine \\ Department of Biochemistry, Microbiology, and Immunology \\ Ottawa Regional Cancer Centre
}

\section{EDUCATION}

M.Sc. of Science in Biochemistry

Sept 2009 - Sept 2011

University of Ottawa (Ottawa, ON)

- Supervisor: Dr. Xiaohui Zha

- Thesis: ABCA1 increases extracellular ATP to mediate cholesterol efflux to apoA-I

\section{B.Sc. Honours in Biopharmaceutical Science} University of Ottawa (Ottawa, ON)

Sept 2004 - Apr 2009

- Honours Project in Ottawa Health Research Institute (OHRI)

- Thesis: Nuclear and cytoplasmic maturation in stage V and VI oocytes of Xenopus laevis

\section{POSTER/SEMINAR PRESENTATIONS}

Lee, J. 2010. The role of extracellular ATP in ABCA1-mediated cholesterol efflux. University of Ottawa Undergraduate Poster Day, Ottawa, ON.

Lee, J. 2011. ABCA1 increases extracellular ATP to mediate cholesterol efflux to apoA-I. University of Ottawa Student Seminar, Ottawa, ON.

Lee, J. 2011. ABCA1 increases extracellular ATP to mediate cholesterol efflux to apoA-I. Arteriosclerosis, Thrombosis and Vascular Biology 2011 Scientific Conference. Chicago, Illinois.

\section{PUBLICATIONS}

Lee, J., Karwatsky, J., Ma, L., Zha, X. (2011) ABCA1 increases extracellular ATP to mediate cholesterol efflux to apoA-I. American Journal of Physiology. Cell physiology. [Epub ahead of print].

\section{WORK EXPEREINCE}

Research Assistant 2009 Summer

Ottawa Health Research Institute (OHRI)- Chronic Diseases (Ottawa, ON)

- Experience in analyzing scientific data from lab experiments

- Familiarized with basic laboratory techniques in biochemistry and cell biology 
- Presented research findings in weekly lab meetings related to the field of cholesterol and lipid metabolism

- Obtained lab safety skills and radioactive safety skills through training

- Organized and kept a record of various experimental methods and results

New Drug Submissions Evaluator

2008 Summer

Bureau of Pharmaceutical Science, Biologics and Genetic Therapies Directorate, Health Canada (Ottawa, ON)

- Performed a cursory evaluation of drug submissions to ensure their completeness and made successful report to manager

- Made recommendations on the disposition of submission based on the analysis against the criteria of New Drug Submissions guidelines

- Initiated and prepared statistics project on completeness of drug submissions by gathering all New Drug Submissions received by Health Canada from 2007-2008

Waitress

$2006-2009$

Suisha Gardens and Wasabi Japanese Restaurant and Sushi Bar (Ottawa, ON)

- Worked as part of a team to deliver excellent service to customers by describing menu items/daily specials in detail, greeting guests and by taking orders

- Maintained high levels of customer satisfaction in a busy, high-end establishment

- Acquired overview of wines and other alcoholic beverages and inspect the ID of patrons to ensure minimum age requirements for consumption of alcoholic beverages are always met

- Developed leadership skills though training 5 new waitresses as a senior waitress

- Successfully completed long shifts over 15 hours without appearing tired

- Ensured that all expectations were met and exceeded by actively checking up with customers and quickly solving and correcting issues

Tutoring Instructor

$2004-2007$

Private (Ottawa, ON)

- Taught students in grade 12 calculus, grade 12 chemistry, grade $9 \mathrm{U} / \mathrm{C}$ math, grade 9 science, grade 11 chemistry and grade 12 physics

- Taught a student in grade 6 in math, science and reading and writing English

- Coached them in effective work and study techniques

Research Intern

Dong-A Pharmaceutical (Republic of Korea)

2005 Summer

- Translated Korean written technical reports into English

- Collected data to input into computer

- Attended various meetings to report finished work

- Operated various computer programs (Microsoft Word, PowerPoint, Excel, Windows 2000/XP and the internet)

\section{VOLUNTEER EXPERIENCE}


Canadian Tulip Festival (Ottawa, ON)

- Volunteered for Canadian Tulip Festival for Korean Pavilion to assign volunteers for different volunteering positions and arranged volunteering time, date and place for volunteers.

- Organized different activities in Korean Pavilion such as Korean traditional food, wedding, games and art.

\section{Assistant Proctor}

2007 and 2011

AKCSE National Mathematics and Science Competition (Ottawa, ON)

- $\quad$ Supervised math and science competition for grade 4 - grade 11

- Assisted the head proctor with distribution of exams and proctoring, answering questions and collecting exams after completion

\section{AWARDS/CERTIFICATES/ACHIEVEMENTS}

- $\quad$ Received 2010-2011 The Association of Korean Canadian Scientists and Engineers (AKCSE) Best Student Member Award, 2011

- $\quad$ Received Travel Awards of \$1,500 from Department of Biochemistry, Microbiology and Immunology (BMI) and Faculty of Graduate and Postdoctoral Studies (FGPS), 2011

- Treasurer/event organizer in Ottawa Korean Young Engineers and Scientists (OKYES), 2010-Present

- Vice-president in Ottawa Korean Community Church (OKCC) Young Adult Group, $2010-2011$

- $\quad$ Radiation Safety Training of the Ottawa Hospital Certificate - Ottawa Health Research Institute (OHRI), 2009

- CCAC's Institutional Animal User Training Program Certificate - Ottawa Health Research Institute (OHRI), 2008

- Successfully completed Pharmaceuticals: Federal and International Regulations, 2007

- Attended Young Generation Forum sponsored by The Korean Federation of Science and Technology Societies (AKCSE) as 1 of 7 candidates in Canada, 2007

- Received University entrance scholarship of $\$ 10,000$ for average higher than $92 \%$, 2004 